Jessica Rodrigues de Oliveira

Avaliação de cenários de investimentos no sistema de transporte do Rio de Janeiro com o software Emme

Dissertação apresentada como requisito parcial para obtenção do grau de Mestre pelo Programa de Pós-graduação em Engenharia de Produção, do Departamento de Engenharia Industrial da PUC-RIO.

Orientador: Prof. José Eugenio Leal Co-orientador: Prof. Orivalde Soares da Silva Junior 
Jessica Rodrigues de Oliveira

\section{Avaliação de cenários de investimentos no sistema de transporte do Rio de Janeiro com o software \\ Emme}

Dissertação apresentada como requisito parcial para obtenção do grau de Mestre pelo Programa de Pós-Graduação em Engenharia de Produção da PUC-Rio. Aprovada pela Comissão Examinadora abaixo assinada.

Prof. José Eugenio Leal Orientador

Departamento de Engenharia Industrial - PUC-Rio

Prof. Orivalde Soares da Silva Junior

Coorientador

IME

Prof. Vânia Barcellos Gouvêa Campos

IME

Prof. Rafael Martinelli Pinto

Departamento de Engenharia Industrial - PUC-Rio 
Todos os direitos reservados. É proibida a reprodução total ou parcial do trabalho sem autorização da universidade, do autor e do orientador.

\section{Jessica Rodrigues de Oliveira}

Graduou-se em Engenharia de Produção na PUCRJ (Pontificia Universidade Catolica do Rio de Janeiro) no ano de 2017.

Ficha Catalográfica

Oliveira, Jessica Rodrigues de

Avaliação de cenários de investimentos no sistema de transporte do Rio de Janeiro com o software Emme / Jessica Rodrigues de Oliveira ; orientador: Jose Eugenio Leal ; co-orientador: Orivalde Soares da Silva Júnior. - 2020.

96 f. : il. color. ; $30 \mathrm{~cm}$

Dissertação (mestrado)-Pontifícia Universidade Católica do Rio de Janeiro, Departamento de Engenharia Industrial, 2020. Inclui bibliografia

1. Engenharia Industrial - Teses. 2. Plano Diretor de Transportes. 3. Modelo de quatro etapas. 4. Alocação de transporte coletivo. 5. EMME. I. Leal, Jose Eugenio. II. Silva Júnior, Orivalde Soares da. III. Pontifícia Universidade Católica do Rio de Janeiro. Departamento de Engenharia Industrial. IV. Título.

CDD: 658.5 


\section{Agradecimentos}

O presente trabalho foi realizado com apoio da Coordenação de Aperfeiçoamento de Pessoal de Nível Superior - Brasil (CAPES) - Código de Financiamento 001.

Agradeço ao meu orientador José Eugenio Leal por além de todo o ensinamento desde a época da graduação, por todo apoio e disponibilidade incomparável ao longo dessa trajetória.

Ao meu coorientador Orivalde Soares da Silva Junior por toda paciência e ajuda no desenvolvimento dessa dissertação.

Aos professores do Departamento de Engenharia Industrial, os quais ajudaram na minha formação acadêmica no Mestrado.

A minha família pelo amor e por estar sempre comigo. Aos melhores amigos que o mestrado poderia ter me dado, Julia e Vinicius.

E por fim, um agradecimento especial a pessoa mais extraordinária que já passou na minha vida, que mesmo não estando mais presente fisicamente nesse mundo é lembrado todo dia, Silvio. 


\section{Resumo}

Oliveira, Jessica Rodrigues de; Leal, José Eugenio; Junior, Orivalde Soares da Silva. Avaliação de cenários de investimentos no sistema de transporte do Rio de Janeiro com o software Emme. Rio de Janeiro, 2020. 96p. Dissertação de Mestrado - Departamento de Engenharia Industrial, Pontifícia Universidade Católica do Rio de Janeiro.

A mobilidade em médias e grandes cidades brasileiras como o Rio de Janeiro tem se caracterizado pela utilização ineficiente do espaço público, juntamente com a redução da utilização do transporte coletivo. Qualquer mudança nas rotas e frequências de linhas no transporte coletivo assim como o surgimento de novas tecnologias e variação das tarifas geram efeitos sobre a distribuição de fluxos de passageiros. Juntando-se a esse contexto, há a atual conjuntura econômica do Rio de Janeiro onde acaba não sobrando recursos para investir em estudos e na implementação de melhoria da mobilidade urbana da cidade. Este trabalho apresenta uma análise de alternativas de cenários focados no metrô e em conexões do BRT com trens por já terem uma infraestrutura pré-existente o que facilitaria a construção dessas obras. Esta pesquisa mostra como as obras incluídas nos cenários propostos para 2016 e 2021 no Plano Diretor de Transportes do Rio de Janeiro estão discrepantes com a rede de transporte no ano de 2019 e por consequência o fluxo de passageiros na rede é diferente do previsto. Com o auxílio do software EMME e utilizando uma rede de transporte simplificada e mais atualizada da Região Metropolitana do Rio de Janeiro, foi realizada a alocação do transporte coletivo baseado no modelo de estratégias ótimas de Spiess (1983), contido no EMME. Dessa forma verificou-se como a construção dessas novas infraestruturas de transporte alteraria o fluxo de passageiros. A partir desses resultados pode-se concluir que investir em conexões entre os modos e em obras que sejam capazes de retirar uma quantidade significativa de veículos da rede é um caminho chave para a Região Metropolitana já que esses investimentos deixam a rede de transporte menos congestionada e melhoram a qualidade de vida da população, além de seguir a apelo pelo desenvolvimento mais sustentável dos sistemas de transportes.

\section{Palavras-chave}

Plano Diretor de Transportes, modelo de quatro etapas, alocação de transporte coletivo, EMME. 


\section{Abstract}

Oliveira, Jessica Rodrigues de; Leal, José Eugenio; Junior, Orivalde Soares da Silva. Evaluation of investment scenarios in the transport system of Rio de Janeiro with Emme software. Rio de Janeiro, 2020. 96p. Dissertação de Mestrado - Departamento de Engenharia Industrial, Pontifícia Universidade Católica do Rio de Janeiro.

Mobility in medium and large Brazilian cities such as Rio de Janeiro has been characterized by the inefficient use of public space, together with the reduction in the use of public transport. Any change in routes and line frequencies in public transport, as well as the emergence of new technologies and variation of fares, have an effect on the distribution of passenger flows. Adding to this context, there is the current economic situation in Rio de Janeiro, where there are no resources left to invest in studies and in the implementation of improving the city's urban mobility. This work presents an analysis of alternative scenarios focused on the trains and on BRT connections, as they already have a pre-existing infrastructure, which would facilitate the construction of these works. This research shows how the works included in the scenarios proposed for 2016 and 2021 in the Rio de Janeiro Transport Master Plan are discrepant with the transport network in 2019 and, consequently, the flow of passengers on the network is different from the forecast. With the aid of the EMME software and using a simplified and more up-to-date transportation network in the Metropolitan Region of Rio de Janeiro, public transportation was allocated based on the optimal strategies model of Spiess (1983), contained in the EMME. Thus, it was verified how the construction of these new transport infrastructures would alter the flow of passengers. From these results, it can be concluded that investing in connections between modes and in works that are capable of removing a significant number of vehicles from the network is a key path for the metropolitan region as these investments make the transportation network less congested and improve the population's quality of life, in addition to following the call for more sustainable development of transport systems.

\section{Keywords}

Transport Master Plan, four-step model, public transport allocation, EMME. 


\section{Sumário}

1 Introdução 13

1.1 Introdução 13

$\begin{array}{ll}\text { 1.2 Problema a abordar } & 14\end{array}$

$\begin{array}{ll}1.3 \text { Relevância do Estudo } & 14\end{array}$

$\begin{array}{ll}1.4 \text { Objetivos } & 15\end{array}$

1.4.1 Objetivo geral 15

$\begin{array}{ll}\text { 1.4.2 Objetivo específicos } & 15\end{array}$

$\begin{array}{ll}1.5 \text { Estrutura da Dissertação } & 16\end{array}$

2 Referencial teórico 17

2.1 Planejamento de Transporte 17

2.2 Planos de Transporte 23

2.2.2. O modelo de quatro etapas 26

2.2.2.1. Geração de viagens 27

$\begin{array}{ll}\text { 2.2.2.2. Distribuição de viagens } & 27\end{array}$

2.2.2.3. Divisão Modal 28

2.2.2.4. Alocação de Fluxo 29

3 Plano diretor de transporte do Rio de Janeiro 31

3.1 O Plano Diretor 31

3.2 O Plano Diretor de Transporte da Região Metropolitana do Rio de Janeiro 31

3.2.1 Definição da Área de Estudo 33

3.2.2 Rede e Sistema de Zoneamento da Região Metropolitana do Rio de Janeiro 36

3.3 Caracterização e Análise do Transporte no Estado do Rio de Janeiro e na

RMRJ 37

3.3.1 Sistema de Ônibus Municipal 37

3.3.2 Sistema Metroviário $\quad 41$

3.3.3 Sistema VLT 43

3.3.4 Sistema Ferroviário $\quad 44$

3.3.5 Sistema de Ônibus Intermunicipal (Metropolitano) 45

3.3.6 Sistema de Barcas $\quad 45$

3.3.7 Análise dos Transportes da Região Metropolitana do Rio de Janeiro 46

4 Metodologia e Método $\quad 51$

4.1 Caracterização e delineamento da pesquisa $\quad 51$

4.2 Passos da concepção do estudo $\quad 51$

4.3 O software EMME $\quad 52$

4.4 Simplificação da rede de transportes 56

5 Nova rede viária do Rio de Janeiro 58

5.1 Comparação dos cenários 58 
$\begin{array}{ll}5.1 .1 \mathrm{VLT} & 59\end{array}$

$\begin{array}{ll}5.1 .2 \text { Metrô } & 60\end{array}$

5.1.3 Ferrovias 66

5.1.4 BRT 67

5.2 Cenários $\quad 72$

5.2.1. Cenário 1: Linha de metrô Gávea $\leftrightarrow$ Carioca 73

5.2.2. Cenário 2: Linha de metrô Gávea ↔ Uruguai 74

5.2.3. Cenário 3: Retorno da utilização do terminal BRT de Campo Grande e conexão do BRT com a Supervia em Campo Grande 74

5.2.4. Cenário 4: Conexão do BRT com a Supervia em Santa Cruz 77

5.2.5. Cenário 5: União de todos os cenários anteriores 77

$\begin{array}{ll}5.3 \text { Limitações da Pesquisa } & 77\end{array}$

5.4 Estrutura de dados de entrada no EMME 78

5.5 Carregamento da Rede $\quad 80$

6 Conclusões e Recomendações 89

6.1 Conclusão $\quad 89$

6.2 Propostas de trabalhos futuros 90

7 Referências 91 


\section{Lista de Figuras}

Figura 1: Ciclo vicioso do carro/transporte público 8

Figura 2: Esquema básico do planejamento de transportes 23

Figura 3: Modelo sequencial de demanda 25

Figura 4: Regiões de planejamento do Estado do Rio de Janeiro 32

Figura 5: RMRJ considerada para estudo do PDTU 2011

Figura 6: Rede urbano intrametropolitana 34

Figura 7: Diagrama da rede de transporte público do Rio de Janeiro 37

Figura 8: Mapa das áreas de concessão 38

Figura 9: Quantidade de linhas do sistema de ônibus municipal do RJ 38

Figura 10: Frota média em operação de ônibus municipais do RJ 39

Figura 11: Número de passageiros pagantes em ônibus municipais do RJ 39

Figura 12: Corredores BRS implantados e em projetos 2015

Figura 13: Corredores BRT da RMRJ 2018

Figura 14: Linhas do sistema metroviário da RMRJ 2018, metrô na superfície e pontos de integração com outros modos $\quad 42$

Figura 15: Linhas do sistema VLT do Rio de Janeiro em 2019

Figura 16: Linhas do sistema ferroviário da RMRJ 2018

Figura 17: Sistema de ônibus intermunicipal da RMRJ (DETRO) 45

Figura 18: Linhas de barcas da RMRJ $2019 \quad 46$

Figura 19: Distribuição percentual horária do transporte individual da RMRJ 47

Figura 20: Distribuição percentual horária do transporte coletivo da RMRJ 47

Figura 21: Distância e tempo médio das viagens por modo de transporte no pico

$\begin{array}{ll}\text { da manhã } & 48\end{array}$

Figura 22: Motivo das viagens de transporte público no pico da manhã $\quad 49$

Figura 23: Áreas de produção(azul) e atração (laranja) de viagens realizadas por transporte coletivo no pico da manhã 49

Figura 24: Rede básica de Transporte do Rio de Janeiro em 2016

Figura 25: Traçado do VLT em 2016

Figura 26: Traçado do VLT em $2018 \quad 60$

Figura 27: Traçado da linha 1 do metrô-rio em 2016

Figura 28: Traçado da linha 2 do metrô-rio em 2016

Figura 29: Traçado da linha 4 do metrô-rio em 2016

Figura 30: Traçado da linha 3 do metrô-rio em 2016

Figura 31: Traçado da rede do metrô-rio em 2019 
Figura 32: Traçado da linha 1 do metrô-rio em 2021

Figura 33: Traçado da linha 2 do metrô-rio em 2021

Figura 34: Traçado da linha 4 do metrô-rio em 2021

Figura 35: Traçado da linha 3 do metrô-rio em 2021

Figura 36: Traçado da linha 6 do metrô-rio em 2021

Figura 37: Traçado da linha ferroviária do rio em $2016 \quad 66$

Figura 38: Traçado da linha ferroviária do rio em $2019 \quad 67$

Figura 39: Traçado da linha ferroviária do rio em 2021

Figura 40: Traçado do BRT TransOeste em 2016

Figura 41: Traçado do BRT TransCarioca em 2016

Figura 42: Traçado do BRT TransBrasil em $2016 \quad 68$

Figura 43: Traçado do BRT TransOlímpico em 2016

Figura 44: Traçado do BRT TransOceânico em 2016

Figura 45: Traçado do BRT Transoceânico em 2019

Figura 46: Traçado do BRT Transcarioca em 2021

Figura 47: Traçado do BRT Magarça em 2021

Figura 48: Traçado do BRT RJ-104 em 2021

Figura 49: Traçado do BRT RJ-106 em 2021

Figura 50: Linha Gávea $\leftrightarrow$ Carioca do metrô $\quad 73$

Figura 51: Linha Gávea $\leftrightarrow$ Uruguai do metrô $\quad 74$

Figura 52: Linha Santa Cruz $\leftrightarrow$ Campo Grande do BRT 75

Figura 53: Linha Campo Grande $\leftrightarrow$ Jardim Oceânico do BRT 75

Figura 54: Conexão entre Supervia e BRT em Campo Grande 76

Figura 55: Conexão entre Supervia e BRT em Madureira feito por passarelas 76

Figura 56: Conexão do BRT com a Supervia em Santa Cruz 77

Figura 57: Tipo de arcos e códigos $\quad 79$

Figura 58: Tipos de modais e códigos $\quad 79$

Figura 59: Resultado da alocação no EMME no cenário base 80

Figura 60: Quantidade de usuário por modal no cenário base 81

Figura 61: Porcentagem de utilização dos modais no cenário base 81

Figura 62: Quantidade de usuário por modal no cenário 1

Figura 63:Comparação entre linhas de metrô no cenário base e no cenário1 82

Figura 64: Quantidade de usuário por modal no cenário 2

Figura 65: Comparação entre linhas do metrô no cenário base e no cenário 283

Figura 66: Lista das 10 estações com maior fluxo de passageiros 84

Figura 67: Quantidade de usuário por modal no cenário $3 \quad 85$

Figura 68: Demonstração integração tarifária entre BRT e trem da Supervia 85 
Figura 69: Aumento de usuários das linhas de BRT

Figura 70: Aumento de usuários no BRT e Supervia em Santa Cruz 86

Figura 71: Porcentagem de utilização dos modais no cenário 5

Figura 72: Quantidade de usuários por modal no cenário 5 87

Figura 73: Resumo dos aumentos e reduções nos 5 cenários 


\section{Lista de Tabelas}

Tabela1: Dados dos municípios que fazem parte do PDTU 35

Tabela 2: Dados de frota por consorcio que operada RMRJ 38

Tabela 3: Indicadores do sistema de transporte público no período de pico da

manhã 48

Tabela 4: valores usados na fórmula de custo generalidade de acordo com o modal 55

Tabela 5:Valores do tempo (Vot) em $\mathrm{R} \$$ /hora segundo o motivo da viagem 55

Tabela 6: Limite das licenças 2 e $7 \quad 56$ 


\section{1 \\ Introdução}

O presente capítulo tem como objetivo apresentar o problema a ser abordado, a relevância do estudo além dos objetivos que devem ser alcançados com a realização do trabalho e a forma como essa dissertação está organizada.

\subsection{Introdução}

A mobilidade nas cidades brasileiras de médio e grande porte, como o Rio de Janeiro, tem se caracterizado pela utilização cada vez mais ineficiente do espaço público, juntamente com a crescente diminuição da utilização do transporte coletivo principalmente devido a precariedade desse tipo de transporte o que gera impactos negativos para o tráfego, para o meio ambiente e para a sociedade em geral. A melhoria das condições da mobilidade urbana representa um dos maiores desafios das cidades atualmente em todo o mundo (Tischer e Polette, 2019).

Tendo isso em mente, o governo do estado do Rio de Janeiro através da Secretaria de Estado de Transporte (SETRANS) elaborou no período de 2012 a 2015, o Plano Diretor de Transporte Urbano da Região Metropolitana de Rio de Janeiro (PDTU-RMRJ). Esse plano teve como objetivo principal propor soluções, diretrizes e estratégias para promover o desenvolvimento de um trânsito sustentável e da mobilidade urbana dentro da RMRJ assim como satisfazer as necessidades de transporte da população.

Contudo o desenvolvimento do transporte coletivo com investimentos focados na construção de novas estradas, rodovias e aumento da frota disponível não são tão eficientes para a qualidade da mobilidade urbana, assim como para solucionar problemas de congestionamento e acessibilidade. Nos últimos anos, o apelo por um desenvolvimento sustentável tem ganhado destaque quando o assusto é desenvolvimento dos sistemas de transportes. Posto isso, em 2016, a prefeitura do Rio de Janeiro por meio da Secretaria Municipal de Transportes (SMTR) desenvolveu o Plano de Mobilidade Urbana Sustentável (PMUS) que visa orientar os investimentos públicos em infraestruturas de transportes para se obter um sistema coeso e sustentável, priorizando o transporte público, contribuindo para um desenvolvimento econômico, social e ambiental.

Parte-se da ideia desses dois planos e considerando que as administrações públicas enfrentam orçamentos cada vez menores devendo, portanto, aproveitar ao máximo os 
recursos disponíveis, esse estudo vem com o objetivo de analisar algumas alternativas de transportes visando o aumento da utilização da rede de transporte coletivo da Região Metropolitana do Rio de Janeiro (RMRJ).

A rede de transportes da RMRJ foi atualizada para o ano de 2019 e simplificada para poder ser usada no Software EMME versão 2, onde foram simulados os cenários propostos. Esses cenários foram escolhidos por já terem uma infraestrutura pré-existente (estações já construídas) que facilitaria a aplicação no cotidiano da população. Após a simulação é possível avaliar os impactos desses novos investimentos sobre a qualidade de vida das populações.

\subsection{Problema a abordar}

O Plano Diretor de Transporte Urbanos da Região Metropolitana do Rio de Janeiro (PDTU-RMRJ) tem como objetivo subsidiar o Governo do Estado no desenvolvimento das políticas públicas setoriais orientando, não só as ações executivas relativas aos investimentos em infraestrutura viária e sistemas de transporte coletivo como, também, definir modelos operacionais e tarifários que possibilitem otimizar o uso das redes de transporte disponíveis. No PDTU 2012, foram projetados cenários para os anos futuros de 2016 e 2021. Contudo Ortúzar e Willumsen (2011) afirmam que preparar cenários que se adequem realisticamente as condições futuras da região não é tarefa fácil. Analisando os cenários propostos para 2016 no PDTU é possível notar que algumas das obras incluídas até o ano de 2016 ainda não foram concluídas no ano de 2019. Consequentemente, os cenários de 2021 possuem projeções de obras que não possuem nem a pretensão de serem realizadas e tarifas mais baixas que as atuais. E como se sabe a criação, extinção ou mudanças nas rotas e frequências de linhas assim como o surgimento de novas tecnologias e variação das tarifas geram efeitos sobre a distribuição de fluxos de passageiros sobre os trechos e veículos do transporte público e afetam o tempo de viagem, o conforto e o número de transferências dos usuários (Aragón e Leal, 2003). Sendo assim, essa dissertação vem apresentar a rede de transporte mais próxima da atual (2019), assim como cenários viáveis de ampliação da rede de transporte metropolitana tendo como base o desenvolvimento sustentável, para auxiliar o governo em decisões futuras.

\subsection{Relevância do Estudo}

As administrações públicas enfrentam o problema de realizar estudos para a melhoria dos serviços públicos em orçamentos cada vez menores, e levando-se em conta a atual conjuntura econômica do estado do Rio de Janeiro, temas como esses acabam ficando em 
segundo plano visto que já existe um plano diretor de transporte para o Estado. Contudo, esses planos deveriam ser realizados com mais frequência já que a rede de transporte sofre constantes mudanças. Além disso é possível notar a discrepância entre os cenários da rede viária proposto para o ano de 2016, e a rede de transporte atual em 2019. Tendo em vista esses pontos, e sabendo da importância do estudo de alocação de fluxos que prevê como os fluxos de passageiros se distribuem sobre a rede de transporte público, a relevância desta dissertação está em propor cenários baseados na realidade da rede viária, para que as infraestruturas de ampliação e integração da rede de transporte possam ser avaliadas corretamente. Sendo assim, decisões estratégicas seriam tomadas de uma forma mais adequada já que elas impactam diretamente da qualidade de vida das populações.

\subsection{Objetivos}

Esta dissertação possui dois níveis de objetivos, geral e específicos, que estão discriminados a seguir.

\subsubsection{Objetivo geral}

O objetivo desta dissertação é analisar alternativas de transportes que possam melhorar a rede de transporte coletivo da Região Metropolitana do Rio de Janeiro.

\subsubsection{Objetivo específicos}

- Revisar a literatura sobre o tema planejamento de transporte;

- Comparar os cenários propostos que estão no PDTU-RMRJ para os anos de 2016 e 2021 com o panorama atual do sistema de transportes da RMRJ em 2019 e identificar a situação dos projetos propostos.

- Atualizar um dos cenários de 2016 do PDTU-RMRJ removendo projetos que não foram concluídos para atingir o mais próximo da realidade do sistema de transporte da RMRJ em 2019 e ao final simplificar a rede de transportes reduzindo o número de nós e arcos.

- Analisar os cenários propostos por essa dissertação utilizando o software EMME, com o objetivo de avaliar o impacto da implantação de novas infraestruturas para ampliação e maior integração da rede viária da RMRJ. 


\section{5}

\section{Estrutura da Dissertação}

Esta dissertação é composta por 6 capítulos. O Capítulo 1 é o capítulo com uma breve introdução, além de retratar o problema a ser abordado e a relevância desta pesquisa, assim como os objetivos e a estrutura do trabalho.

O Capítulo 2 traz uma revisão da literatura sobre os temas pertinentes ao trabalho permitindo ao leitor ter uma base para compreender melhor o que será feito nesta pesquisa.

No Capítulo 3 é apresentado o Plano Diretor de Transportes da Região Metropolitana do Rio de Janeiro e feita uma caracterização e análise do transporte na região metropolitana do RJ.

No Capítulo 4 são abordados os aspectos metodológicos adotados nesta pesquisa assim como as etapas de concepção do estudo e é apresentado o software EMME com suas principais funcionalidades.

O Capítulo 5 mostra a escolha dos cenários e a alocação realizada no software, além das análises feitas.

O Capítulo 6 conclui o trabalho com considerações finais, explora as limitações da pesquisa e aborda propostas de continuação do trabalho. 


\section{2 \\ Referencial teórico}

Neste capítulo apresenta-se uma revisão de literatura com temas relevantes para o desenvolvimento do trabalho, como uma visão geral sobre o planejamento de transporte, conceitos importantes para o desenvolvimento de um plano diretor como o modelo de quatro etapas, dentre outros assuntos.

Ressalta-se que objetivo deste capítulo não é realizar uma longa discussão acerca dos temas citados, mas sim, fazer com que o leitor tenha o conhecimento básico necessário para entender o conceito do planejamento de transporte e como este trabalho se insere em um plano diretor.

\section{1 \\ Planejamento de Transporte}

Uma área urbana é um complexo de atividades humanas inter-relacionadas e interconectadas. Requer, portanto, um sistema de transporte eficiente para garantir a movimentação de pessoas, alimentos e serviços eficientemente, um sistema de comércio eficaz e um crescimento e desenvolvimento econômico sustentável a longo prazo. Esse sistema deve, portanto, ser sustentável para atender às necessidades básicas de transporte de todos os cidadãos sem esgotar os recursos a longo prazo. A importância do transporte para o desenvolvimento de um país se encontra no fato de que a mobilidade e a acessibilidade são essenciais para o crescimento econômico. Por exemplo, o transporte permite a acessibilidade a terras agrícolas, saúde, educação, emprego, comércio, base de recursos minerais, florestas, indústrias e várias atividades em uma comunidade. O setor de transporte é, portanto, o setor de serviços básicos para os outros setores da economia de uma nação e por isso, geralmente, é chamado de "setor de atores e conectores" (Chima, 1990).

Apesar do transporte ser um elemento muito importante no bem-estar dos moradores urbanos e rurais de diversas nações, ele traz consigo uma série de problemas como congestionamento, poluição, acidentes, déficits financeiros e bolsões de acesso precário. Machado e Piccinini (2018) afirma que ao mesmo tempo que o transporte é a solução para o desenvolvimento das cidades, ele também é responsável por externalidades negativas que 
impactam diretamente na economia e qualidade de vida urbana, sendo um desafio para as políticas públicas.

Os problemas gerados afetam tanto países desenvolvidos como os emergentes, como é o caso do Brasil. Contudo, os países emergentes ainda enfrentam condições mais agravantes como rendas relativamente baixas, urbanização e mudança rápidas, alta demanda do transporte público, etc. O crescimento econômico desses países ainda gerou o que se chama de ciclo vicioso do carro / transporte público representado na Figura 1 (Ortúzar e Willumsen, 2011).

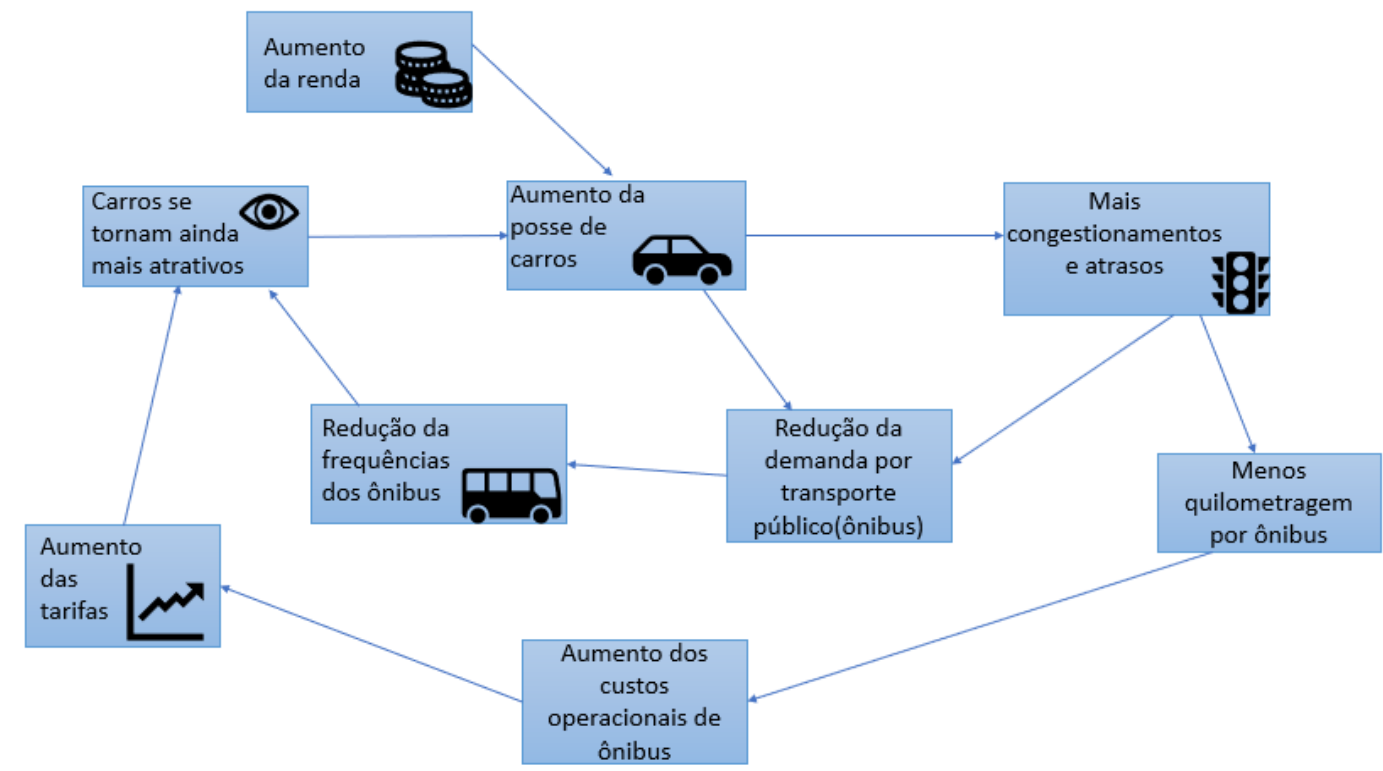

Figura 1: Ciclo vicioso do carro/transporte público. Adaptado de Ortúzar e

Willumsen (2011)

Nesse ciclo, o crescimento econômico fornece o primeiro impulso para a aquisição de carros. Mais proprietários de automóveis significa mais pessoas querendo migrar para o uso de transporte particular ao invés do transporte coletivo. Menos passageiros de transporte público pode acarretar o aumento de tarifas para os lucros não decaírem, ou diminuição do nível de serviço (frequência das linhas) ou ambos. Estas medidas tornam o uso do carro ainda mais atraente do que antes e induzem mais pessoas a comprar carros, acelerando assim o círculo vicioso. Após alguns ciclos (anos), os níveis de congestionamento estão extremamente altos, os níveis de serviço do transporte público ainda pior, tornando o estado final pior que originalmente.

Esses problemas dificilmente irão desaparecer em um futuro próximo. Surge assim, a necessidade de se fazer um bom planejamento de transporte para maximizar as vantagens da nova oferta de transporte, minimizando simultaneamente os seus custos monetários e efeitos secundários indesejados (Ortúzar e Willumsen, 2011). 
Um plano de transporte é essencialmente um produto do planejamento urbano, do uso da terra e da tecnologia de transporte (Akinbami e Fadare, 1997). Löfgren et al. (2018) afirma que um dos objetivos mais importantes no planejamento de transportes é entender e gerenciar as mudanças da cidade causadas pela construção de estruturas de transporte. Assim, para facilitar o planejamento e a política de transporte, é indispensável compreender e modelar como a mudança no uso da terra se relaciona com o transporte, explorar as dinâmicas e os impulsionadores da mudança do uso da terra e refletir as mudanças necessárias nas políticas de transporte (Su et al., 2014). A introdução e manutenção de um sistema de transporte eficaz e eficiente é uma tarefa desafiadora, mas possível. Exige que as autoridades apropriadas transformem a terra disponível e recursos financeiros em infraestrutura e redes de transporte relevantes para fornecer a combinação equilibrada entre os vários modos de transporte individual motorizado ou coletivo/público e não motorizado, bem como transferências fáceis entre eles para atender à demanda de mobilidade (UNECE, 2015)

Vários estudos tem se dedicado a essa área de planejamento e modelagem de transporte, tais como: Waddella et al. (2007) que apresentam um estudo de caso sobre a aplicação de um sistema detalhado de simulação de uso do solo, o UrbanSim, e sua integração com um modelo regional de demanda de viagens em Utah; Ferreira et al. (2010) também fez uso do Urbansim, desenvolvendo uma estrutura que liga o modelo de transporte e o modelo de uso da terra; Clay et al. (2011) propuseram utilizar os dados do InfoUSA para o desenvolvimento do modelo de uso do solo e relacionaram com o modelo de transporte; Wang et al. (2011) discutem a integração incremental do uso da terra e a modelagem de viagens baseada na atividade no local de trabalho e a demanda de viagens; Zhao e Zhong-Ren Peng (2010) propõem um modelo de dois níveis para explorar a alocação e o uso do solo, etc.

Portanto, não há dúvidas de que a análise quantitativa desempenha um papel importante na formulação de políticas de transporte e o uso de modelos avançados em tal análise é crucial (Givoni et al., 2016).

Os métodos tradicionais de planejamento de transporte foram desenvolvidos durante um período em que os ambientes de tráfego urbano cresciam rapidamente, de modo que o planejamento de transportes se concentrou principalmente na expansão da rodovia (Cervero, 2003). Contudo Hansson (2020) afirma que a expansão de um sistema rodoviário hoje como solução não é eficaz e muitas vezes se mostra contraproducente, pois estas melhorias na rede rodoviária não reduzirão a restrição de tráfego. Além de restrições econômicas e limitações territoriais também acabarem se tornando grandes empecilhos para continuar as expansões desse tipo de infraestrutura. Essas estratégias tradicionais de planejamento de transporte tentam melhorar as velocidades dos veículos, minimizar o 
congestionamento do tráfego e reduzir as taxas de acidentes usando um conjunto limitado e bem estruturado de ferramentas de engenharia, arquitetura e financiamento (Kane e Romano, 2003).

Nos últimos anos, o agravamento dos problemas de transportes e a necessidade de uma nova abordagem para o planejamento de transportes expandiu-se para incluir e destacar os modos não veiculares, além de se preocupar com fatores como segurança dos pedestres, impactos na saúde e efeitos ambientais (Costa, 2008). Teve início, assim, o paradigma de mobilidade sustentável. Segundo Banister (2011), o paradigma de mobilidade sustentável significa encorajar uma abordagem de planejamento que estimule a diminuição do uso do carro e o aumento de meios alternativos de transporte, visando reduzir o número e duração das viagens e incentivar uma mudança modal para gerar uma maior eficiência no sistema de transporte. Garantir a sustentabilidade do transporte tornouse, portanto, uma prioridade para os governos em todo o mundo (Porta et al., 2019).

Assim, as tendências atuais de pesquisa no campo do planejamento de transportes foram mais redirecionadas para uma análise de tráfego abrangente e multimodal, levando em consideração uma gama mais ampla de opções e impactos (Litman, 2011).

O planejamento de transporte multimodal se refere ao planejamento de várias opções de transporte, geralmente incluindo caminhada, ciclismo, transporte público e automóvel, e contabiliza os fatores de uso da terra que afetam a acessibilidade (Williams et al., 2016). Esse tipo de planejamento é complexo porque os modos de transporte diferem em vários aspectos, incluindo disponibilidade, velocidade, custos, restrições e usabilidade. A análise de tráfego se torna ainda mais complexa porque cada modo inclui várias subcategorias com características distintas (Litman, 2013).

Por ser uma tarefa desafiadora que envolve uma análise comportamental complexa de cenários de tráfego multimodal, estratégias efetivas de tráfego devem ser exploradas para mitigar questões relacionadas ao congestionamento crescente do tráfego. Antes que essas novas soluções sejam implantadas em ambientes de tráfego real, é necessário que experimentos recorrentes e que ciclos extensivos de testes sejam realizados. Assim, os simuladores desempenham um papel crucial de apoio ao emular ambientes reais durante os testes (Rakkesh et al., 2016). Dessa forma, esse estudo vem exatamente para preencher essa necessidade de realização de testes antes da tomada de decisão sobre a expansão do sistema de transporte da RMRJ.

Na realização desses testes em simuladores são criados cenários alternativos para se avaliar as questões pertinentes. Segundo Song et al. (2005) o desenvolvimento de cenários como um meio de representar possíveis alternativas futuras tem sido utilizado por várias décadas pelos planejadores e sua popularidade se deve ao fato de: os planejadores podem usar cenários para delimitar incertezas; podem incorporar premissas explícitas para 
construir diferentes conjuntos de alternativas; podem vislumbrar seletivamente um conjunto de contingências hipotéticas de desenvolvimento juntamente com as metas e prioridades, dentre outros (Xiang e Clarke, 2003).

Van der Heijden (1996) define cenário como um conjunto de futuros possíveis, mas estruturalmente distintos que possibilita diferentes perspectivas da situação, conduzindo o planejador a optar pelas melhores estratégias. Logo, o uso de cenários não só contribui para a modelagem e planejamento de desenvolvimentos alternativos, mas também melhora a qualidade da tomada de decisão (Song et al., 2005).

Contudo como citado por Ortúzar e Willumsen (2011), a preparação de cenários realistas e consistentes não é simples, pois é muito fácil construir futuros que não são financeiramente viáveis nem que se adequem ao provável contexto da evolução do uso do solo e atividades na área de estudo. Não há muita orientação para a construção de cenários no campo do planejamento (Avin e Dembner, 2000). Song et al. (2014) mostra em seu estudo, três passos para se construir cenários. O primeiro passo é fazer uma revisão do sistema de planejamento de transportes atual para entender o contexto geral em que o crescimento urbano se desenvolveu, tais como esforços de planejamento, características políticas e econômicas. O segundo passo consiste em fazer uma análise dos padrões de desenvolvimento urbano existentes, apurando a densidade populacional atual, as redes de transporte, a densidade e acessibilidade de emprego atual, a distribuição da população e emprego, etc. E finalmente o último passo baseia-se em sintetizar as análises de planejamento prévio e estabelecer a estrutura necessária para a criação de cenários alternativos de desenvolvimento.

Após o estabelecimento de um possível cenário alternativo para o futuro, é importante verificar se ele realmente está adequado ao que foi proposto. Xiang e Clarke (2003) propuseram três critérios para um cenário ser considerado bom: Primeiro, o cenário deve incorporar a incerteza futura, a probabilidade de resultados alternativos e a diversidade dos valores e objetivos dos stakeholders; segundo, deve ser composto por informações relevantes e apresentadas de maneira nítida; e terceiro, deve especificar o número de temas ou dimensões, o tamanho e o período de tempo de um conjunto de cenários e escolhê-los cuidadosamente para que os cenários possam representar efetivamente a necessidade dos usuários. No entanto essa incerteza e probabilidade não serão levadas em consideração nesse estudo.

O setor de transportes apresenta questões controversas em relação ao desenvolvimento sustentável, mas chegou-se ao consenso que o transporte público está posicionado como uma transição para um ambiente urbano sustentável e atrativo (Banister, 2008; Sorensen e Gudmundsson, 2010). Uma mudança do uso do modal carro para o modal transporte público, ciclismo e caminhada são considerados necessários para a redução da 
poluição (Sims et al., 2014) melhorando, assim, a saúde (Wen e Rissel, 2008) e habitabilidade das comunidades (Kenworthy, 2006). No entanto, a capacidade real de convencer os passageiros a reduzir o uso de carros particulares em favor de formas mais sustentáveis depende principalmente de como o setor de transportes é governado, quais alavancas de governança são usadas e como são utilizadas (Porta et al., 2019).

Um sistema de transporte urbano sustentável requer o fortalecimento de várias características do sistema, incluindo acessibilidade e mobilidade, confiabilidade e eficiência, assim como segurança, equidade social, conveniência e conforto. $\mathrm{O}$ sistema de transportes públicos urbanos deve levar a uma maior mobilidade e gerar uma maior equidade entre os cidadãos de diferentes classes econômicas (Jackiva e Budilovich, 2017).

Nos últimos anos, houve uma crescente percepção dentro do governo brasileiro de que a sempre crescente motorização das cidades é insustentável, e que é preciso haver uma mudança para sistemas de transporte sustentáveis. Desde então, algumas iniciativas foram lançadas pelo Governo do Estado do Rio de Janeiro, como o Plano de Mobilidade Urbano Sustentável, já citado anteriormente. O Plano de Mobilidade Urbana tornou-se o instrumento de efetivação da Política Nacional de Mobilidade (Brasil, 2012). Diante desta determinação, os municípios com mais de vinte mil habitantes estão obrigados a entregar o Plano de Mobilidade Urbana (PMU), como condição para receber recursos federais destinados a projetos de mobilidade urbana. Além de estar integrado ao Plano Diretor de Desenvolvimento Urbano, o PMU deve apresentar as ações para materializar os objetivos e metas que pretendem resolver os problemas e as necessidades da população (Brasil, 2012).

A integração dos diferentes modos de transporte também é uma alternativa para aumentar a mobilidade urbana de forma sustentável, pois permite o aumento do número de rotas, reduz custos, minimiza impactos ambientais além de contribuir para a redução do congestionamento da malha urbana. Logo, para melhorar a circulação nas cidades e aumentar a qualidade de vida das pessoas, deve-se otimizar o sistema de transportes com o aumento da integração entre os diversos modais (Maciorowski et al., 2017).

Para Carvalho (2005), a integração é a chave para resolver os desafios atuais da mobilidade urbana, além de ser um dos pilares para a sustentabilidade. Segundo esse autor, a integração possibilita que o transporte público saia do papel restrito de transporte de alta capacidade e passe a oferecer soluções de mobilidade complementar e global. Segundo Gray e Hoel (1979), os sistemas de integração são um conjunto de técnicas de gestão aplicadas para um grupo de funções que atualmente são administradas independentemente, mas que poderiam ser mais eficientes se fossem tratadas como partes interrelacionadas de um único sistema. 


\subsection{Planos de Transporte}

O planejamento de transportes é uma área de estudo que visa identificar os problemas do sistema de transporte atual e propor meios de desenvolvê-lo, seja implementando novos sistemas, seja aperfeiçoando os já existentes. É importante destacar que um plano de transporte deve estar voltado exclusivamente para uma determinada região, pois cada região possui suas características e limitações estruturais, a demanda por transporte depende do seu desenvolvimento atual e futuro e esses fatores fazem com que o plano mude de acordo com a local estudado (Campos, 2013).

Apesar dos planos variarem de acordo com a região estudada, algumas práticas de planejamento de transporte, segundo Feitelson e Cohen-Blankshtain (2018) continuam sendo transferidas de um local para outro por terem premissas e objetivos semelhantes, como é o caso das etapas para formação de um plano de transportes. De acordo cm Bruton (1979), as etapas são:

1. Estabelecimento de metas e dos respectivos prazos.

2. Reconhecimento da malha viária da área de estudo e caracterização dos sistemas de transportes que a compõem, ou seja, a oferta.

3. Coleta de dados sobre o uso do solo, população, condições econômicas e padrões de viagens para a situação atual, ou seja, a demanda.

4. Escolha dos modelos a serem usados para estimação da demanda futura.

5. Previsão da demanda futura.

6. Desenvolvimento de redes alternativas com as opções de transporte disponíveis e dimensionado para acomodar a demanda futura.

7. Avaliação das redes alternativas de transporte propostas, tanto em termos econômicos como sociais e ambientais.

8. Escolha da melhor alternativa.

9. Desenvolvimento do plano detalhado de transporte acompanhado de um programa de financiamento.

10. Implementação da rede de transporte alternativa mais apropriada de acordo com um cronograma.

$\mathrm{Na}$ figura 2 é mostrado um esquema que resume as etapas de um plano de transporte: 


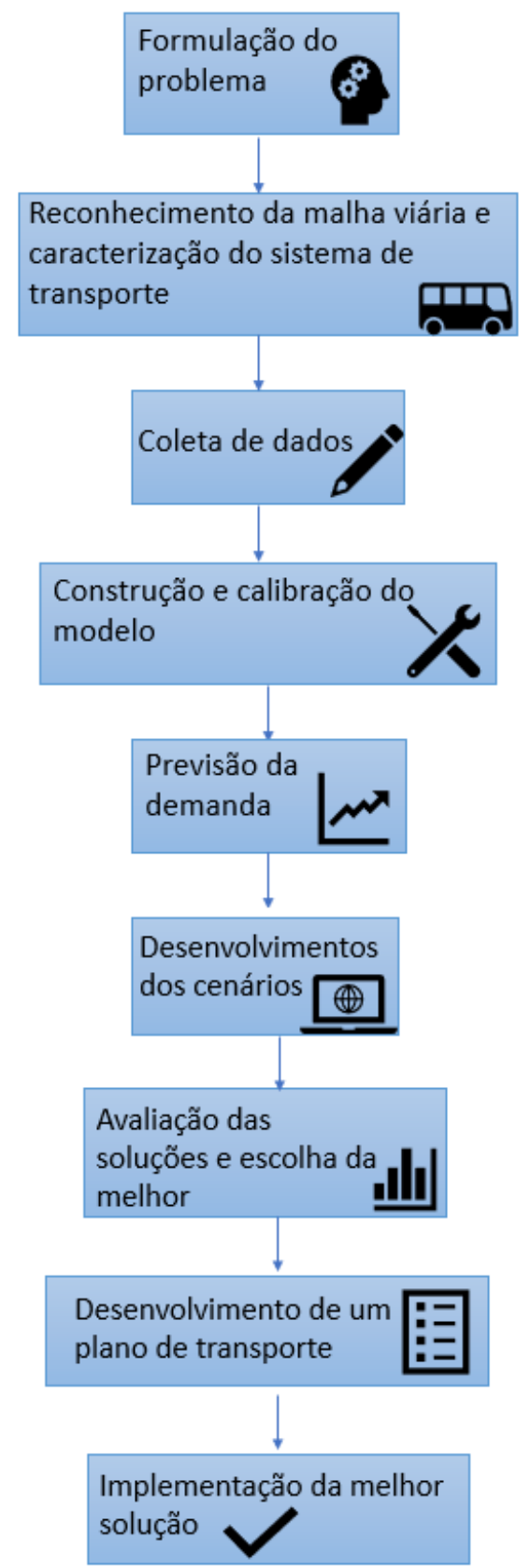

Figura 2: Esquema básico do planejamento de transportes. Adaptado de Bruton (1979).

Segundo Novaes (1986), os procedimentos de análise e previsão da demanda têm como objetivo auxiliar na tomada de decisão em relação a mudanças que o sistema de transporte necessita e que melhor se adequem a realidade da região. A demanda por transporte é totalmente dependente das características físicas, sociais e econômicas da região de estudo. Qualquer mudança no uso do solo tem efeito sobre a movimentação das pessoas.

Assim, segundo Bruton (1979), faz-se necessário uma coleta de dados para definir o padrão de viagens e o uso do solo na área de estudo e fazer um diagnóstico sobre o sistema de transporte existente através de pesquisas na via (contagem de tráfego e pesquisas no 
tráfego), no sistema (pesquisa de embarque e desembarque em ônibus e no cordão externo), com usuário ou com a comunidade (entrevistas). Para que seja feito de forma eficiente, é necessário fazer a delimitação da área de estudo. A área de estudo é delimitada pelo que chamamos de cordão externo que deve abranger todos os movimentos importantes no cotidiano da área urbana estudada. Também devem estar inclusas as áreas que serão desenvolvidas no futuro, dentro do período de planejamento. E satisfazendo critérios técnicos, o cordão externo deve cruzar as principais vias e corredores da região.

Delimitada a área de estudo é necessário fazer o zoneamento, que nada mais é do que dividir a área de estudo em regiões menores chamadas de zonas de tráfego. Essa divisão permite que os dados sejam coletados em detalhes suficientes que permitam tirar conclusões significativas. Dois tipos de zonas de tráfego devem ser utilizados: zonas internas, definidas dentro do cordão externo e zonas externas localizadas fora deste cordão. Após a definição das zonas de tráfego, é possível fazer a coleta de dados que vai dar suporte aos modelos de previsão de demanda.

Um plano de transporte pode ser estratégico, tático ou operacional dependendo do horizonte de sua aplicação, que pode ser de longo, médio ou curto prazo, dos recursos disponíveis e dos níveis de decisão contidas nele (Campos, 2013). Um plano estratégico foca em ações de longo prazo. O planejamento de transporte se insere nesse nível pois o plano estratégico engloba metas da região e políticas do estado e do país (Carter e Homburger, 1978), considera o uso presente e futuro do solo, ações estas que fazem parte do planejamento de transporte. Além disso, o planejamento de transportes também visa desenvolver um sistema de transportes integrado e otimizar seu gerenciamento e operação.

De acordo com (Campos, 2013), um plano tático contém ações que podem ser tanto consequências das diretrizes do planejamento estratégico como de decisões baseadas em problemas operacionais, ou seja, são ações de médio e longo prazo. Neste nível de análise, são exemplos de tarefas: projeto geométrico das vias (determinação de largura de faixas, dimensionamento de áreas para pedestres e largura de calçadas e de passeios, etc.), elaboração de projetos de sinalização e de controle eletrônico do tráfego, dentre outros

Ainda de acordo com (Campos, 2013), o plano operacional está relacionado basicamente com ações de curto prazo, que devem possuir o máximo de detalhes possível. Análises que normalmente conseguem ser feitas nesse espaço de tempo são: configuração do uso das faixas de tráfego, aplicação de dispositivos de controle de tráfego, programação de semáforos, espaçamento e localização de paradas de ônibus, frequência de um serviço de ônibus, etc. 


\subsubsection{O modelo de quatro etapas}

O procedimento clássico para planejamento de transportes se inicia com uma coleta de dados conforme descrito anteriormente na Seção 2.2. De posse dos dados necessários parte-se para fase de previsão da demanda futura e para a configuração dos padrões de fluxo nos diferentes cenários. Para tal, utiliza-se mais comumente o modelo sequencial de demanda, também conhecido como modelo de quatro etapas que compreende: modelos de geração de viagens, de distribuição de viagens, de divisão modal e por fim, de alocação de fluxo.

O modelo de quatro etapas pode incorporar um processo iterativo entre distribuição e alocação de viagens, o que deixa a geração de viagens inalterada. A principal desvantagem dessa abordagem é que as mudanças na rede acabam não tendo efeitos sobre as produções e atrações da viagem (Ortúzar e Willumsen, 2011).

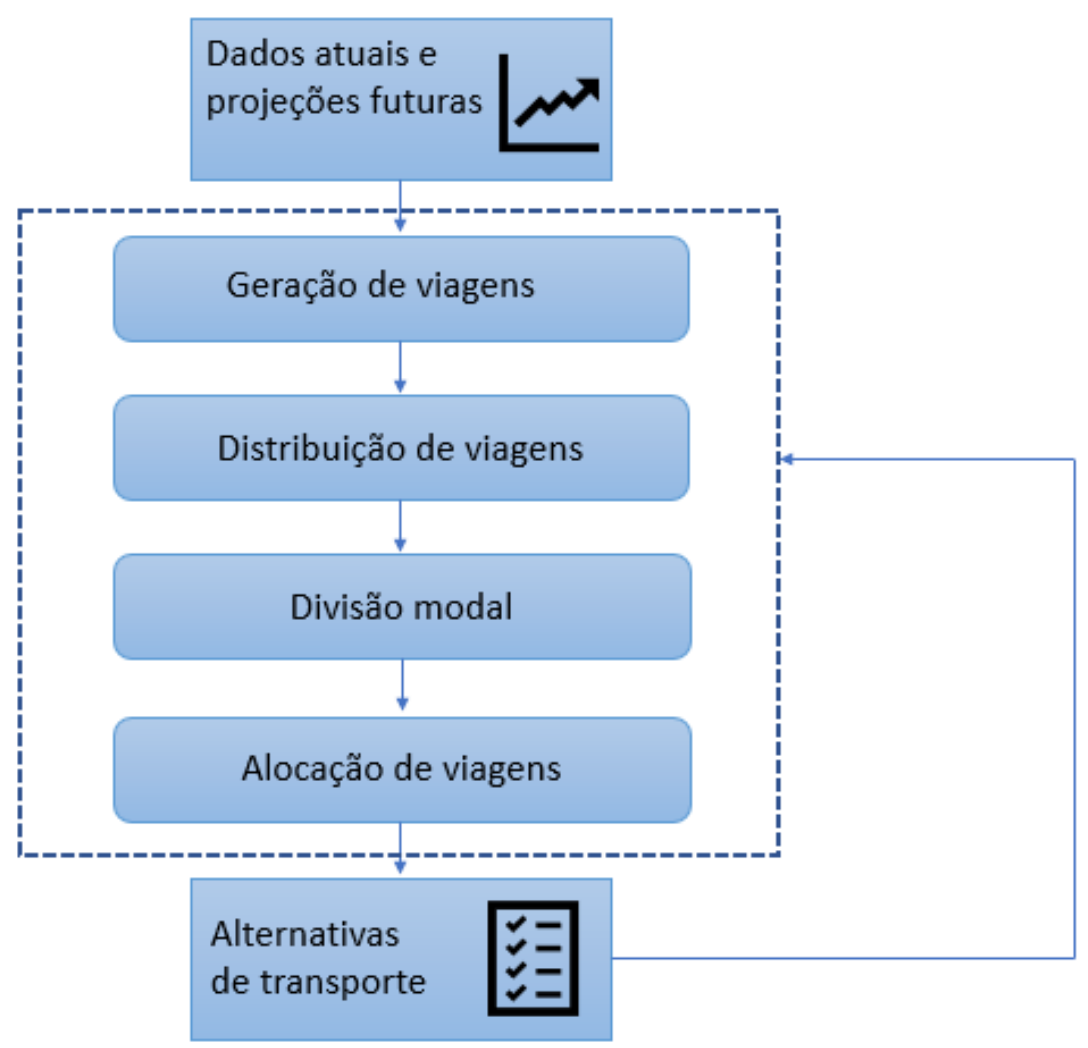

Figura 3: Modelo sequencial de demanda. Adaptado de Campos (2013).

A Figura 3 apresenta a ordem mais usada do modelo de 4 etapas, contudo Ortúzar e Willumsen (2011) relata que alguns estudos já colocaram a divisão modal antes da distribuição da viagem e imediatamente após a geração de viagem. Isso permitiu uma maior ênfase nas variáveis de decisão. Outra abordagem foi realizar a distribuição e divisão modal simultaneamente. 


\subsubsection{Geração de viagens}

Esta é a primeira etapa da análise de dados, e de acordo com Bruton (1979) procurase determinar a quantidade futura de viagens de cada zonas de tráfego através das relações observadas entre as viagens, dados socioeconômicos da população, uso e desenvolvimento do solo da área de estudo e as características do sistema de transporte. Por ser o início de todo o processo deve ser realizada com o maior nível de precisão possível.

A geração consiste na soma das viagens que se iniciam numa determinada zona de tráfego, que recebe o nome de zona de produção, e as viagens que chegam numa determinada zona de tráfego, que se chamará de zona de atração.

Ortúzar e Willumsen (2011) apresentam os seguintes fatores que influenciam na geração de viagens: uso do solo pelo comércio, indústria e educação, densidade residencial, renda familiar, tamanho da família, tipos de domicílio, propriedade de automóvel, dentre outros.

Os modelos de geração de viagem que podem ser citados são: Fator de Crescimento, Taxas de Viagens, Classificação Cruzada ou Análise de Categorias e Regressão (Ortúzar e Willumsen, 2011).

\subsubsection{Distribuição de viagens}

As produções e atrações obtidas através da etapa anterior fornecem uma ideia do volume de viagens em uma área de estudo, mas só isso raramente é suficiente para modelagem e tomada de decisão. É necessário se ter uma ideia melhor dos padrões de viagens (Ortúzar e Willumsen, 2011).

A distribuição de viagens, segundo Bruton (1979) é a parte do processo de planejamento de transporte onde as origens e destinos de cada zona de tráfego são interrelacionados. O objetivo é definir o tráfego futuro entre zonas a partir dos dados do ano base e das projeções de viagens produzidas e atraídas. O produto dessa etapa pode ser representado por pelo menos duas maneiras diferentes, segundo Ortúzar e Willumsen (2011). A primeira seria uma matriz Origem-Destino que armazena as viagens feitas de uma origem para um destino durante um determinado período de tempo. A segunda maneira de apresentar seria uma matriz de produção-atração que armazena viagens feitas entre zonas de atração e zonas de produção de passageiros.

Essa distribuição, em geral, é feita independente do meio de transporte usado para realizar tais viagens e da rede utilizada, pois o que se procura é quantificar os fluxos futuros de movimentos entre zonas. 
Os modelos de distribuição de viagens podem ser classificados em modelos de fator de crescimento (Crescimento uniforme, Crescimento Médio, Fratar e Furness) e modelos Gravitacionais.

O método de Fratar, Furness e os modelos gravitacionais são os mais utilizados segundo Ortúzar e Willumsen (2011) e podem ser executados pelo software EMME no módulo de balanceamento bidimensional de matrizes.

\subsubsection{Divisão Modal}

A divisão modal tem como objetivo dividir o total de viagens realizadas entre os diferentes modos de transporte, ainda sem se preocupar com a rede (Bruton, 1979). O produto dessa etapa são matrizes Origem-Destino para cada um dos modos de transporte.

A escolha do modo de transporte é provavelmente um dos estágios mais importantes do modelo clássico de planejamento de transportes devido ao papel que o transporte público desempenha na formulação de políticas públicas (Bai et al., 2017). Isto porque o transporte público utiliza o espaço viário mais eficientemente e produz menos acidentes e emissões de gases poluentes ao meio ambiente do que o transporte individual. Além disso, os modos subterrâneos e outros modos ferroviários não contribuem para o congestionamento rodoviário. Portanto se alguns motoristas pudessem ser persuadidos a trocar o automóvel pelo transporte público, todos os usuários da via se beneficiariam de melhores níveis de serviço, o que poderia amenizar os problemas do ciclo vicioso do automóvel/transporte público, retratado na Figura 1.

A escolha por um determinado modo de transporte em áreas urbanas não é um processo estático ou aleatório (Ortúzar e Willumsen, 2011). Segundo Asmael e Alkawaaz (2019) características socioeconômicas como renda, idade e propriedade do automóvel e características dos serviços dos modos de transporte, como velocidade, conforto, conveniência, custo, propósito da viagem, duração e trajeto da viagem influenciam a escolha modal. A inclusão desses fatores na formulação de modelos de escolha modal depende da possibilidade desses atributos serem quantificados com exatidão e confiabilidade. Consequentemente, quando a influência desses fatores é mínima, eles podem ser omitidos da formulação (Bruton, 1979).

Os modelos de divisão modal são classificados em dois tipos: determinísticos e probabilísticos (Ortúzar e Willumsen, 2011). Os determinísticos fazem uso de métodos quantitativos mais simples como a regressão linear, por exemplo. Já os probabilísticos são mais elaborados pois levam em consideração a probabilidade de escolha de cada modo, e essa probabilidade é função da atratividade da opção escolhida dentre todas as alternativas possíveis. Essa atratividade é representada pela função utilidade que reúne uma 
combinação de variáveis sobre as características do modo e do indivíduo para revelar seu grau de satisfação com aquela alternativa (Asmael e Alkawaaz, 2019). O modelo Logit é o modelo probabilístico mais frequentemente usado na literatura. O Modelo de Logit é o nome de um grupo de modelos composto por modelo de Logit Multinomial, modelo de Logit Aninhado, modelo de Logit Misto, etc (Bai et al., 2017). Esses modelos baseiam-se na ideia de que um indivíduo deve selecionar o melhor modo, o que lhe confere a maior utilidade dentre os modos disponíveis (Lindner e Pitombo, 2016).

\subsubsection{Alocação de Fluxo}

Segundo Menezes (1971), a alocação de fluxo é o processo no qual o fluxo de viagens entre zonas de um determinado modo de transporte é alocado a rede correspondente. Essa etapa fornece estimativas de fluxos de tráfego em vias estratégicas tendo como objetivo avaliar as deficiências do sistema de transporte atual e testar propostas alternativas de sistema de transporte assim como melhorias no sistema atual e avaliar seus efeitos a médio e longo prazo.

Segundo Campos (2013), o problema de alocação de fluxos em redes de transporte é divido em dois subproblemas: o problema de escolha de rotas e o problema de distribuição de fluxos nas rotas escolhidas a partir de uma matriz de fluxos entre diversas origensdestinos. Ambos problemas, partem do ponto de vista do usuário que tenta minimizar seu tempo de viagem. Os métodos de resolução desses problemas procuram seguir um dos dois princípios extremos, definido por Wardrop (1952): os tempos de viagem nas rotas utilizadas devem ser iguais ou menores que um caminho não usado qualquer feito por um único veículo; e o tempo médio global de viagem de todos os motoristas é mínimo. A aplicação destes princípios relaciona dois importantes problemas de alocação de fluxos em redes que são a determinação da rota de menor custo (tempo) na rede, e a minimização do custo total na rede.

A alocação de fluxo pode ser dividida para transporte individual, coletivo ou multimodal. No transporte individual os métodos usados são os modelos tudo-ou-nada, estocásticos ou de equilíbrio (Ortúzar e Willumsen, 2011). Já na alocação para o transporte coletivo que será a realizada nesta dissertação, dois modelos são considerados os mais importantes e utilizados e, portanto, merecem ser mencionados: os modelos de rota mínima e de estratégia ótima.

Nos modelos de rota mínima, o passageiro do sistema de transporte coletivo utiliza a rota que minimiza seu custo generalizado. Custo generalizado é função dos fatores envolvidos na decisão como o conforto, custo da passagem, tempo gasto na viagem e de espera, etc (Ortúzar e Willumsen, 2011). 
O modelo de estratégia ótima foi formulado por Spiess (1983) e baseia-se em escolher um subconjunto de linhas para minimizar o valor esperado total do custo da viagem. Ayari et al. (1995) define que uma estratégia de viagem é um conjunto de linhas e possíveis pontos de desembarque e transbordo que o usuário considera como atrativo para chegar ao seu destino. Contudo a possibilidade de trechos do caminho serem atendidos por mais de uma linha de ônibus, gera várias alternativas de escolha para o passageiro tornando a modelagem mais difícil de se fazer. Spiess (1983), então, através da programação linear propõe um modelo que possibilita determinar as rotas ótimas de viagem entre dois nós, ou seja, aquela que minimiza o valor esperado do custo total de viagem. Segundo Cea et al. (1990), a alocação usando a abordagem de rotas mínimas é mais eficiente em termos de tempo de cálculo.

O modelo de Spiess (1983) generaliza o custo de viagem em veículo como uma função crescente do fluxo de passageiros em um arco, não levando em consideração, portanto, o efeito do congestionamento. Só posteriormente com Gendrau (1984) que os efeitos do congestionamento começaram a ser considerados. Este autor considerou os efeitos do congestionamento na distribuição de passageiros e nos tempos de espera nas paradas. Spiess e Florian (1989) consideraram o efeito do congestionamento como o desconforto dos passageiros dentro de um ônibus lotado ao propor um modelo em que os custos do deslocamento em veículo são funções crescentes do número de passageiros. Já Cea e Fernández (1993) consideram o congestionamento como um parâmetro exógeno, assumindo que o tempo de viagem em veículo é fixo e os tempos de espera dependem da capacidade dos arcos e do fluxo de passageiros.

Após essa revisão sobre o modelo de 4 etapas, é possível perceber a importância fundamental dessa ferramenta para o desenvolvimento de um bom plano de transportes. 


\section{Plano diretor de transporte do Rio de Janeiro}

Neste capítulo é apresentado o conceito de Plano Diretor e é resumida a história do Plano Diretor de Transporte do Rio de Janeiro (PDTU-RMRJ), juntamente com os passos de como foi a definição da área de estudo e o processo de zoneamento. Também é caracterizado e analisado o sistema de transporte do estado do Rio de Janeiro.

\subsection{O Plano Diretor}

Os planos diretores exigidos aos municípios representam a visão de como o desenvolvimento urbano local deve ser projetado. Num plano diretor estão estabelecidas metas sustentáveis destinadas a aliviar o impacto da expansão urbana e a gestão do desenvolvimento urbano, concentrando-se em equilibrar o desenvolvimento econômico e social (Qian, 2013).

Os planos diretores são desenvolvidos, implementados, avaliados, revisados e readaptados pelos municípios que tentam dar a direção coesa do crescimento urbano de sua região. Logo, o processo de desenvolvimento de um plano diretor com todos esses ajustes, revisões, readaptações e consequentemente criação de novos planos diretores acaba se tornando um processo circular iterativo e heurístico entre os governos do Estado e do município (Qian, 2013).

Conclui-se que o plano diretor de uma cidade reflete a visões políticas do governo local fornecendo a direção ideal para o crescimento da região em termos de objetivos demográficos, econômicos e sociais. Tais fatos, o tornam um dos mais importantes mecanismos legais de orientação para o desenvolvimento urbano.

Com isso percebe-se a importância dos planos diretores reafirmado pela quantidade de estudos na literatura sobre o tema. Contudo, quando a busca foi direcionada para o tema proposto nessa dissertação não foi encontrado nenhum estudo semelhante. $\mathrm{O}$ mais próximo encontrado foi o estudo do transporte de cargas usando o PDTU-RMRJ (Perez, 2015).

\subsection{O Plano Diretor de Transporte da Região Metropolitana do Rio de Janeiro}

As populações dos municípios da Região Metropolitana do Rio de Janeiro (RMRJ) vêm crescendo ano após ano além da parte econômica e social. Com tudo isso, o transporte 
urbano está ficando cada vez mais complexo e com maiores exigências. O serviço de transporte intermunicipal na RMRJ é atribuição da Secretaria de Estado de Transportes (SETRANS), assim como a implantação de um plano diretor integrado para esta região. Vinculados à secretaria, podem-se destacar, do corpo institucional: a Agência Metropolitana de Transportes Urbanos (AMTU); a Agência Reguladora de Serviços Públicos Concedidos de Transportes Aquaviários, Ferroviários e Metroviários e de Rodovias do Estado do Rio de Janeiro (AGETRANSP); e a Companhia de Transportes sobre Trilhos do Estado do Rio de Janeiro (RioTrilhos) (Santos e Costa, 2013).

Conforme destacado por Santos e Costa (2013), a heterogeneidade de atores e a fragmentação das funções no âmbito dos transportes no Estado dificultam a tomada de decisões, bem como a desejável integração entre esta função e as demais de interesse comum.

Desde 1999, iniciou-se a elaboração de planos para o desenvolvimento da área de transportes. O Programa Estadual de Transportes, desenvolvido nesse ano, estabeleceu uma série de ações e investimentos necessários à promoção de um sistema integrado de transportes urbanos (Santos e Costa, 2013). Contudo as tecnologias específicas para o transporte em massa não estavam sendo plenamente aproveitadas e o transporte rodoviário continua sendo o principal meio de transporte em detrimento daqueles de maior capacidade potencial. Esta situação era proveniente da falta de investimentos nos sistemas de alta capacidade, especialmente ao longo da primeira metade da década de 90, e da falta de políticas objetivando a racionalização e a integração dos modos de transporte. Foi assim que em 2003, um novo instrumento de ordenamento do transporte público foi lançado pelo Governo de Estado mediante a SETRANS, e recebeu o nome de Plano Diretor de Transportes Urbanos (PDTU) da Região Metropolitana do Rio de Janeiro. As políticas propostas resultantes desse plano serviram como delineamentos para investimentos em infraestrutura viária para todos os modais presentes na cidade com fim de melhorar a utilização das redes de transporte.

No ano 2011 foi contratado o Consórcio HALCROW - SINERGIA - SETEPLA para a elaboração, desenvolvimento e atualização do PDTU, tendo como objetivos gerais a avaliação de resultados anteriores e a elaboração de novas propostas no horizonte de dez anos, considerando os investimentos relevantes que estão sendo realizados nos municípios da RMRJ.

Dois fundos são utilizados para viabilizar a política pública de transportes na Região Metropolitana: o Fundo Estadual de Transportes, voltado para viabilizar subsídios à operacionalização do bilhete único, e o Fundo para Operação e Melhoria dos Transportes Coletivos Metropolitanos, voltado para a modernização do sistema. Contudo é possível notar que a maior parcela desses investimentos está concentrada no município-núcleo da 
RM do RJ, o que reforça e condiciona a interdependência dos demais municípios com a cidade do Rio de Janeiro (Santos e Costa, 2013).

O PDTU faz uso de um modelo matemático de transporte sofisticado que surge como resposta às dificuldades que estão sendo geradas em relação ao transporte da cidade (tanto na parte da oferta como da procura) e visa se tornar uma ferramenta de planejamento que consiga lidar com as futuras alterações e/ou necessidades de transporte da RMRJ. O PDTU utiliza um modelo matemático de 4 etapas, que são, o Modelo de Geração, Modelo de Distribuição, Modelo de Divisão Modal e Modelo de Alocação na Rede. Trata-se de uma ferramenta que contempla os problemas de congestionamento da rede, fazendo uso de simulação de cenários e projeções de viagens futuras.

\subsubsection{Definição da Área de Estudo}

O estado do Rio de Janeiro é composto por 92 municípios e tem como capital o município do Rio de Janeiro. Estes municípios são agregados em oito regiões de planejamento, que são: Região Metropolitana, Região da Costa Verde, Região do MédioParaíba, Região Centro-Sul Fluminense, Região Serrana, Região das Baixadas Litorâneas, Região Norte Fluminense e Região Noroeste Fluminense. Estas regiões de planejamento e seus municípios podem ser visualizadas na Figura 4.

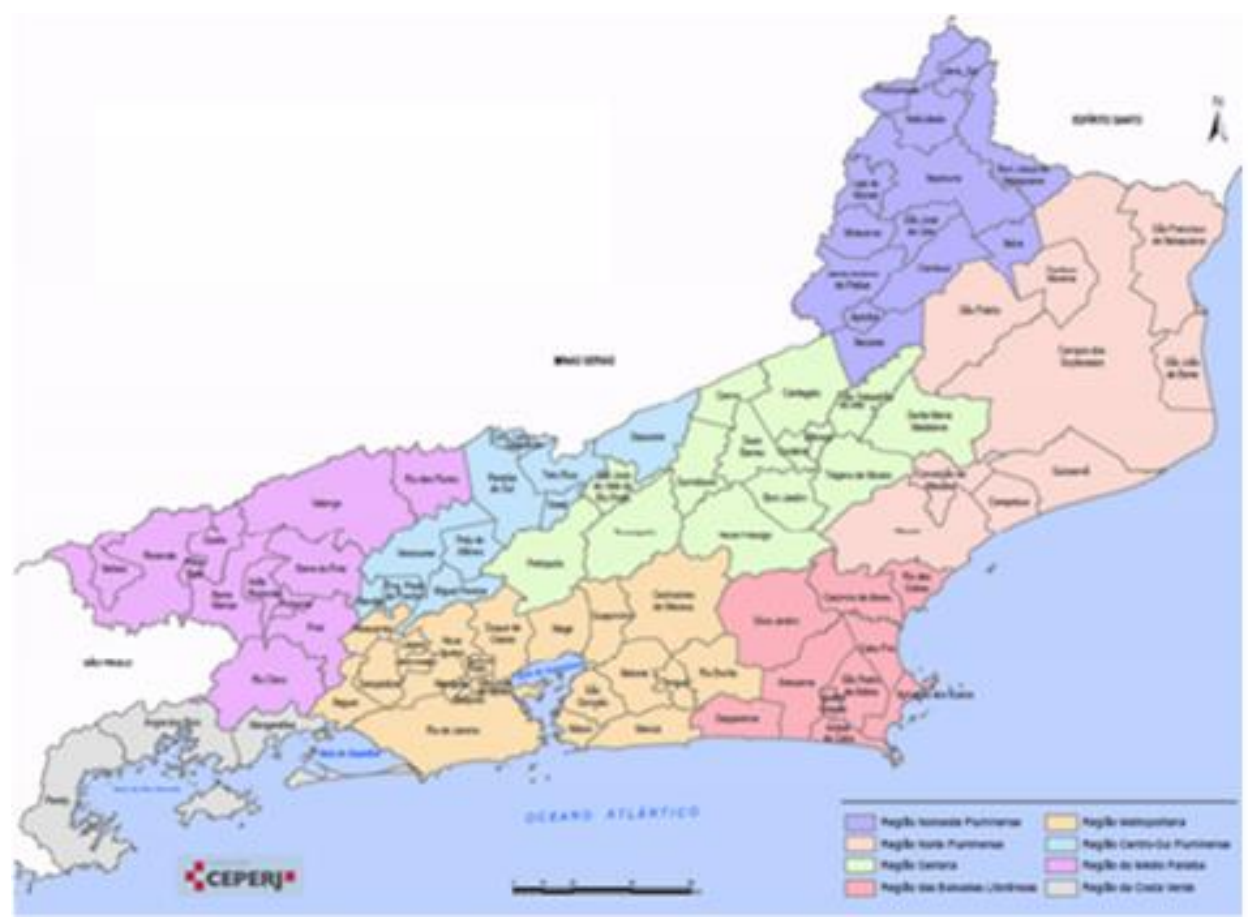

Figura 4: Regiões de planejamento do Estado do Rio de Janeiro (CEPERJ 2014)

A RMRJ é produto da fusão de 21 municípios sendo considerado uma das maiores áreas metropolitanas do país. Para a realização do PDTU foram considerados, entretanto, 
20 municípios, e para o desenvolvimento desta dissertação decidiu-se manter a mesma área de estudo definida para o PDTU, como mostrado na Figura 5.

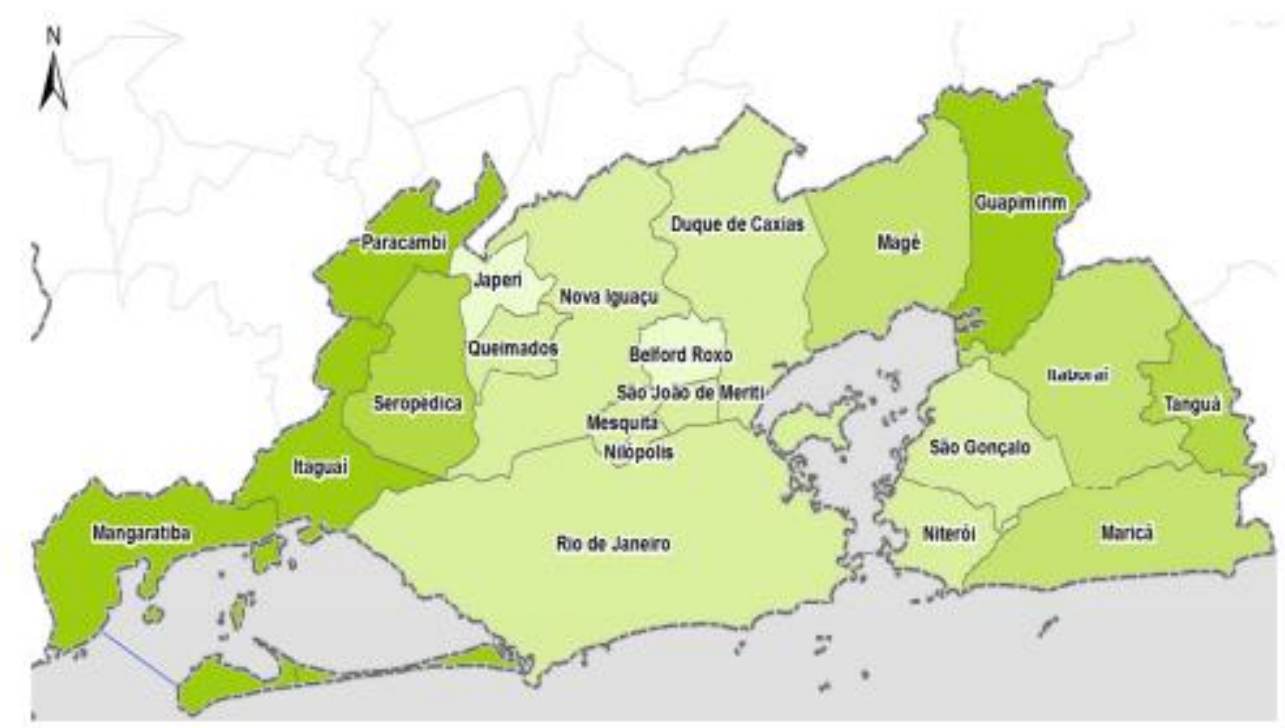

Figura 5: A RMRJ considerada para estudo do PDTU 2011 (Consórcio HALCROWSINERGIA-SETEPLA)

Na Figura 5 é possível notar que para o projeto do PDTU, foi excluído da RMRJ , os municípios de Rio Bonito e Cachoeiras de Macacu e acrescentado o município de Mangaratiba. O motivo principal de este município ser adicionado é porque faz parte da "Rede Urbana Metropolitana" (Figura 6), a qual é uma rede que permite unir os principais focos logísticos, comerciais, educacionais e de saúde com as áreas urbanas através de acessos rodoviários, metroviários, ferroviários e que contribuem na economia e desenvolvimento da RMRJ. 


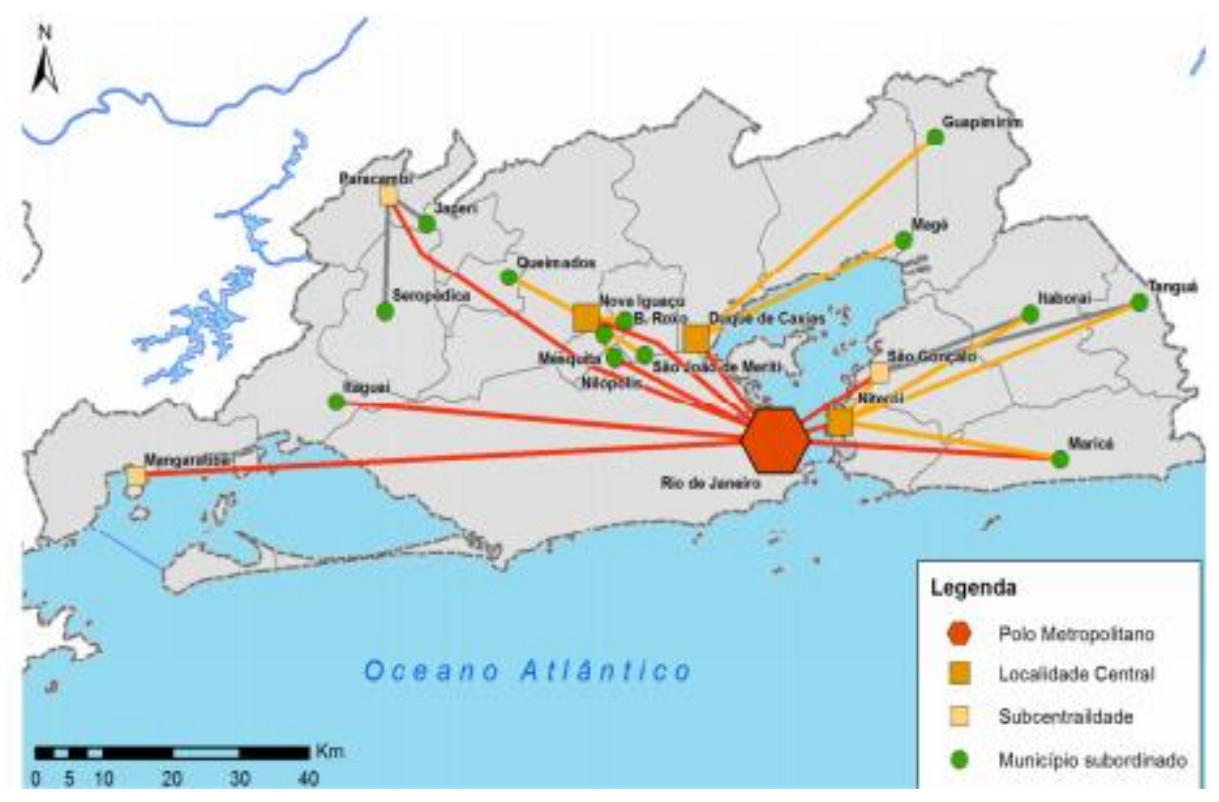

Figura 6: Rede urbano intrametropolitana (Consórcio HALCROW-SINERGIA-SETEPLA)

Definida a área de estudo, mostra-se na Tabela 1 algumas características e dados numéricos importantes com relação aos municípios que fazem parte do plano diretor de transporte da RMRJ.

Tabela1: Dados dos municípios que fazem parte do PDTU (IBGE 2018)

\begin{tabular}{|l|c|c|c|}
\hline \multicolumn{1}{|c|}{ Município } & Área $\left(\mathbf{k m}^{\mathbf{2}}\right)$ & População & Número de estudantes \\
\hline Rio de Janeiro & $1.200,1$ & 6.668 .927 & 757.505 \\
\hline São Gonçalo & 247,8 & 1.077 .687 & 76.120 \\
\hline Duque de Caxias & 467,6 & 914.383 & 112.702 \\
\hline Nova Iguaçu & 521,1 & 818.875 & 100.774 \\
\hline Niterói & 133,9 & 511.786 & 55.501 \\
\hline Belford Roxo & 77,8 & 508.614 & 49.773 \\
\hline São João de Meriti & 35,2 & 471.888 & 43.668 \\
\hline Magé & 388,5 & 243.657 & 32.971 \\
\hline Itaboraí & 430,5 & 238.695 & 17.634 \\
\hline Mesquita & 39,1 & 175.620 & 19.305 \\
\hline Nilópolis & 19,4 & 162.269 & 22.752 \\
\hline Queimados & 75,7 & 149.265 & 22.961 \\
\hline Maricá & 362,7 & 157.789 & 23.413 \\
\hline Itaguaí & 275,7 & 125.913 & 15.990 \\
\hline Japeri & 81,8 & 103.960 & 15.259 \\
\hline Seropédica & 283,7 & 86.743 & 9.103 \\
\hline Guapimirim & 360,9 & 59.613 & 5.929 \\
\hline Paracambi & 179,6 & 51.815 & 7.977 \\
\hline Mangaratiba & 356,2 & 43.689 & 5.756 \\
\hline Tanguá & 145,6 & 33.870 & 1.440 .546 \\
\hline Total: & $5.682,9$ & 12.605 .058 & \\
\hline
\end{tabular}




\section{de Janeiro}

\subsubsection{Rede e Sistema de Zoneamento da Região Metropolitana do Rio}

Conforme citado na Seção 2.2, após a delimitação da área de estudo é necessário fazer o zoneamento, dividindo a área de estudo em zonas de tráfego. Para a realização de um estudo intramunicipal é necessário que a unidade espacial analisada seja mais desagregada que os dados municipais e distritais, e compatíveis com os dados dos setores censitários e as áreas de ponderação disponibilizados pelo Instituto Brasileiro de Geografia e Estatística (IBGE). A base de dados fornecida pelo IBGE é umas das mais utilizados nos estudos demográficos brasileiros e a vantagem de trabalhar com os dados menos agregados é que apesar da especificidade da informação, são mantidas as características de abrangência, confiabilidade e periodicidade, típicas dos dados censitários oficiais (IBGE, 2002).

Para a realização do zoneamento do PDTU 2012 se sobrepôs o mapa do zoneamento do PDTU anterior (485 zonas de tráfego) e as áreas de ponderação, gerando assim 730 zonas. Áreas de ponderação, segundo o IBGE (2002) são a unidade mínima de análise constituída por um agrupamento mutuamente exclusivo de setores censitários, onde já é possível extrair resultados significativos das estatísticas e, portanto, pode ser aplicado em procedimentos de calibração de estimativas.

Para o desenvolvimento desse estudo, foi escolhido fazer o zoneamento somente em áreas de ponderação (338). Foram considerados 20 municípios da Região Metropolitana. O IBGE divulga arquivos vetoriais das áreas de ponderação somente para os municípios maiores, e juntando com uma tabela do PDTU que relacionava os setores censitários e as áreas de ponderação, chegou-se ao número de 338 áreas de ponderação que será a quantidade de zonas de tráfego usadas nesse estudo. Campos (2019) também usou a divisão do Rio de Janeiro em 338 zonas de tráfego.

O maior número de zonas disponíveis no PDTU 2012 traz a vantagem de poder estudar as zonas com maior detalhe, pois quanto maior a divisão, melhor é a precisão dos resultados dos modelos de Geração e Distribuição. Contudo quanto mais zonas, maior a complexidade da rede e maior o custo para a coleta de dados. Quando se trabalha com um modelo estratégico onde a visão é em um nível mais macro, reduzir o número de zonas traz mais facilidade sem gerar perdas na análise. 


\subsection{Caracterização e Análise do Transporte no Estado do Rio de Janeiro e na RMRJ}

O estado do Rio de Janeiro apresenta um importante centro logístico com portos localizados no município do Rio de Janeiro e Itaguaí assim como terminais de passageiros e de consolidação de cargas, aeroportos, uma rede metroviária, ferroviária, hidroviária e rodoviária.

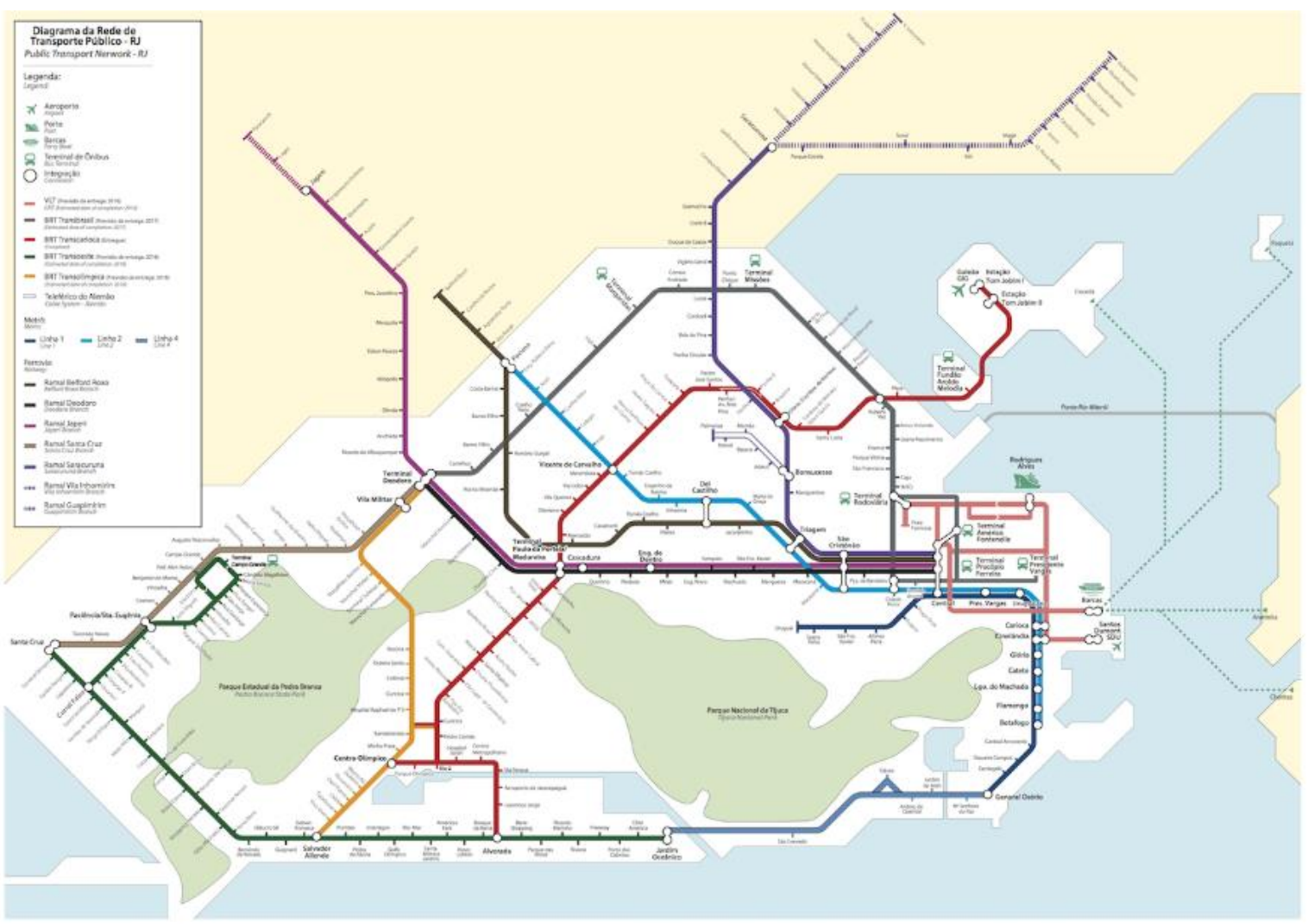

Figura 7: Diagrama da rede de transporte público do Rio de Janeiro (PMUS).

\subsubsection{Sistema de Ônibus Municipal}

O sistema de ônibus da cidade do Rio de Janeiro é o principal modo de transporte por atender o maior volume de passageiros, estimado em torno de 3,66 milhões/dia. É operada por 43 empresas que estão agrupadas em quatro consórcios, sendo eles Internorte, Intersul, Transcarioca e Santa Cruz. Cada consórcio é responsável por uma única região. Na Figura 8 são mostrados as áreas de atuação de cada consórcio e na Tabela 2 são mostrados dados dos consórcios separadamente. 


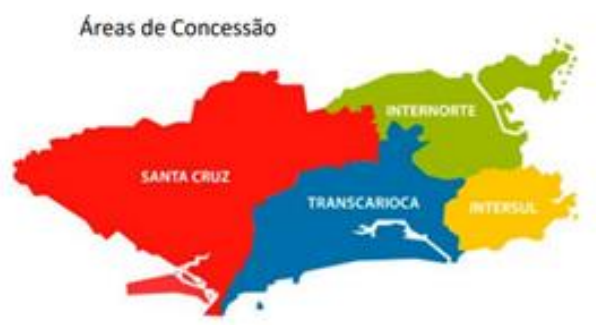

Figura 8: Mapa das áreas de concessão

Tabela 2: Dados de frota por consórcio que operada RMRJ 2016

\begin{tabular}{|c|c|c|c|c|}
\hline Consórcio & Linha & Frota Operacional & Frota Total & $\begin{array}{c}\text { Participação } \\
\text { Demanda }\end{array}$ \\
\hline Intersul & 130 & 1.505 & 1.861 & $19,8 \%$ \\
\hline Internorte & 292 & 2.441 & 2.684 & $33,0 \%$ \\
\hline Transcarioca & 147 & 1.784 & 2.110 & $27,2 \%$ \\
\hline Santa Cruz & 207 & 1.598 & 2.156 & $20,0 \%$ \\
\hline Total: & 776 & 7.328 & 8.811 & $100 \%$ \\
\hline
\end{tabular}

São 776 linhas que são classificadas em:

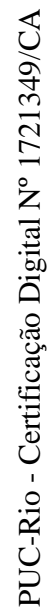

- Troncais: Linhas concentradoras de demandas agrupadas em Principal e Secundária.

- Alimentadoras: Linhas locais que integram com as troncais.

- Interbairros: Linhas de conexão entre bairros.

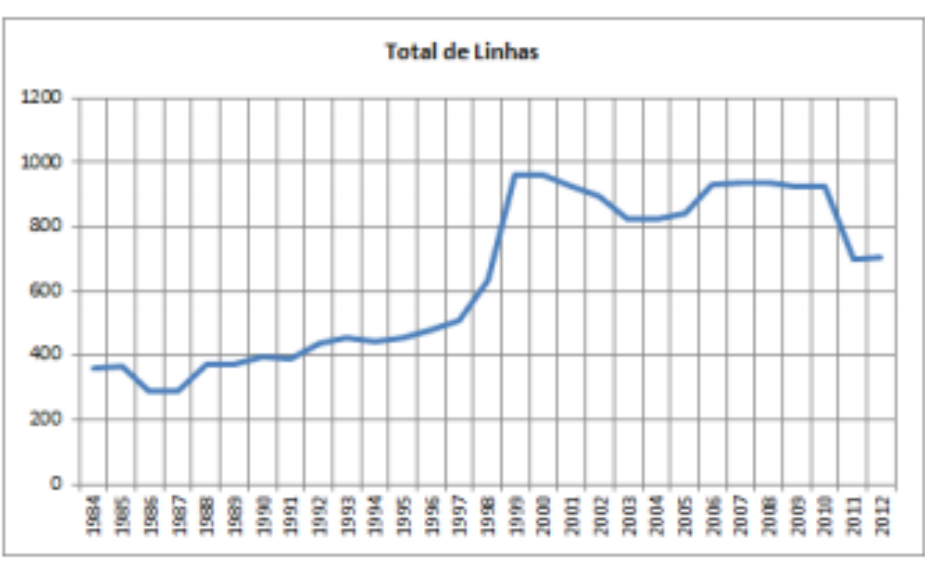

Figura 9: Quantidade de linhas do sistema de ônibus municipal do RJ(PDTU-2012) 


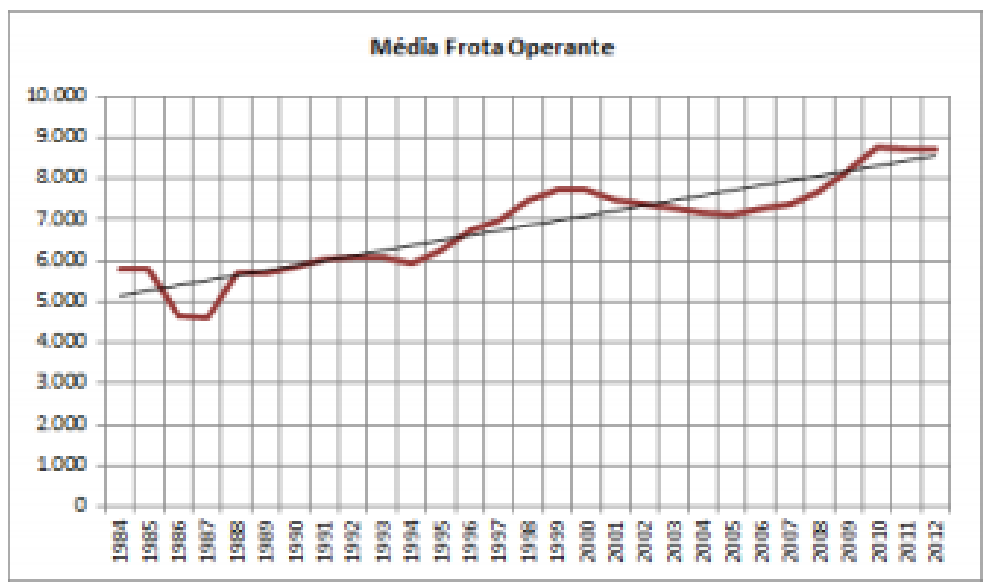

Figura 10: Frota média em operação de ônibus municipais do RJ (PDTU-2012)

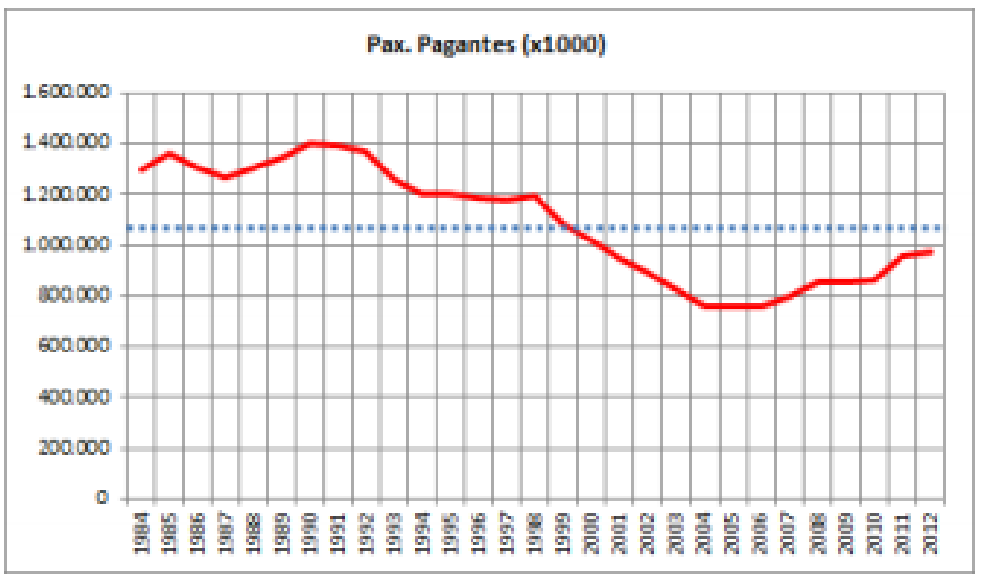

Figura 11: Número de passageiros pagantes em ônibus municipais do RJ (PDTU 2012)

Observa-se no Figura 9 que o total de linhas de uma média de 400 linhas até 1998 sofre um aumento abrupto para um patamar de 900 linhas a partir de 1998. Em 2011 a nova concessão trouxe o patamar para em torno de 700 linhas no esforço de promover a racionalização.

A frota operante vem apresentando uma tendência de crescimento ao longo dos anos, de acordo com o Figura 10. Por outro lado, o total de passageiros pagantes vem sofrendo uma queda ao longo do tempo com relação à média do período de 1994 a 2012 que foi de 1,09 bilhão de passageiros anuais, segundo o Figura 11.

\subsubsection{Sistema BRS}

Os sistemas BRS (Bus Rapid System) começaram a operar na cidade do Rio de Janeiro em 2011 para melhorar o transporte coletivo por ônibus. Esse sistema consiste em destinar uma ou duas faixas preferencias de ônibus no lado direito da pista e os pontos de 
paradas são escalonados para grupos de linhas. São 20 corredores em operação totalizando $61 \mathrm{~km}$ de vias em 2015, de acordo com SMTR, conforme Figura 12. Pensando no desenvolvimento sustentável da rede de transportes urbanos, um ônibus com sua capacidade média é capaz de substituir mais de 50 carros particulares.

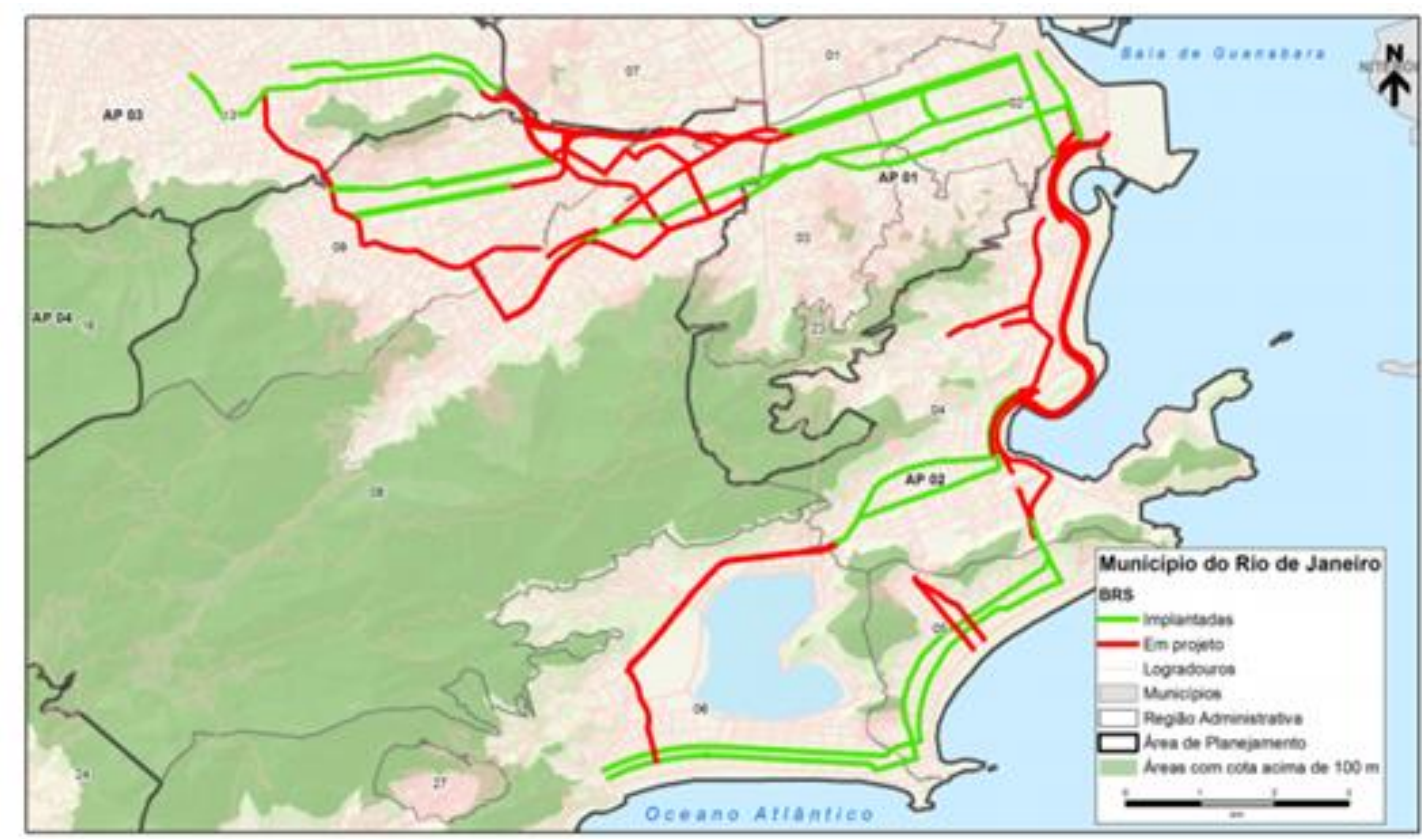

Figura 12: Corredores BRS implantados e em projetos 2015 (SMTR)

\subsubsection{Sistema BRT}

O BRT (Bus Rapid Transit) é um sistema de transporte baseado em ônibus que apresenta características operacionais diferenciadas. A principal diferença em relação ao sistema convencional é que ele opera em via segregada, normalmente no canteiro central das vias e a cobrança é feita fora do veículo reduzindo o tempo de embarque dos passageiros. Outra característica é relacionada ao aumento da capacidade devido à possibilidade de ultrapassagens nos pontos de parada e, consequentemente, a flexibilidade para se operar linhas expressas e paradoras. A adoção de veículos de maior capacidade com os ônibus articulados também contribui para o transporte de maior volume de passageiros.

O sistema do BRT de 2018 é composto por 440 carros articulados e $125 \mathrm{~km}$ de corredores exclusivos. Segundo dados do BRT Rio, aproximadamente, 450 mil passageiros são transportados por dia.

Um fato que mostra que o BRT é um bom investimento para o desenvolvimento da rede de transporte urbano sustentável é que segundo a empresa, um ônibus articulado substitui 126 carros particulares. 


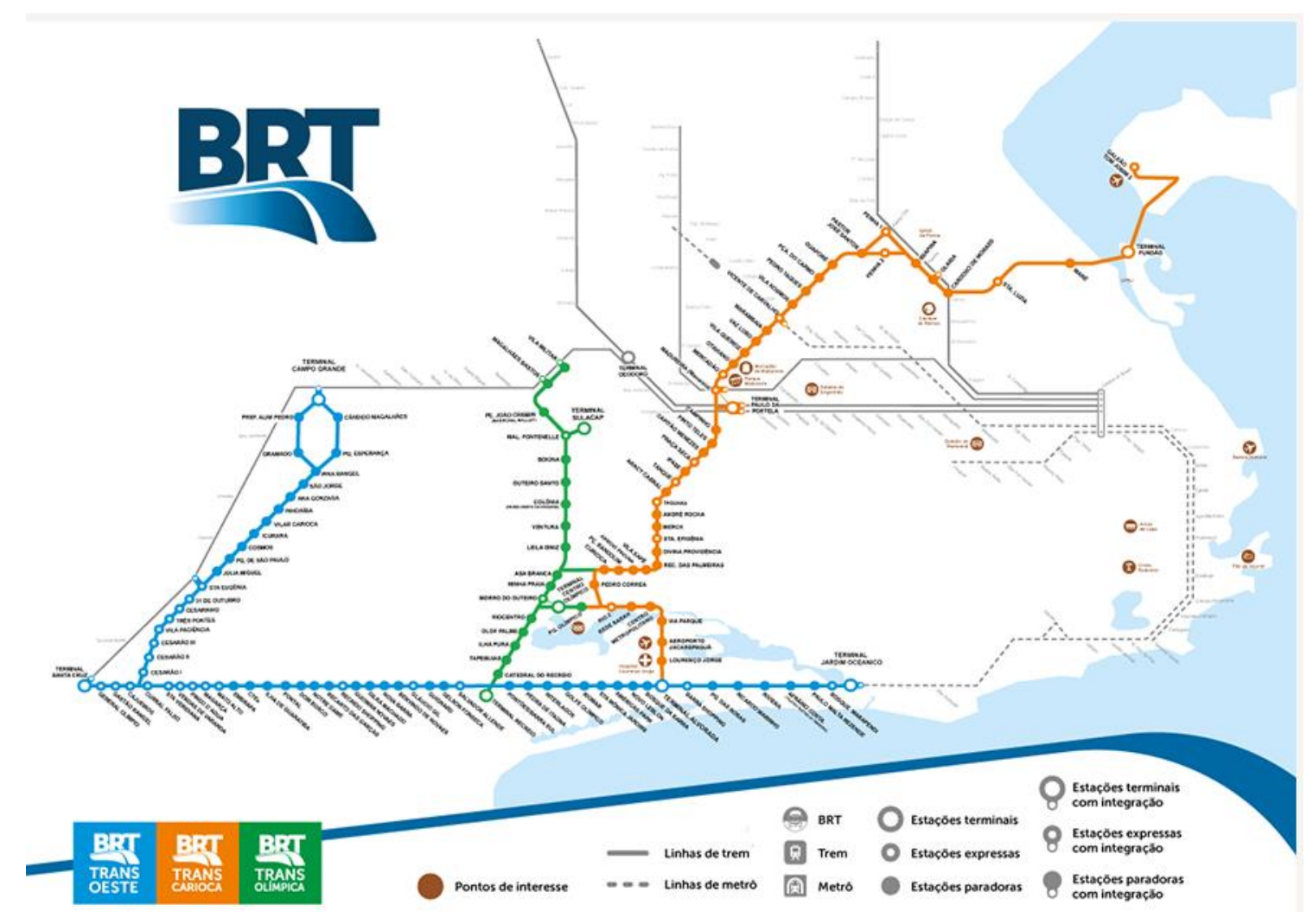

Figura 13: Corredores BRT da RMRJ 2018 (BRT-Rio)

\subsubsection{Sistema Metroviário}

O Metrô do Rio de Janeiro foi inaugurado em março de 1979 inicialmente construído e operado pelo Governo do Estado do RJ. O início das operações contou com apenas 5 Estações: Praça Onze, Central, Presidente Vargas, Cinelândia e Glória. Apesar de contar somente com 5 estações, o sistema metroviário já transportava 60 mil pessoas diariamente. Em 1998 a empresa MetrôRio, que hoje faz parte do grupo Invepar, assumiu a administração e a operação das Linhas sob o sistema de concessão. Atualmente, o metrô do Rio de Janeiro conta com 41 estações, $56 \mathrm{~km}$ de extensão, transporta em média $880 \mathrm{mil}$ passageiros por dia e é dividida em 3 linhas. Linha 1 que, com extensão de 17,9 km, liga os bairros da Tijuca e de Ipanema; Linha 2 que liga os bairros da Pavuna e Botafogo com 30,4 km de extensão; e Linha 4 ligando o bairro de Ipanema a Barra da Tijuca com extensão de $16 \mathrm{~km}$. A linha 1 possui 9 estações exclusivas e 10 compartilhas com a linha 2, totalizando 19 estações. A linha 2 possui 16 estações exclusivas e 10 compartilhadas com a linha 1, totalizando 26 estações. Já a linha 4, por dar continuidade ao trajeto da linha $1 \mathrm{e}$ não apresentar ramificação das outras linhas, na sua atual configuração de operação se caracteriza mais como uma extensão da linha 1 do que como uma nova linha (Metrô- Rio). 
O sistema tenta fazer a integração com vários modais, ao todo são 14 pontos de integração que envolvem BRT, ônibus expressos e intermunicipais, trens, vans, além dos ônibus do próprio metrô que são chamados de metrô na superfície.

Uma pesquisa realizada em 2017 pelo Instituto de Políticas de Transporte e Desenvolvimento feita com usuários da linha 4 aponta que aproximadamente $16 \%$ dos entrevistados relatou um ganho de tempo no deslocamento e cerca de $92 \%$ dos usuários consideravam que a nova linha de metrô melhorou suas condições de viagem diária. Numa comparação com o cenário base anterior, foi possível constatar que a implementação das novas estações provocou uma redução de $87 \%$ das emissões de $\mathrm{CO}_{2}$ no sistema além de eliminar as emissões locais de material particulado (MP) e óxido de nitrogênio $\left(N O_{\mathrm{x}}\right)$ na operação de transporte. Além disso, uma só composição de metrô pode tirar de circulação mais de 1.000 veículos particulares das ruas. Esses dados mostram que o sistema metroviário é uma ótima opção para o desenvolvimento sustentável da rede de transporte urbano.

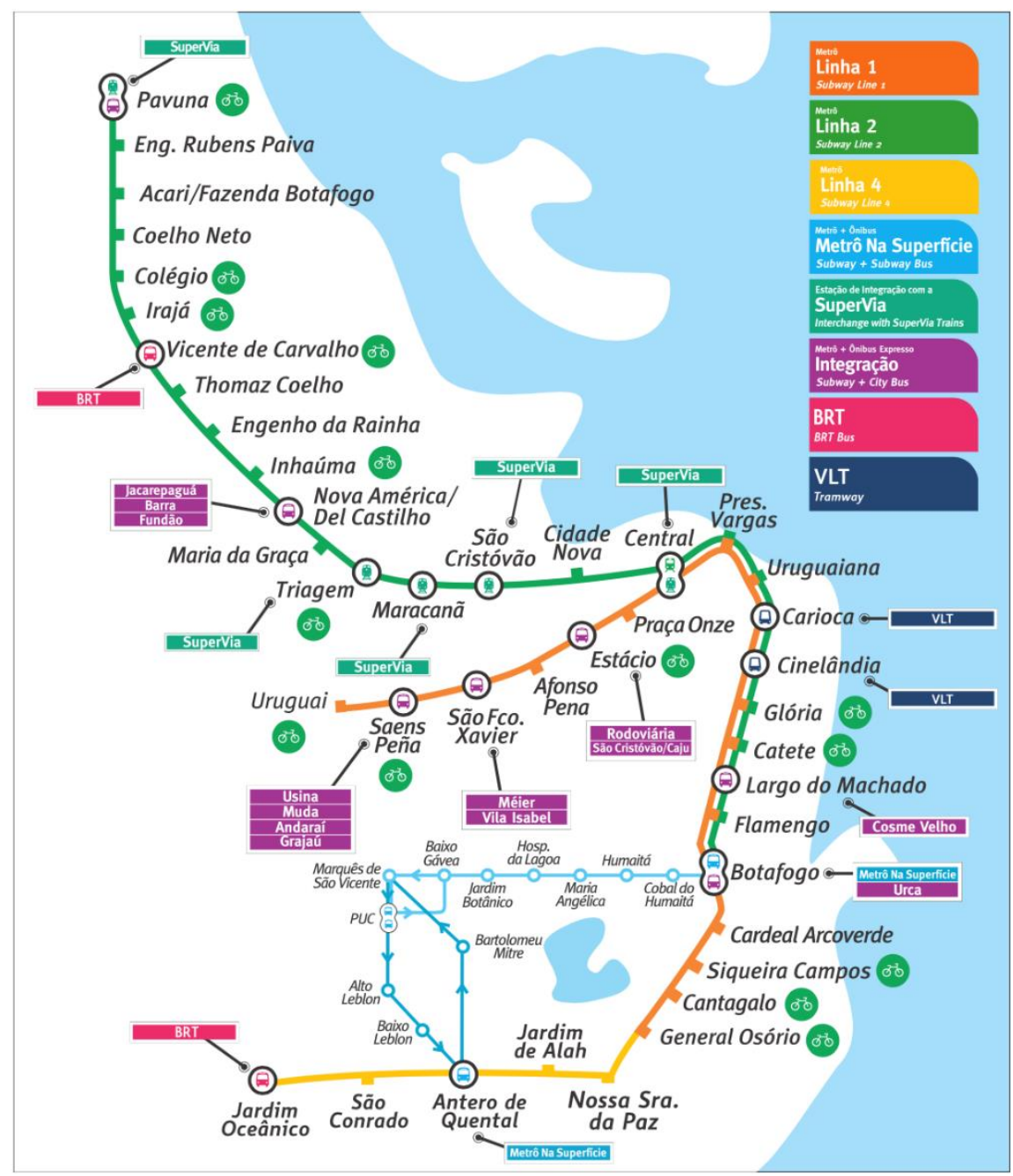

Figura 14: Linhas do sistema metroviário da RMRJ 2018, metrô na superfície e pontos de integração com outros modos (Metrô-Rio) 


\subsubsection{Sistema VLT}

O VLT Carioca (Veículo Leve sobre Trilhos) tem a função de facilitar a locomoção no Centro e Região Portuária conectando todas as demais redes de transporte metropolitano (metrô, trens, ônibus, barcas e teleférico) além de aeroporto, rodoviária e terminal de cruzeiros. Ele opera com energia elétrica em um sistema chamado APS - Alimentação Pelo Solo - uma solução de mobilidade que não só dispensa combustíveis fósseis, mas também preserva a paisagem urbana. A construção do VLT Carioca foi parte de um antigo projeto de revitalização da região central do Rio de Janeiro que teve início em 2016. Pertence à Prefeitura do Rio de Janeiro, mas foi construído e será operado por 25 anos (de 2013 a 2038) pela Concessionária do VLT Carioca, um consórcio formado por quatro empresas brasileiras (com 99,7\% do controle da companhia) e duas empresas estrangeiras.

É composto por 39 linhas e 29 paradas, sendo elas Linha 1,2 e 3. A linha 1 opera saindo da Praia Formosa, próximo à Rodoviária com destino ao Santos Dumont, a linha 2 possui a mesma origem, mas o destino é a Praça XV. Já a linha 3 sai da Central do Brasil em direção ao Santos Dumont (Figura 17). A frota é composta por 32 trens Alstom Citadis com 44 metros de comprimento, capacidade para 420 passageiros e velocidade média de $17 \mathrm{~km} / \mathrm{h}$. Segundo um levantamento feito pela Universidade de São Paulo (USP), um carro transporta em média 1,4 pessoas, sendo assim, cada veículo do VLT é responsável por tirar em média 300 veículos particulares das ruas.
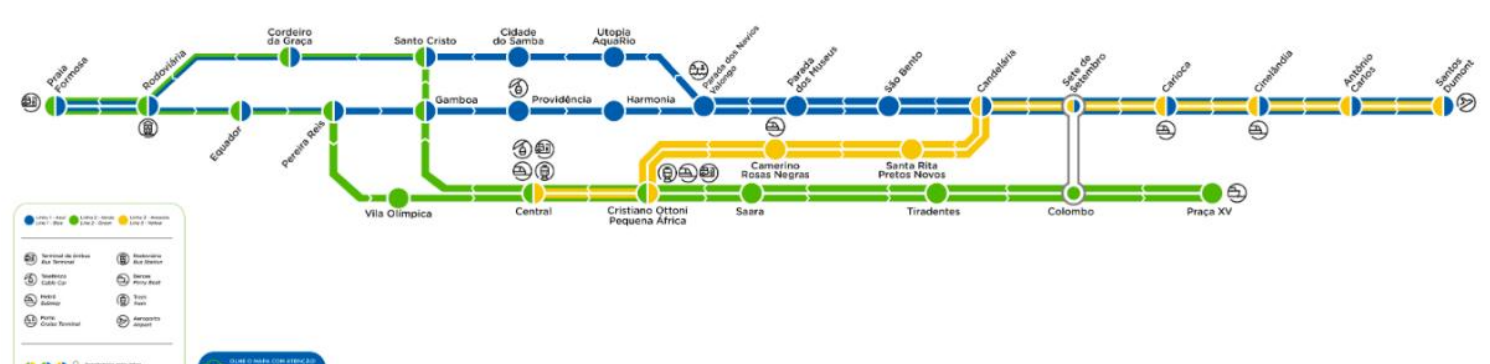

Figura 15: Linhas do sistema VLT do Rio de Janeiro em 2019 (site VLT Carioca)

Nesses 3 anos e meio de operação, o VLT é responsável por transportar mais de 56 milhões de passageiros transportados, 500 mil viagens realizadas e cerca de 1,8 milhão de quilômetros percorridos. Só a linha 3 inaugurada no ano de 2019 já é responsável pelo incremento de mais de 30 mil usuários por dia útil (VLT Carioca). Esse mesmo ano foi marcado pela consolidação do sistema com um crescimento de $45 \%$ na média de passageiros que hoje transporta mais 110 mil pessoas diariamente (VLT Carioca).

As paradas de maior fluxo no período foram: Colombo (linha 2), Praça XV (linha 2), Cristiano Ottoni-Pequena África (linhas 2 e 3), São Bento (linha 1) e Cinelândia (linhas 
1 e 3). Dos cinco pontos de embarque e desembarque, quatro são locais de conexão com outros modais ou entre linhas do VLT, confirmando a intenção do projeto de ser um integrador para quem chega no Centro.

\subsubsection{Sistema Ferroviário}

O sistema ferroviário de transporte de massa da Região Metropolitana do Rio de Janeiro, originalmente, estava sob a responsabilidade do Governo Federal. Nessa época caracterizou-se pela falta de investimentos regulares e contínuos, gerando ao longo dos anos uma demanda por melhorias em infraestrutura e mais trens. Desde 1 de novembro de 1998 é operado pela empresa Supervia, sob regime de concessão.

Segundo dados do Governo do Rio de Janeiro, a malha ferroviária possui $270 \mathrm{~km}$ de extensão, dividida em 8 ramais com 102 estações, ao longo de 12 municípios da Região Metropolitana. Transporta uma média de 750 mil passageiros/dia, viajando em 204 trens. Uma composição ferroviária tem a capacidade para transportar até 2.600 passageiros, sendo responsável por retirar em média 1.800 veículos particulares das ruas. Os principais eixos de demanda metropolitana são atendidos pelos ramais de Nova Iguaçu, Duque de Caxias, Belford Roxo e Santa Cruz. O sistema ferroviário é utilizado basicamente por usuários situados na faixa de renda familiar de até 3 salários mínimos, representando $83 \%$ da demanda, com uma frequência semanal predominante de 3 a 5 dias (51\%) e tendo o trabalho como motivo principal de $91 \%$ das viagens realizadas (PMUS).

Por muitos anos o sistema ferroviário foi perdendo sua função sofrendo com a concorrência direta das linhas de ônibus que correm paralelamente aos ramais. Após a concessão o sistema vem gradualmente recuperando a capacidade com a modernização do sistema e aquisição de novos veículos.
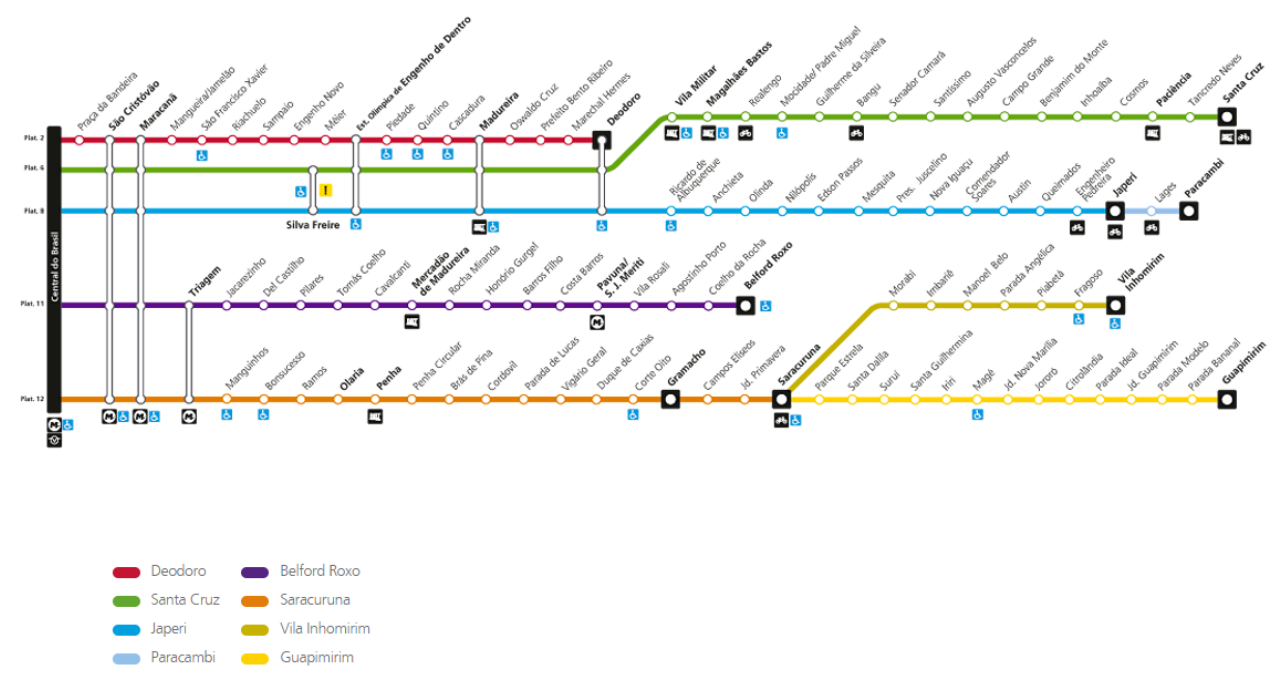

Figura 16: Linhas do sistema ferroviário da RMRJ 2018 (SuperVia) 


\subsubsection{Sistema de Ônibus Intermunicipal (Metropolitano)}

O sistema de ônibus metropolitano é de responsabilidade do DETRO (Departamento de Transporte Rodoviários da Secretaria de Transporte do Estado do Rio de Janeiro). Composto por 565 linhas que são operadas por 56 empresas de acordo com dados do site da Fetranspor. A frota operante é composta por 5.835 veículos. São realizadas mensalmente 942 mil viagens (o conceito de viagem seria o caminho de uma origem a um destino) resultando em 52,78 milhões de quilômetros percorridos. Com relação ao tipo de veículo utilizado, $89 \%$ das linhas do sistema metropolitano utilizam ônibus convencional e o restante dos outros 11\% são Midiônibus, conforme dados do PDTU. São transportados 1,9 milhão de passageiros no total diariamente na região metropolitana do Rio de Janeiro de acordo com dados da pesquisa Origem /Destino do PDTU em 2012.

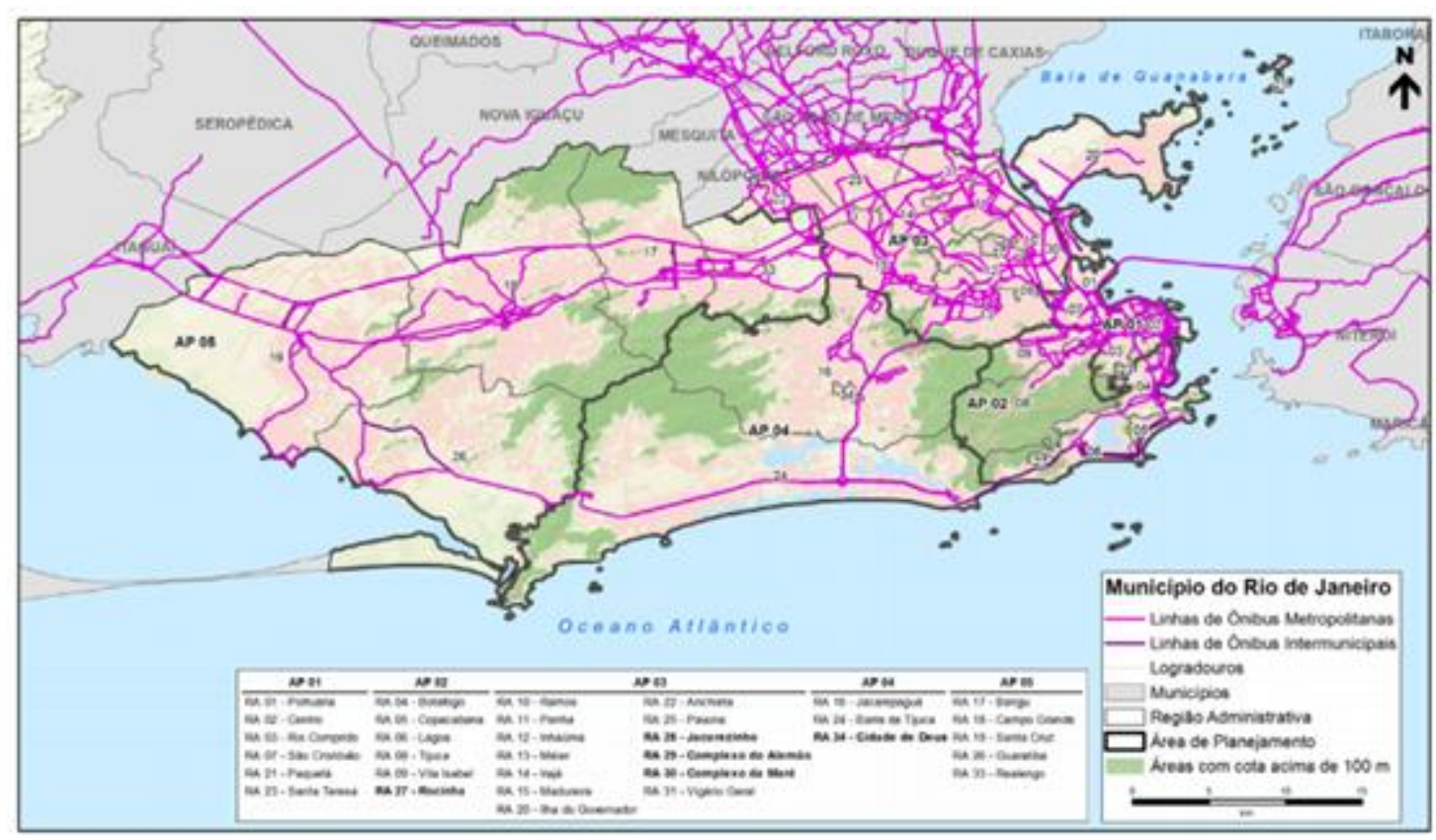

Figura 17: Sistema de ônibus intermunicipal da RMRJ (DETRO)

\subsubsection{Sistema de Barcas}

O serviço de barcas é operado pelo grupo CCR em regime de concessão desde o dia 2 de julho de 2012 quando o grupo assumiu o controle acionário da Concessionária Barcas S/A.

A frota é composta de 19 embarcações, sendo 13 catamarãs e 6 barcas. Somadas, possuem capacidade para 19.819 passageiros.

Segundo dados do governo do estado do Rio de Janeiro, o transporte aquaviário conduz, em dias úteis, cerca de 90 mil passageiros. A Concessionária transporta por ano, 
aproximadamente, 25 milhões de usuários, realizando mais de 80 mil viagens, o que totaliza cerca de 745 mil quilômetros navegados.

A CCR Barcas opera seis linhas em cinco estações: Praça XV/ Araribóia, Praça XV/ Cocotá, Praça XV/ Paquetá, Praça XV/ Charitas, Ilha Grande/ Mangaratiba e Ilha Grande/ Angra dos Reis.

Contudo, no estudo do PDTU só entraram as primeiras quatro linhas. A oferta de serviço nessas linhas é de 21.830 passageiros em ambos os sentidos no período de pico de manhã e de 22.400 no pico da tarde.

O principal problema identificado com relação a esse modo de transporte é a segregação física e operacional entre este sistema e os demais modos. Os canais de navegação não têm sido identificados como problemas para a operação, mas a sujeira das águas tem se mostrado razão de constantes dificuldades sobre as embarcações e à navegação, provocando até mesmo paradas operacionais inapropriadas

Em termos operacionais, o sistema atende de forma eficiente à demanda das linhas. As recentes embarcações compradas possuem maior capacidade aumentando o potencial de transporte. Contudo este fator acabou acarretando em intervalos maiores de espera, o que gera mais impedância à escolha deste modo.

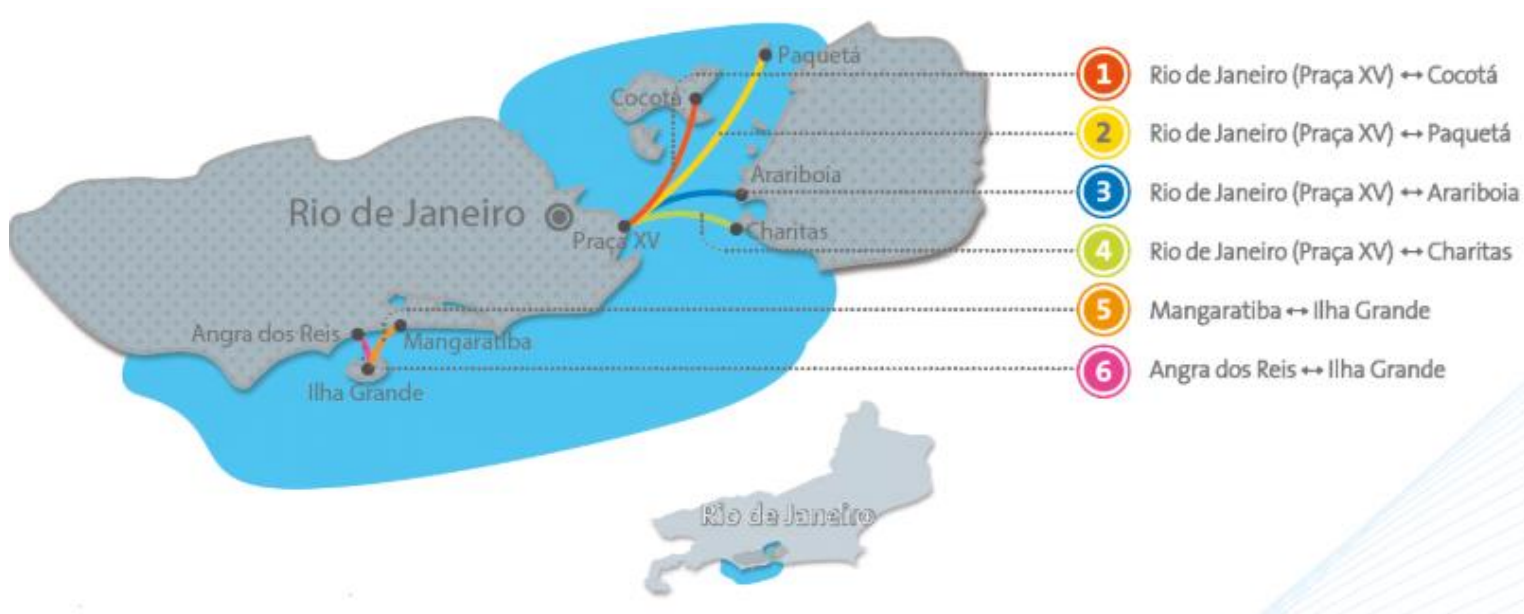

Figura 18: Linhas de barcas da RMRJ 2019 (VisitRio)

\subsubsection{Análise dos Transportes da Região Metropolitana do Rio de}

A análise dos modos de transporte e do seu impacto na malha viária é muito importante pois ela fornece dados de entrada muito importantes para um plano de transportes. A seguir, serão retratados dados importantes obtidos pela equipe do PDTU.

Falando um pouco sobre flutuação horaria, a Figura 4 e 5 foi obtida através de diversas pesquisas de contagens na via realizadas em 169 (23\% aproximadamente) zonas 
de tráfego do total das zonas (730) em que foi dividida a RM no PDTU. Esse tamanho de amostra foi calculado pelo consórcio responsável, assim como os locais de pesquisa. Umas das principais pesquisas foi a de Contagens Volumétricas, a qual consiste em contabilizar veículos durante o dia em determinadas vias da cidade. Os veículos alvo do PDTU são: autos, táxis, motos, ônibus, caminhões de 2 eixos e 3 a mais eixos, van (transporte alternativo) e veículos utilitários. Essa pesquisa originou as distribuições percentuais horárias de circulação de veículos conforme apresentado no Figura 19 e 20.

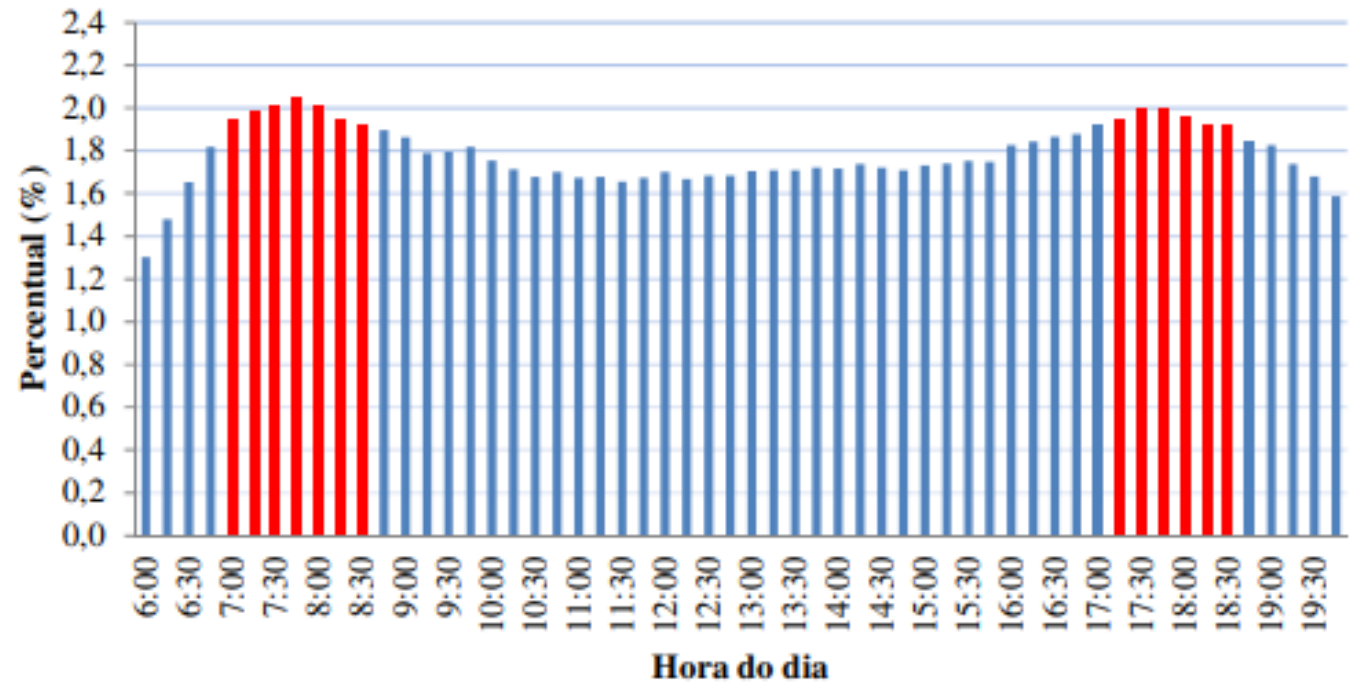

Figura 19: Distribuição percentual horária do transporte individual da RMRJ (PDTU-2012)

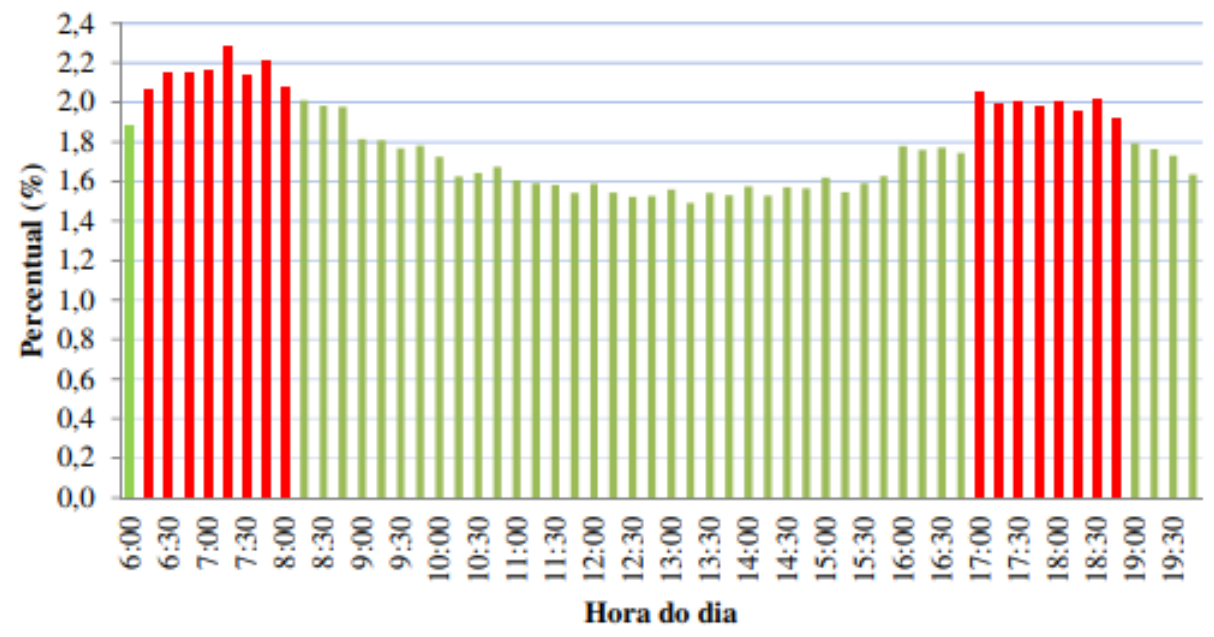

Figura 20: Distribuição percentual horária do transporte coletivo da RMRJ (PDTU-2012)

Com relação ao transporte individual (formado, principalmente, por autos) pode-se observar que o horário de maior carregamento no período de manhã ocorre entre $7 \mathrm{~h}$ às $8 \mathrm{~h}$ 
( $8 \%$ aproximadamente do volume total diário) e de tarde ocorre entre $17 \mathrm{~h}$ às $18 \mathrm{~h}(7,86 \%$ do volume total diário).

Já em relação ao transporte coletivo (formado por ônibus principalmente) é possível observar que o horário de maior carregamento no período de manhã começa mais cedo que o transporte individual ocorrendo entre $6 \mathrm{~h}$ às $8 \mathrm{~h}(8,79 \%$ aproximadamente do volume total diário) e de tarde ocorrendo no mesmo horário do transporte individual entre $17 \mathrm{~h}$ às $18 \mathrm{~h}$ (7,86\% do volume total diário).

Com esses gráficos, é possível concluir que as duas curvas de distribuição percentual horária apresentam certa similitude, principalmente nas mesmas faixas horárias nos seus horários de pico (entre $7 \mathrm{~h}$ às $8 \mathrm{~h}$ e $17 \mathrm{~h}$ às $18 \mathrm{~h}$ ). Pode-se interpretar estes resultados baseados na realidade. As pessoas saem das suas residências e se deslocam (de auto, de ônibus, etc.) de manhã (7h, por exemplo) para chegar a seus centros de estudo e a seus trabalhos (normalmente o horário de entrada é às $8 \mathrm{~h}$ ) e logo após de realizar suas atividades ( 8 horas de trabalho, por exemplo) retornam a suas residências correspondendo à faixa horária entre $17 \mathrm{~h}$ às $18 \mathrm{~h}$. É possível observar também que o transporte coletivo tem um vale entre os picos diferentemente do transporte individual, o que confirma exatamente o comportamento acima relatado.

A Tabela 3 e a Figura 21 mostram dados relativos ao transporte coletivo no período do pico da manhã.

Tabela 3: Indicadores do sistema de transporte público no período de pico da manhã

\begin{tabular}{|c|c|c|c|c|}
\hline Modo de transporte & $\begin{array}{l}\text { Passageiros } \\
\text { transportados }\end{array}$ & Passageiros x KM & Passageiros x hora & $\begin{array}{c}\text { Velocidade média } \\
(\mathbf{k m} / \mathbf{h})\end{array}$ \\
\hline Barcas & 12.402 & 95.248 & 5.957 & 16,0 \\
\hline BRT & 52.525 & 1.059 .219 & 27.928 & 37,9 \\
\hline Metrô & 66.603 & 867.502 & 30.117 & 28,8 \\
\hline Ônibus Intermunicipal & 543.933 & 6.818 .783 & 411.707 & 16,6 \\
\hline Ônibus municipal RJ & 579.460 & 5.474 .149 & 291.665 & 18,8 \\
\hline Trem & 64.436 & 1.569 .107 & 44.761 & 35,1 \\
\hline Total: & 1.254 .923 & 14.314 .901 & 767.374 & 18,7 \\
\hline
\end{tabular}




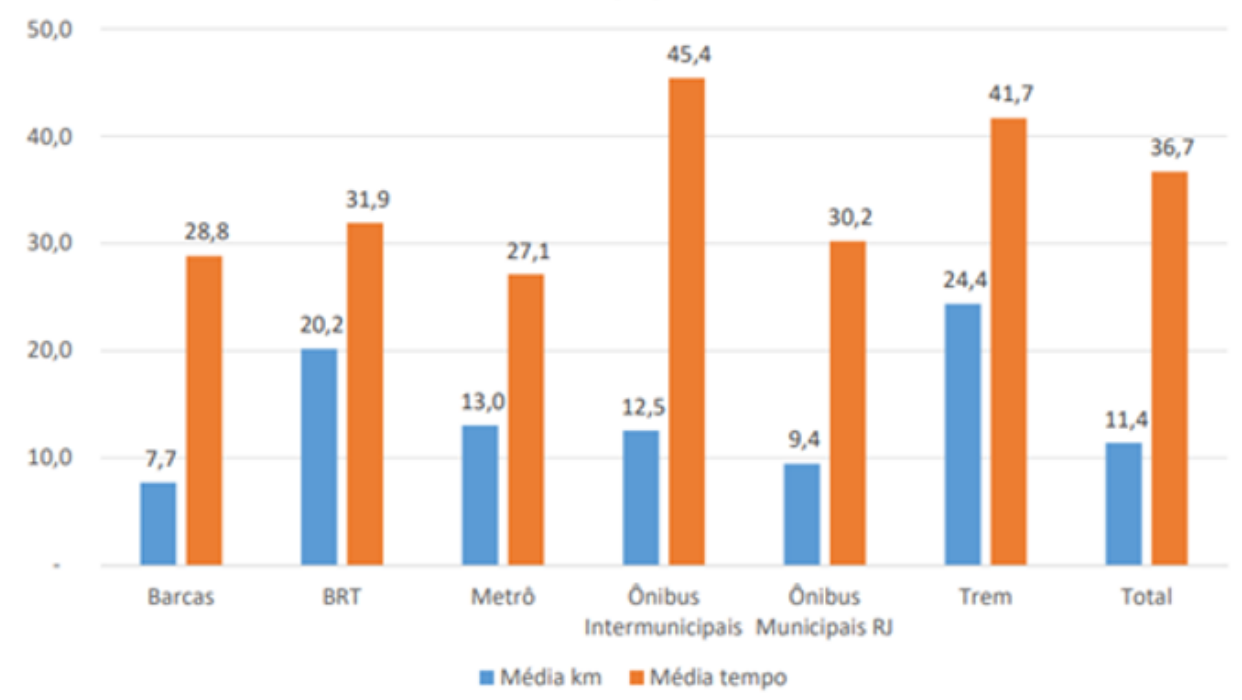

Figura 21: Distância e tempo médio das viagens por modo de transporte no pico da manhã

Com os dados da Tabela 3, podemos notar que 1,25 milhão de pessoas são transportadas durante o pico da manhã na RMRJ, sendo $46 \%$ dos passageiros transportados por ônibus municipais. Esse dado só confirma o fato de as linhas de ônibus municipais estarem sobrecarregadas neste horário.

É possível perceber, através do Figura 21, que o maior tempo de viagem está com os ônibus intermunicipais (45,4 minutos), sendo que $43 \%$ da população usa esse modo de transporte. Isso revela que se gasta muito tempo em transporte, indicando que grande parte da população tem que sair de seu bairro de residência para trabalhar/estudar em outros bairros. A Figura 22 mostra os principais motivos para o uso do transporte público. Como é possível notar, trabalho e estudo somam mais de $80 \%$ das viagens.

Os deslocamentos mais longos por modo de transporte estão com trem (média de $24,4 \mathrm{~km}$ por viagem) e BRT (20,2 km). Ambos modos possuem características de viagens pendulares, com viagens radiais com destino a região central do Rio de Janeiro. A Figura 23 mostra que realmente a região central, assim como a Zona Sul e Barra da Tijuca são regiões predominantemente de atração de viagens.

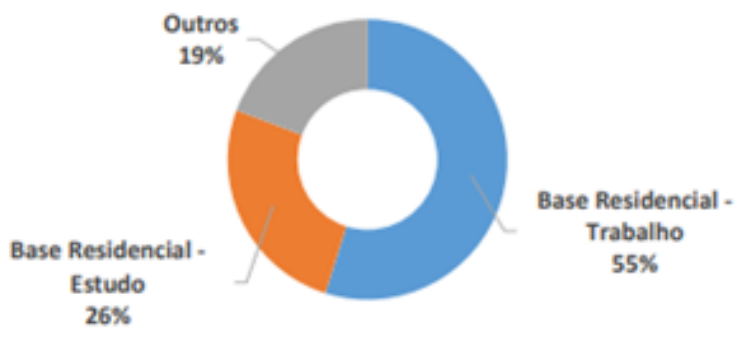

Figura 22: Motivo das viagens de transporte público no pico da manhã (PDTU-2012) 


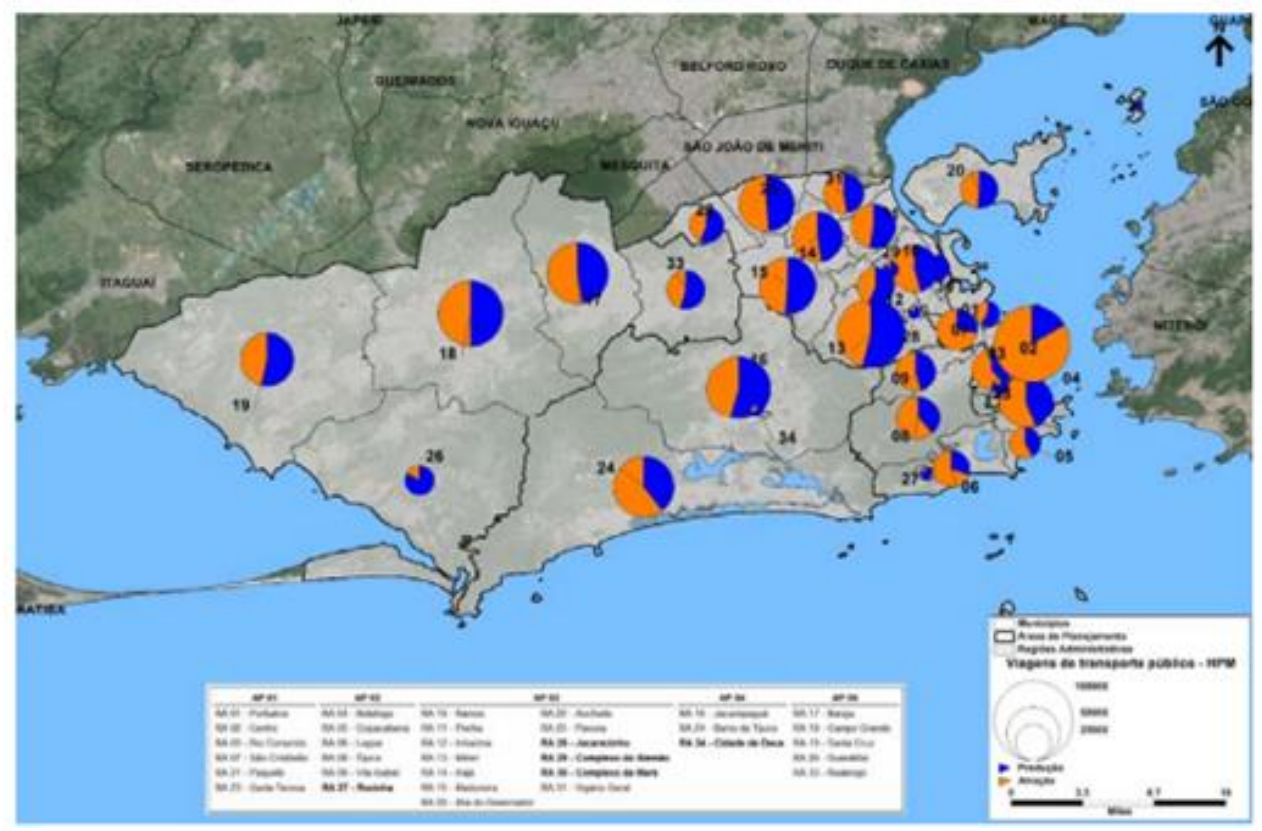

Figura 23: Áreas de produção(azul) e atração (laranja) de viagens realizadas por transporte coletivo no pico da manhã (PDTU-2012)

O crescimento da frota de veículos automotores e do consumo de combustíveis fósseis ocorridos nos últimos anos levou a um aumento da poluição atmosférica (gases tóxicos, carbono, material particulado), diminuindo a qualidade de vida na cidade (PMUS, 2016). Devido a isso em 2016, surgiu o Plano de Mobilidade Urbana Sustentável (PMUS), desenvolvido pela Prefeitura do Rio por meio da Secretaria Municipal de Transportes (SMTR), que visa orientar os investimentos públicos em infraestruturas de transportes da cidade pelos próximos dez anos, até 2026. O PMUS deverá integrar modais motorizados e não motorizados em um sistema coeso e sustentável, priorizando o transporte público. $\mathrm{O}$ PMUS trabalha em conjunto com o PDTU, pois além de usar os dados básicos para elaboração de um modelo de transportes que foram coletados pelo PDTU, visa identificar quais trajetos estarão saturados com o aumento da população e deverão ser prioritários para a implantação de infraestrutura de transporte de alta capacidade.

Segundo o relatório de análise integrada do PMUS, o transporte coletivo tem uma alta participação no total de viagens ocorridas no município, representando $47 \%$ do total. Como esse plano tem uma base sustentável, encaminhou-se propostas como: desenvolvimento de um programa de educação ambiental que articule conceitos oriundos da educação urbana e da educação para o trânsito, e incentive o uso sistemático de transporte público; Racionalização do Sistema Público de Transportes, de forma a orientar a oferta e reduzir a ociosidade no sistema, reduzindo também as emissões de gases; Implantar gradativamente novas tecnologias e o uso de combustíveis menos poluentes no Sistema Público de Transportes. 


\section{4 Metodologia e Método}

Este capítulo detalha metodologicamente, com base nos conceitos de Silva e Menezes (2005), a elaboração deste trabalho. Apresenta-se a caracterização e delineamento da pesquisa, também são elencadas as etapas de concepção deste estudo e apresentado o software escolhido para a pesquisa.

\section{1}

\section{Caracterização e delineamento da pesquisa}

A natureza dessa pesquisa é aplicada, pois objetiva gerar conhecimento prático para um problema direcionado.

A forma de abordagem é quantitativa, pois traduz em números informações a fim de analisá-las.

É uma pesquisa de ponto de vista exploratório, pois assume forma de pesquisa bibliográfica e de aplicação em um caso.

Do ponto de vista de procedimentos técnicos, é uma pesquisa bibliográfica, pois houve etapa de buscas na literatura e experimental, pois foram realizados experimentos computacionais os quais os efeitos foram observados.

\section{2}

\section{Passos da concepção do estudo}

Os passos para execução desta dissertação foram:

- Definição do problema, elaboração e apresentação do projeto de dissertação;

- Revisão da literatura acerca de temas relacionados ao planejamento de transporte, sustentabilidade no planejamento de transporte, modelo de 4 etapas, informações sobre o plano diretor de transporte do Rio de janeiro;

- Escolha do software a ser usado. A opção selecionada foi o EMME, o mesmo software utilizado pelo PDTU. Contudo o tamanho utilizado foi o tamanho 2 que era o disponível no Departamento de Industrial da PUC-Rio onde esse estudo foi desenvolvido.

- Escolha do cenário base que representa o mais próximo da realidade da rede de transporte da RMRJ em 2019 e onde serão desenvolvidas as propostas de infraestrutura para ampliação e maior integração da rede. Para o desenvolvimento desse cenário base foi 
comparado os cenários do ano de 2016 e 2021 do PDTU-RMRJ com a rede viária de transportes da RMRJ no ano de 2019 e identificado quais projetos propostos no PDTU não haviam sido concluídos. Após essa identificação, remove-se essas infraestruturas do cenário do ano de 2016, pico da manhã do PDTU e simplificou-se a rede chegando ao cenário base, ou seja, a rede de 2019 da RMRJ simplificada.

- Escolha das infraestruturas que seriam analisadas gerando os cenários que serão estudados nessa dissertação e representação deles na rede com a utilização do software EMME.

- Realização das alocações de transporte nos cenários propostos baseando-se no modelo de estratégias ótimas (Spiess, 1984) utilizando a demanda do ano de 2016 fornecida pelo PDTU-RMRJ no software EMME.

- Análise do impacto dessas novas infraestruturas na rede viária da RMRJ, conclusões e elaboração de propostas de trabalhos futuros.

\subsection{0 software EMME}

Para a elaboração dos cenários e uma análise completa dos impactos foi escolhido para ser usado nessa dissertação o software EMME, por ser usado em mais da metade das cidades mais populosas do mundo executando alguns dos modelos de previsão da demanda por transportes mais complexos do mundo (INRO 2014), além de ser o mesmo utilizado no PDTU-RMRJ. Segundo Wright (2008), os softwares com pacotes mais completos para a proposta geral de um planejamento de transportes são EMME, CUBE/Trips, VISUM e TransCAD. O modelo do PDTU 2005 foi desenvolvido na plataforma do software TransCAD, contudo a representação da rede de transporte público foi considerada uma deficiência do modelo. Foi proposto, então, a mudança para o software EMME em 2012, segundo o relatório 1 do PDTU, já que o EMME é capaz de lidar com alocações multimodais e teve aprimorada a funcionalidade de matriz que permite que uma variedade de modelos seja trabalhada considerando a geração, distribuição, distribuição e escolha modal, além da alocação.

O EMME é um sistema de modelagem e seus recursos incluem previsão de demanda, planejamento de transporte coletivo e de tráfego multimodais e integrados além de possibilidade de análises econômicas, ambientais e de emissões (INRO, 2014).

No módulo de previsão de demanda é possível utilizar diversos modelos agregados de demanda como geração de viagens, distribuição e escolha modal, encadeamento de viagens, redes de tráfego, etc. 
No planejamento de transportes coletivos é possível avaliar alterações na rede, como as linhas/rotas, trânsito, nível de serviço, estruturas tarifárias complexas, serviços de transporte público concorrentes ou com integração tarifária, etc.

Já no planejamento de tráfego é possível analisar a expansão da rede viária e seus impactos, inclusão de pedágio e atrasos nas interseções, gerenciamento da demanda de tráfego, o transporte de cargas, dentre outras funções.

No módulo impacto ambiental e custo é possível analisar condições operacionais do veículo e geração de poluentes, utilizar procedimentos flexíveis e customizados para as análises de custo-benefício e outros métodos de avaliação de projetos que justifique o investimento, comparar técnicas de gerenciamento da demanda, etc.

Todas essas funções citadas anteriormente são executadas no ambiente chamado Modeller. O Modeller também dispõe da possibilidade direta de executar macros e de acessar a linha de comandos e o prompt do EMME, que utiliza a linguagem python. Tal fato permite desenvolver novos procedimentos para ampliar o ambiente de aplicações.

Já na área de trabalho do EMME é onde se se localizam as ferramentas gráficas de edição da rede que permite a criação de mapas, edição e comparação de cenários. Ela também oferece mapas dinâmicos, gráficos e relatórios detalhados e sempre atualizados, uma apresentação geo-referenciada em diversos formatos.

Quando se fala de distribuição de viagens no EMME, o módulo de balanceamento de matrizes é responsável por rodar os modelos gravitacionais e os métodos de Fratar e Furness do modelo de Fator de Crescimento. Para a execução é necessário o total de viagens produzidas e atraídas em cada zona, obtidos através de modelos de geração de viagens e a matriz de tempos de viagens futuros resultado da expressão $e^{c t}$ (Modelo Gravitacional), onde, t é o tempo futuro médio de viagens entre zonas e c é a constante obtida na calibração do Modelo Gravitacional.

$\mathrm{Na}$ alocação de transporte individual, o modulo responsável por essa tarefa é o Traffic Assignment. O EMME realiza a alocação por equilíbrio que utiliza o algoritmo de aproximação linear proposto por Bruynooghe et al. (1968), baseado no princípio de "ótimo usuário" desenvolvido por Wardrop (1952). É uma solução iterativa que através do método de aproximação linear busca minimizar a área sob a curva de volume por tempo de espera.

O método segue os seguintes passos:

- $1^{\circ}$ alocação tudo-ou-nada com a demanda total nos caminhos mínimos calculados com base nos custos das ligações

- $2^{\circ}$ atualização dos custos das ligações;

- $3^{\text {o }}$ alocação tudo-ou-nada ainda com a demanda total, mas agora nos novos caminhos mínimos calculados; 
- $4^{\circ}$ cálculo da variável para carregamento incremental que minimize a área sob a curva volume por tempo de espera;

- $5^{\circ}$ alocação dos volumes nas ligações com base nesta variável;

- $6^{0}$ verificação do critério de parada, caso os resultados não sejam satisfatórios, retornar ao $4^{\circ}$ passo.

Já no transporte coletivo, o EMME baseia-se no modelo de estratégias ótimas (Spiess, 1984; Spiess e Florian, 1989) e é possível executar esse tipo de alocação no modulo Transit Assignment. Esse método segue a seguinte lógica: O usuário com as informações disponíveis escolheria um conjunto de caminhos possíveis e embarcaria no primeiro veículo que chegasse entre as linhas consideradas atrativas (mesmo que esta escolha resulte em mais tempo para chegar ao destino já que nesta decisão o usuário buscou minimizar seu tempo espera). Só quando ele embarcasse no veículo é que efetivamente ele definiria qual caminho utilizaria. O modelo trabalha com a hipótese que a única informação disponível para o passageiro durante a viagem é a que ele descobre, enquanto está em um nó da rede, qual será a próxima linha a passar e, ele deve decidir naquela hora se vai ou não embarcar no veículo. Definido o conjunto de estratégias, os passos seguintes são:

- $1^{\circ}$ definição do nó onde o usuário está como origem;

- $2^{\circ}$ embarque no veículo que chegar primeiro entre as linhas atrativas;

- $3^{\circ}$ desembarque no nó predeterminado pela estratégia;

- $4^{\circ}$ se ainda não estiver no destino, volte ao $1^{\circ}$ passo.

Um aspecto importante a ser observado é que a alocação de tráfego é realizada inteiramente com base nos custos generalizados que são mensurados em unidade de tempo (geralmente em minutos). Para fins de modelagem, os custos generalizados incluem todos os componentes de custo que um usuário gasta para realizar uma viagem $\mathrm{O} / \mathrm{D}$, como por exemplo, as tarifas de embarque e integração e os tempos reais das viagens, considerando, além da viagem em si, tempos de espera, transbordo e efeitos de congestionamento, todos devidamente parametrizados e calibrados para simular o comportamento da rede de transportes e dos usuários na área de estudo.

Os custos generalizados de transporte coletivo são calculados para cada motivo de viagem, sendo diferenciados de acordo com o VoT (valor do tempo). Eles são calculados de acordo com a fórmula:

$$
C_{i j}=\frac{f}{v(p t)}+I_{i j}+\mathrm{w}^{*} W_{i j}+\mathrm{x}^{*} X_{i j}+\mathrm{a}^{*} A_{i j}
$$

Onde:

$C_{i j}=$ Custos generalizados de transporte coletivo entre ' $\mathrm{i}$ ' e ' $\mathrm{j}$ '; 
$\mathrm{f}=$ tarifa em Reais $(\mathrm{R} \$)$;

$v(p t)=$ valor do tempo (VoT) por motivo de viagem 'p' em valor monetário por minuto

(Tabela 5);

I = tempo gasto pelo veículo, em minuto;

$\mathrm{W}=$ 'peso' do tempo de espera (Tabela 4);

$\mathrm{W}=$ tempo de espera em minutos;

$\mathrm{x}=$ 'penalidade' da transferência em minutos (Tabela 4);

$\mathrm{X}=$ quantidade de transferências;

$\mathrm{a}=$ 'peso' do tempo de embarque e desembarque;

$\mathrm{A}=$ tempo de embarque e desembarque em minutos.

Tabela 4: Valores usados na fórmula de custo generalizado de acordo com o modal

\begin{tabular}{|c|c|c|}
\hline Modal & $\begin{array}{c}\text { Penalidade associada aos } \\
\text { transbordos em } \mathbf{m i n}-\mathbf{x}\end{array}$ & $\begin{array}{c}\text { Fator de espera em min } \\
\text { (Multiplicador de headway) - w }\end{array}$ \\
\hline Metrô & 7 & 0,1 \\
\hline Trem & 10 & 0,3 \\
\hline BRT & 2 & 0,2 \\
\hline Ônibus & 15 & 0,5 \\
\hline Barca & $0,01^{60}$ & 0,01 \\
\hline
\end{tabular}

Tabela 5: Valores do tempo (Vot) em R $\$$ hora de acordo com o motivo da viagem

\begin{tabular}{|c|c|}
\hline Motivo da viagem & $\begin{array}{c}\text { VoT } \\
\text { (Transporte Coletivo) }\end{array}$ \\
\hline Base Domiciliar - Casa/Trabalho (HBW) & $\mathrm{R} \$ 15,50$ \\
\hline Base Domiciliar - Casa/Estudo (HBEd) & $\mathrm{R} \$ 11,25$ \\
\hline Base Domiciliar - Casa/Outros (HBO) & $\mathrm{R} \$ 13,13$ \\
\hline Base Não Domiciliar (NHBO) & $\mathrm{R} \$ 13,13$ \\
\hline
\end{tabular}

O tempo de embarque e desembarque (A) é um parâmetro que possui mais variações de valores, pois além de mudar de acordo com o modal também pode ser diferente de acordo com o volume de passageiros em algumas estações. $\mathrm{O}$ 'peso' do tempo de embarque e desembarque (a) ficou definido em 2,0 para pedestres.

O software EMME utilizado nessa dissertação foi o EMME tamanho 2, enquanto para a realização do estudo do PDTU do RJ foi utilizado o tamanho 7. As diferenças entre essas versões podem ser visualizadas na Tabela 6 . 
Tabela 6: Limite das licenças de tamanho 2 e 7

\begin{tabular}{|l|c|c|}
\hline \multicolumn{1}{|c|}{ Conjunto } & Tamanho 2 & Tamanho 7 \\
\hline Número de cenários & 5 & 100 \\
\hline Zonas ou centroides & 500 & 1750 \\
\hline Nós (incluindo as zonas) & 5000 & 17.500 \\
\hline Arcos & 25.000 & 87.400 \\
\hline Tipos de veículos de transporte & 30 & 999 \\
\hline Linhas de transporte ou rotas & 2.000 & 7.000 \\
\hline Segmentos de transporte & 80.000 & 280.000 \\
\hline Tabelas de entradas de conversões & 40.000 & 140.000 \\
\hline Matrizes completas & 10 & 9.999 \\
\hline Matrizes de origem & 999 & 9.999 \\
\hline Matrizes de destino & 999 & 9.999 \\
\hline Tamanho de atributos extra & 456.015 & 9.999 .999 \\
\hline
\end{tabular}

Devido a essas diferenças de tamanho, houve a necessidade de se adaptar os dados de entrada do PDTU para atender as restrições da licença, através de uma simplificação na rede de transportes.

\subsection{Simplificação da rede de transportes}

A simplificação de uma rede de transportes é uma tática recorrente na literatura, pois gerenciar dados de tráfego a partir de milhares de links simultaneamente e extrair informações importantes e significativas desse emaranhado de dados é uma tarefa desafiadora (Casadei et al., 2018). A ideia de se reduzir o número de nós e arcos de redes de transportes tem sido aplicada por alguns autores para resolução do Problema do Caixeiro Viajante (PCV), pois neste problema, quanto maior o número de nós, maior é o tempo computacional para a resolução (Grotschel e Holland, 1991). A redução da rede é extensivamente utilizada nos estudos de Grotschel e Holland (1991) e Padberg e Rinaldi (1990). A redução de uma rede é comumente usada como uma etapa de processamento na busca de planos de corte para o PCV e segundo Padberg e Rinaldi (1991) esses procedimentos de encolhimento podem ser exatos ou heurísticos.

O objetivo do agrupamento é reduzir a complexidade de um grafo original, respeitando um certo critério pré-definido (Fortunato, 2010; Malliarosa e Vazirgiannisa, 2013). Enquanto por um lado a agregação permite simplificar a complexidade de representação e cálculo através da rede, por outro a precisão na avaliação do estado da rede é afetada.

Para executar a redução da rede nesta dissertação foi utilizado o software EmmeResize que contém 7.105 linhas de código na linguagem de programação Java (Silva Júnior e Leal, 2016). 
Ele permite realizar a redução do banco de dados do EMME através de duas formas, a exclusão direta de elementos de um conjunto e a exclusão indireta através da agregação dos elementos de um conjunto.

Para redução do número de zonas foi criada uma pontuação para cada zona definida pelo intervalo de 0 a 100 . Somava-se 70 pontos quando a zona possuía conexão com transporte de massa e 30 pontos quando a zona estava totalmente contida geograficamente dentro de um bairro, ou seja, não fazia parte de dois ou mais bairros. As zonas com menores pontuações foram agregadas com outras zonas do mesmo bairro, até chegar ao total de 338 zonas de tráfego (áreas de ponderação). A redução das matrizes segue esse mesmo critério.

O processo de redução do número de arcos foi realizado com base na análise da composição da rede, pois faz-se necessária a manutenção da consistência da rede, ou seja, manter uma rede conexa e com linhas de transporte conexas e com a perda mínima de dados. Por exemplo, dois arcos consecutivos com o mesmo número de faixas (Lanes) e função de atraso (Volume-Delay Function - VDF) podem ser reduzidos para um único arco, caso contrário não podem. Além disto, arcos com menores prioridades como vias locais também removidos. A redução do número de nós está diretamente relacionada com a redução dos arcos e o critério de redução considerado foi eliminar os nós que deixaram de possuir conexão com pelo menos um arco após a etapa de redução de arcos.

E, por último, o processo de redução das linhas de transporte coletivo, que reduz os nós do início e do fim da linha, limitado pelo número máximo de nós $\mathrm{N}$ em cada extremidade e sendo aplicada apenas nas linhas de ônibus normais (exclui-se BRT, metro, trem barcas e outros modos). Nos cenários do PDTU da RMRJ, o número máximo nós foi calibrado através de vários experimentos, variando de 1 até 20 nós, onde 10 foi o número ideal para atender os limites do número de arcos e nós da rede. 


\section{$5 \quad$ Nova rede viária do Rio de Janeiro}

Nesse capítulo é apresentado uma comparação dos cenários propostos pelo PDTU e como a rede de transporte está atualmente. Também são mostrados, os cenários propostos nesse estudo assim como o resultado da alocação e as análises dos impactos que a nova formatação da rede viária pode trazer para o Rio de Janeiro.

\subsection{Comparação dos cenários}

O PDTU usou como cenário base o ano de 2012, sendo assim ele usou a rede de transportes que havia no ano de 2012 e segundo as projeções de obras para o município do Rio de Janeiro desenvolveu os cenários de 2016 e 2021, com a expectativa de que essas obras já estivessem prontas nos respectivos anos. Contudo, analisando os cenários propostos no PDTU para o ano 2016, é possível observar tanto obras que foram concluídas para o ano do cenário, como obras que não chegaram nem a ser concluídas no ano de 2019. O mesmo vale para o cenário de 2021, que possui muitas obras que não se tem a expectativa de estarem concluídas ou nem mesmo foram iniciadas. Descrito tudo isso é possível concluir que uma alocação feita com uma rede mais de acordo com a atual rede de transporte do Rio de Janeiro levaria a tomadas de decisões mais eficientes para a população. Abaixo veremos as discrepâncias entre a rede básica esperada para o ano de 2016 e a rede que realmente existe em 2019. A Figura 24 representa como era pra estar a rede viária do Rio de Janeiro em 2016, segundo o PDTU. 


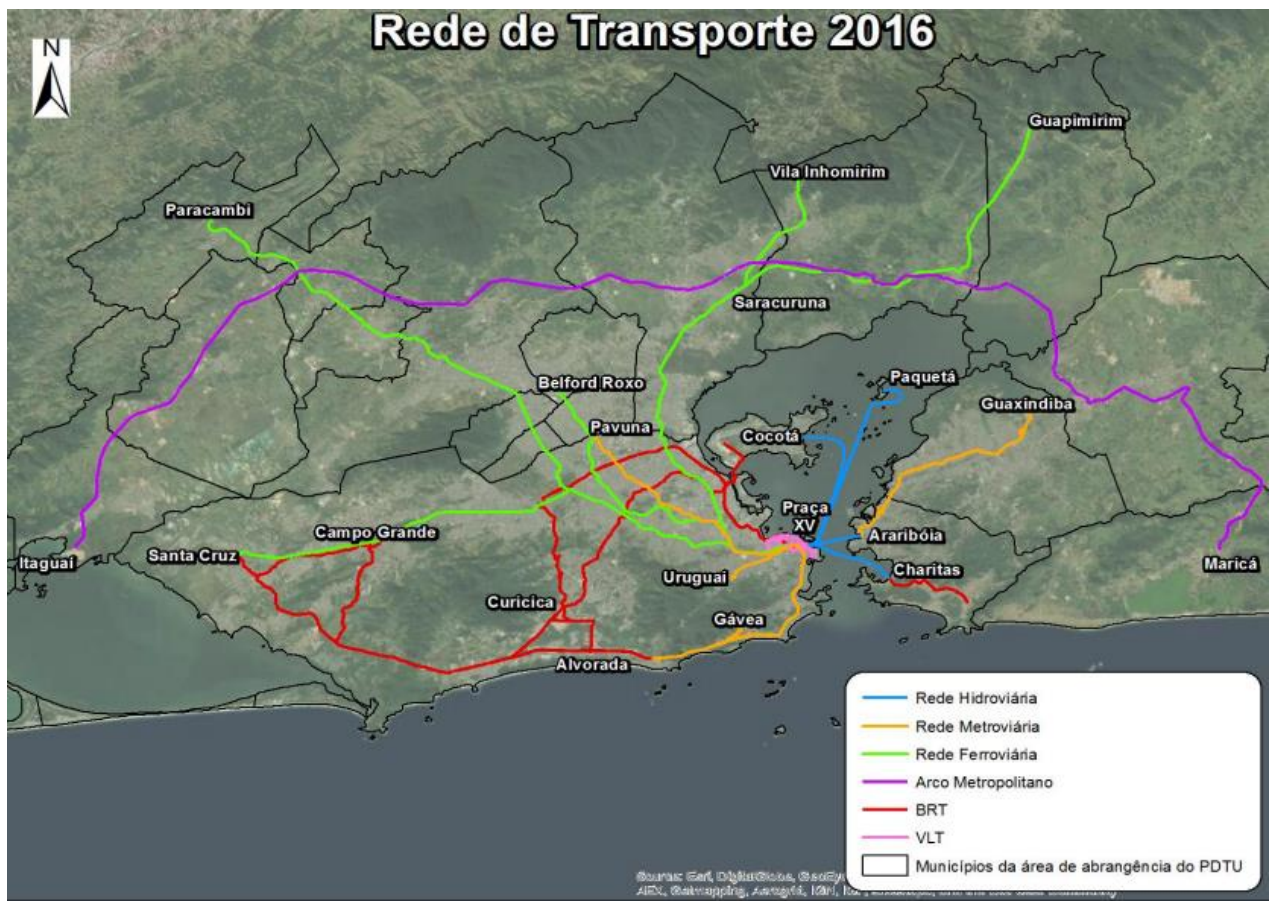

Figura 24: Rede básica de Transporte do Rio de Janeiro em 2016 (PDTU-2012)

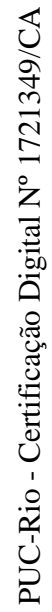

\subsubsection{VLT}

O VLT é descrito em 2016 como possuindo 6 linhas, com 44 estações, com capacidade de 400 pessoas por veículo e tarifa a 3,00 (Figura 25). O VLT em 2019, possui 3 linhas (sendo a última inaugurada em 2019) com 29 estações com capacidade de 420 pessoas por veículos e tarifa de 4,40 (Figura 26). O VLT no cenário de 2021 é a mesmo de 2016. Não há planos para ampliação do VLT.

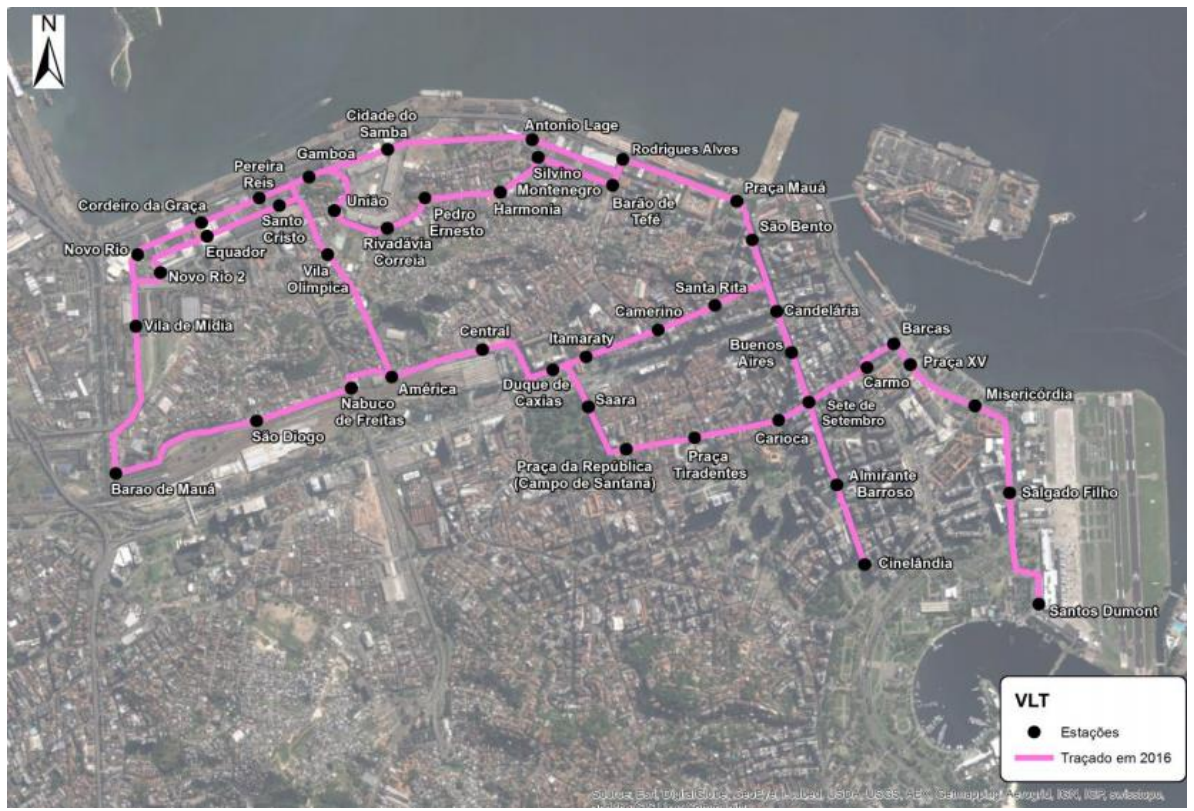

Figura 25: Traçado do VLT em 2016 (PDTU-2012) 
Comparando o cenário de 2016 e a rede atual em 2019, é possível reparar que o traçado previsto para 2016 é muito mais amplo que o atual.

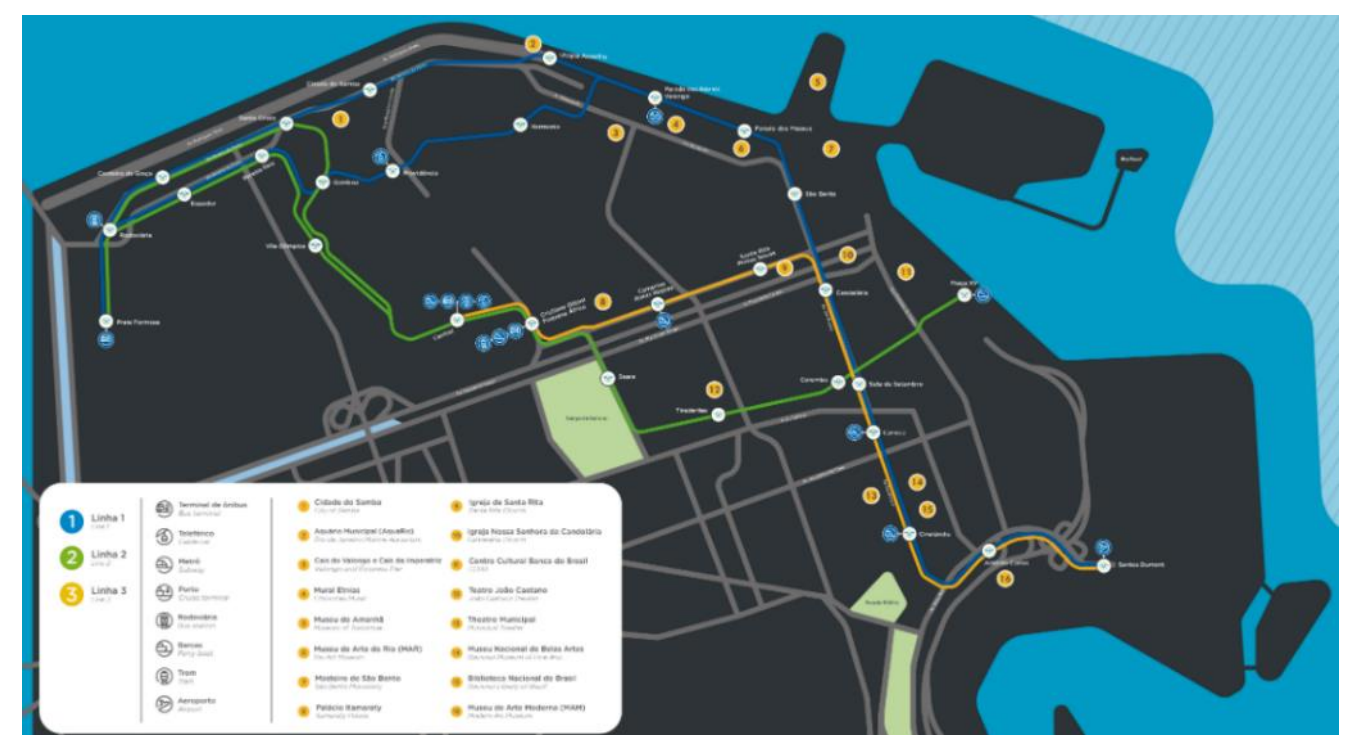

Figura 26: Traçado do VLT em 2018 (site VLT-RIO)

\subsubsection{Metrô}

O metrô em 2016 é descrito como possuindo quatro linhas, sendo três ( linha um, dois e quatro) no município do Rio de Janeiro e uma ( linha três) no município de Niterói. As linhas um, dois e quatro estavam operando em 2016, com exceção da estação gávea que faria parte da linha quatro, enquanto a linha três não existia. Em 2019 a situação continua a mesma (Figura 31). 


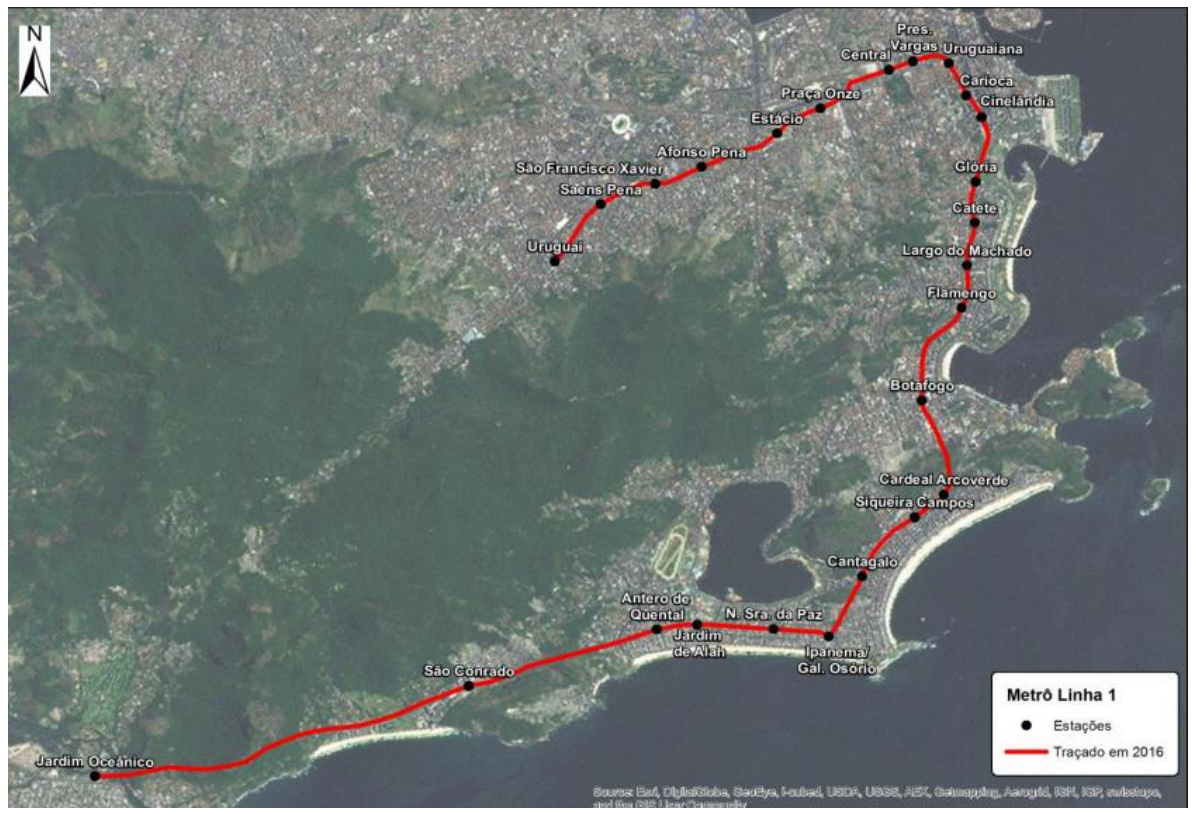

Figura 27: Traçado da linha 1 do metrô-rio em 2016 (PDTU-2012)

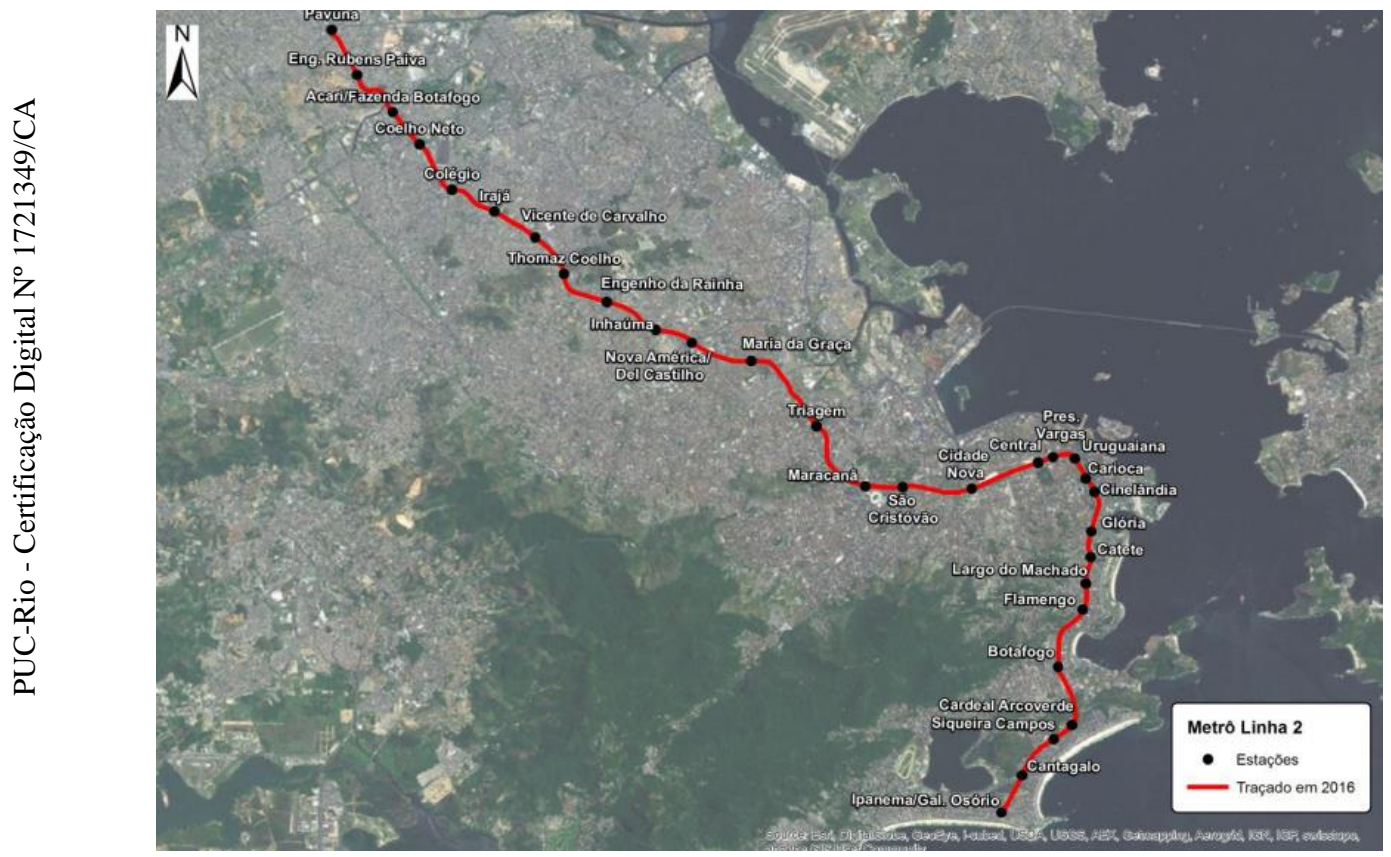

Figura 28: Traçado da linha 2 do metrô-rio em 2016 (PDTU-2012) 


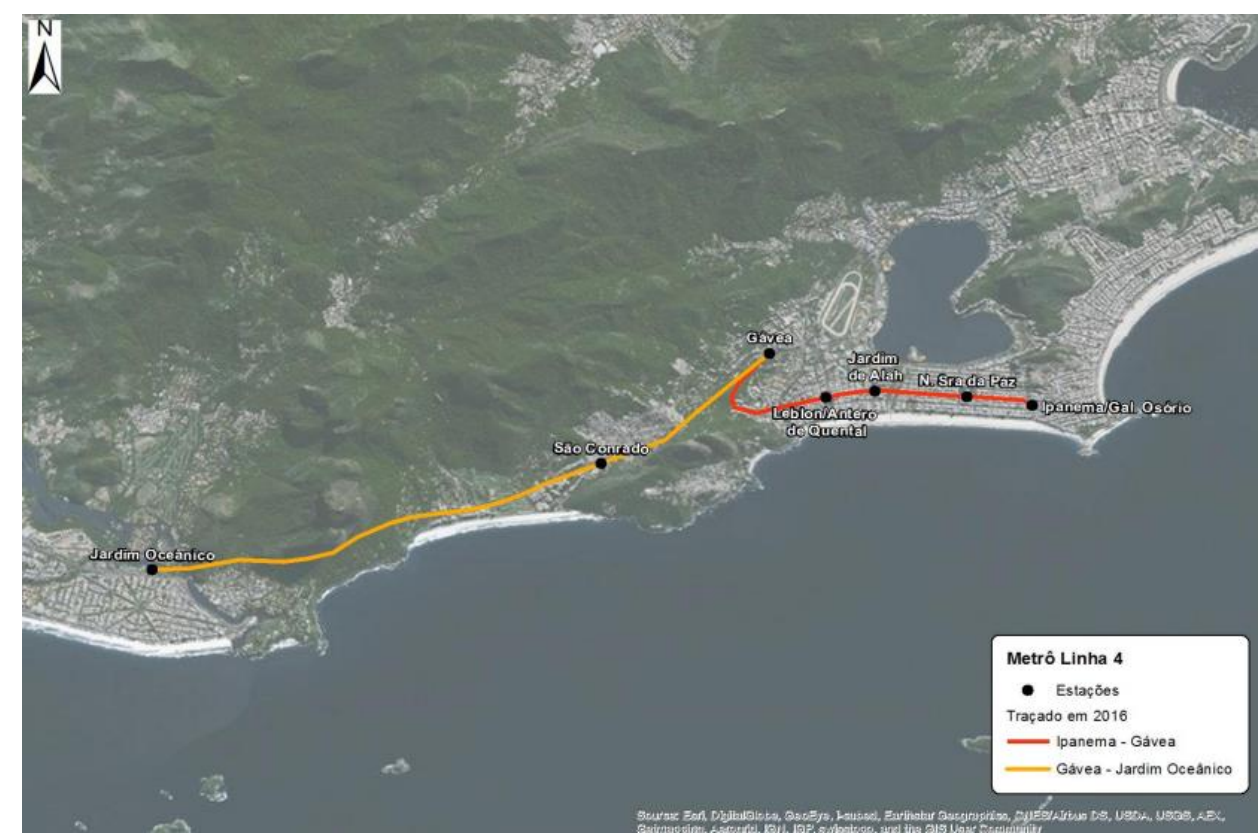

Figura 29: Traçado da linha 4 do metrô-rio em 2016 (PDTU-2012)

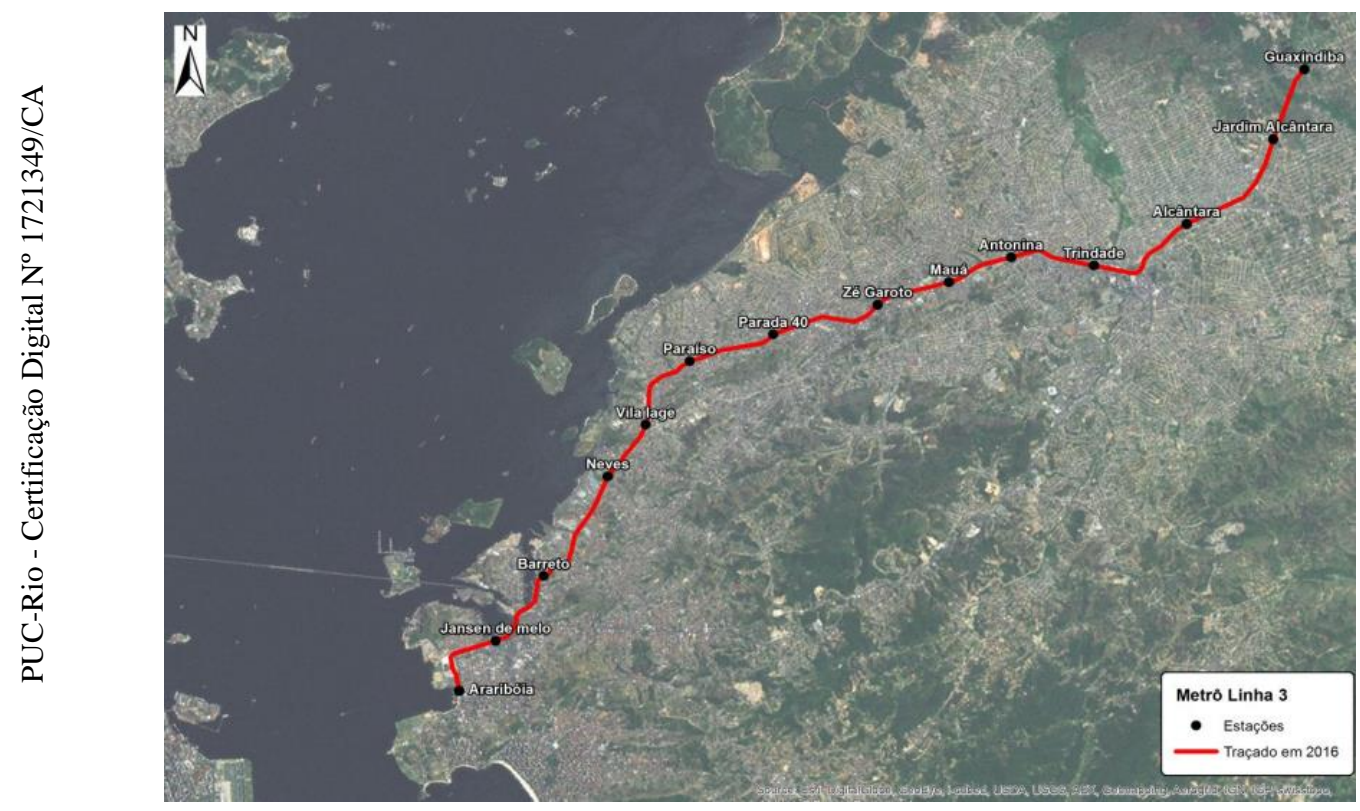

Figura 30: Traçado da linha 3 do metrô-rio em 2016 (PDTU-2012) 


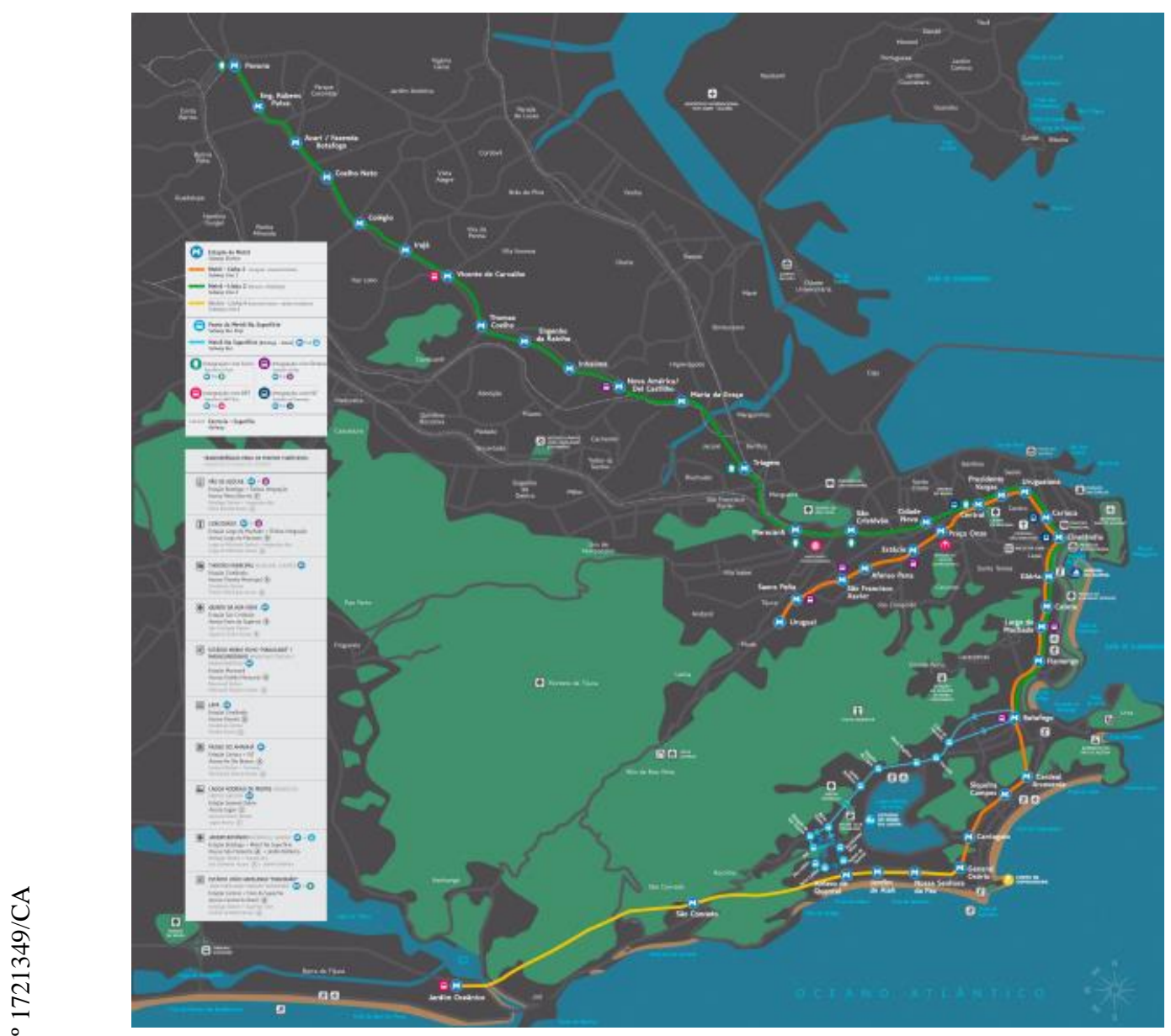

Figura 31: Traçado da rede do metrô-rio em 2019 (site metrô-rio)

Nos cenários do ano de 2021, é possível observar a ampliação da malha metroviária na linha um, dois, três e quatro além da criação da linha seis. A linha três (Arariboia $\leftrightarrow$ Visconde de Itaboraí) prevista no cenário de 2016 atualmente está em processo de licitação, sem previsão para inauguração. O governo do Rio de Janeiro havia anunciado em 2017 a construção da Linha 5 (Gávea $\leftrightarrow$ Carioca), contudo a Estação Gávea continua sem existir, e a obra continua em licitação do projeto básico. Não há nenhuma previsão da ampliação das linhas como previsto nos cenários para 2021.0 valor da tarifa usado tanto no cenário 2016 como 2021 foi de $\mathrm{R} \$ 3,20$ enquanto o valor real em 2016 era $\mathrm{R} \$ 4,10$ e em 2019 era de $\mathrm{R} \$ 4,60$. 


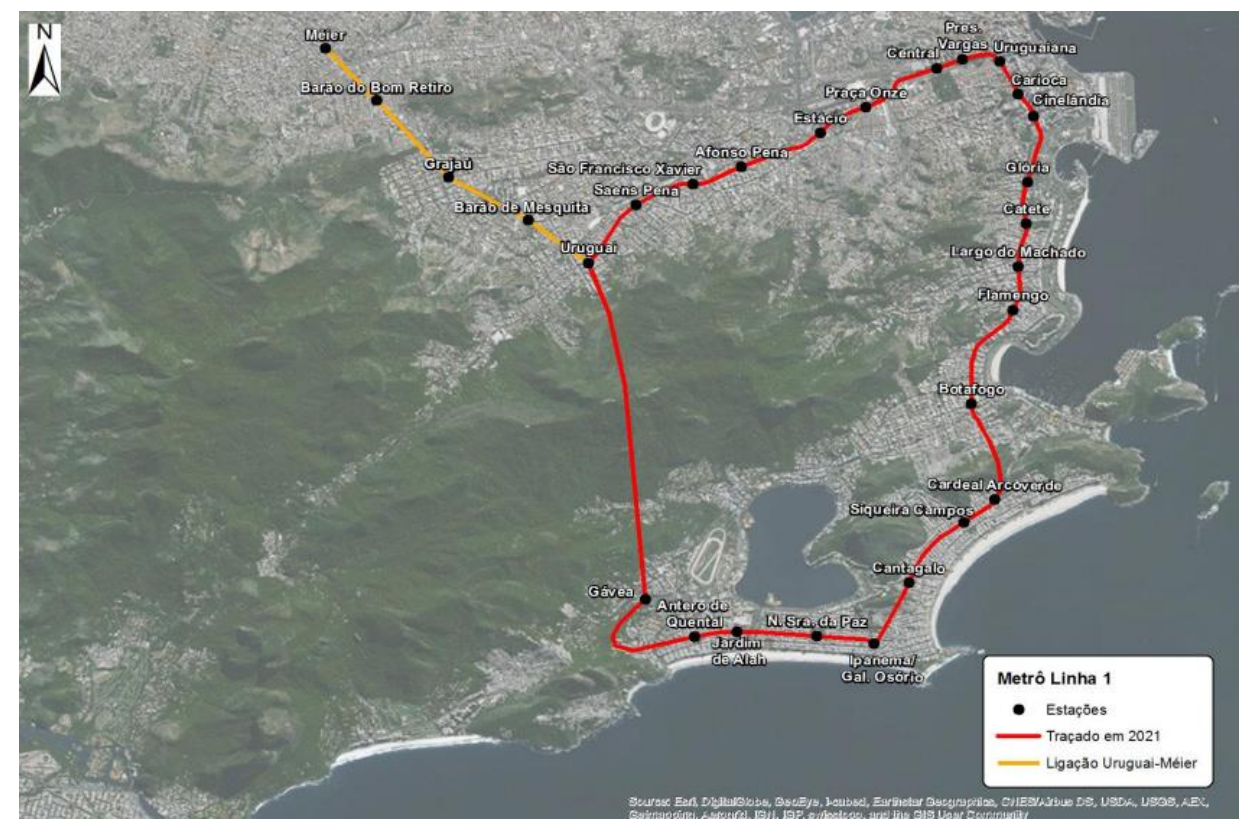

Figura 32: Traçado da linha 1 do metrô-rio em 2021 (PDTU-2012)

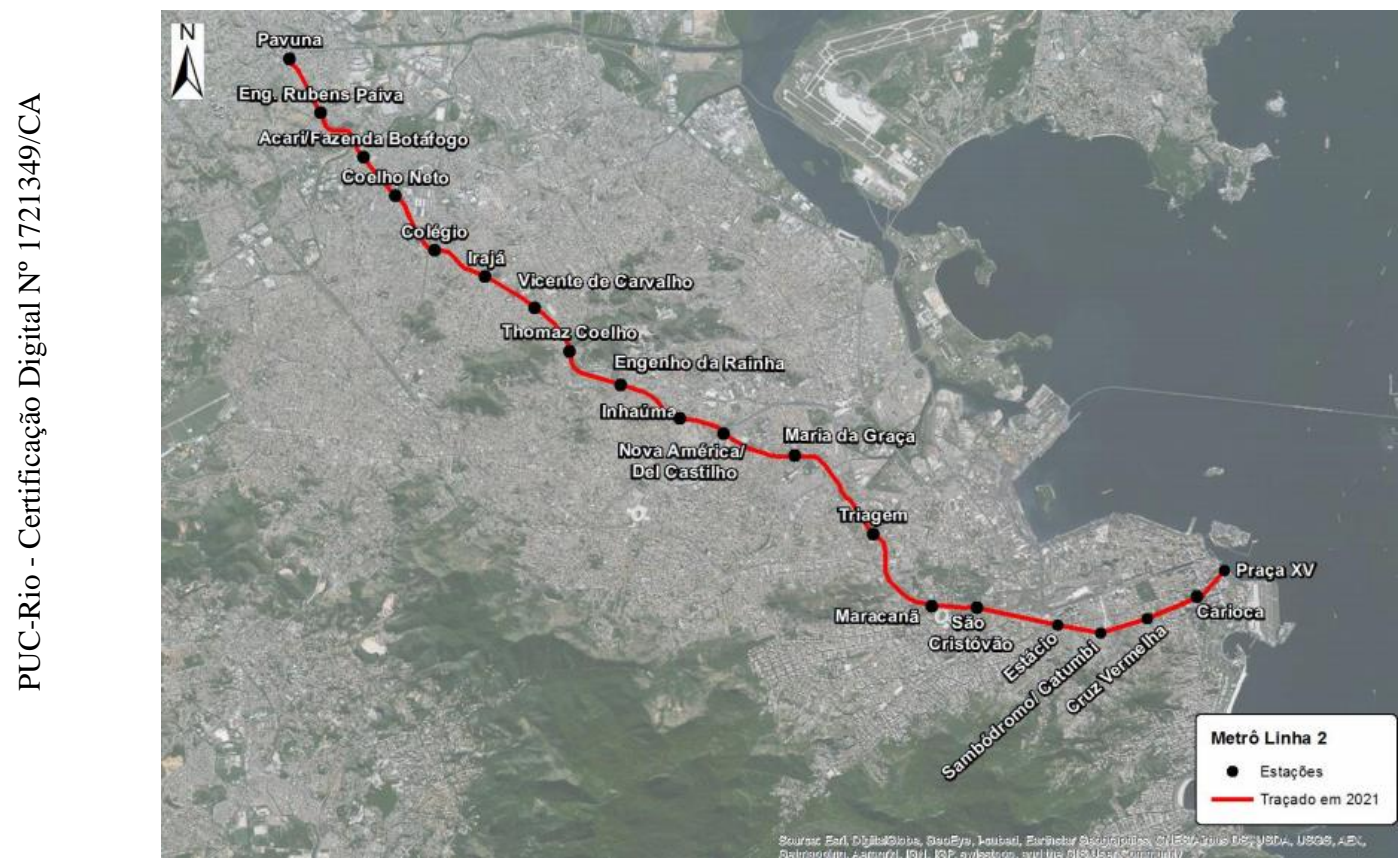

Figura 33: Traçado da linha 2 do metrô-rio em 2021 (PDTU-2012) 


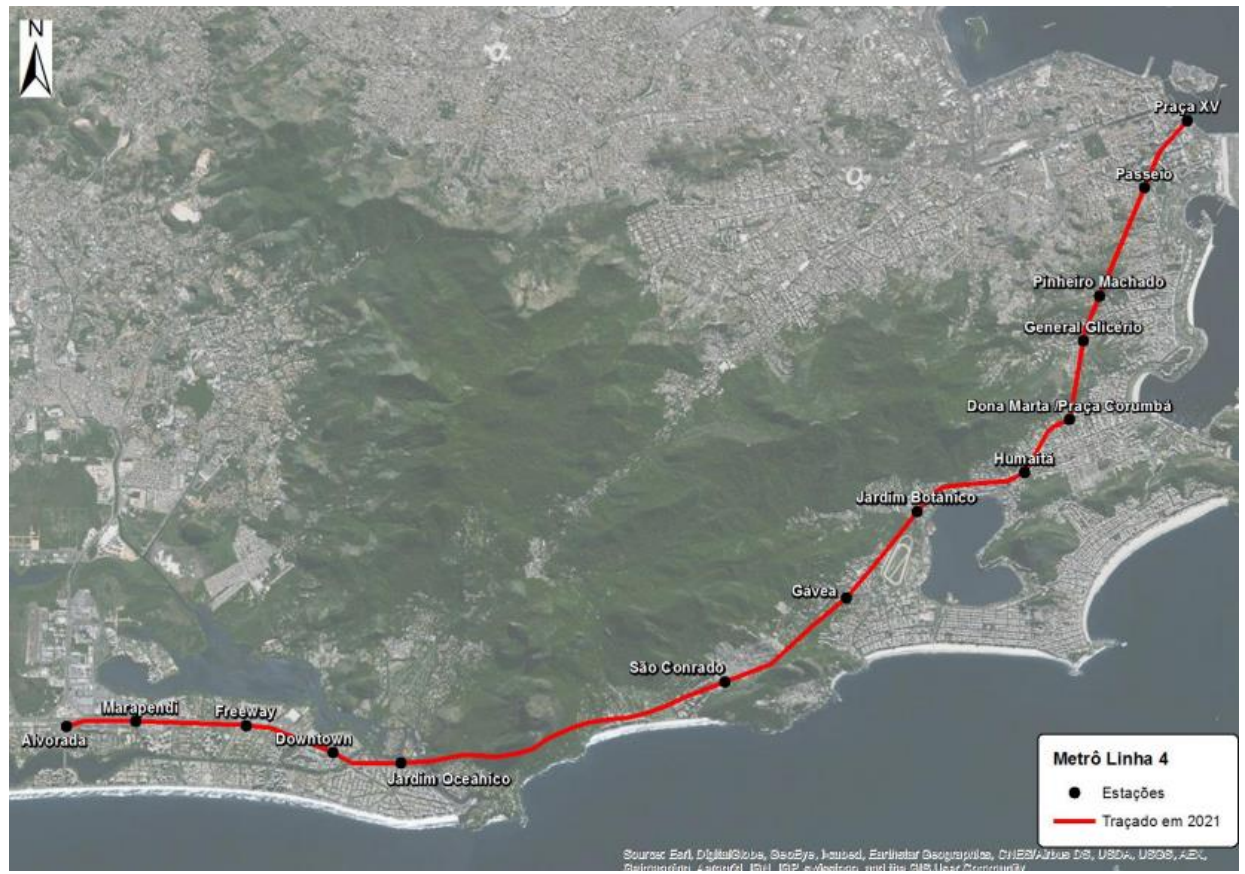

Figura 34: Traçado da linha 4 do metrô-rio em 2021 (PDTU-2012)

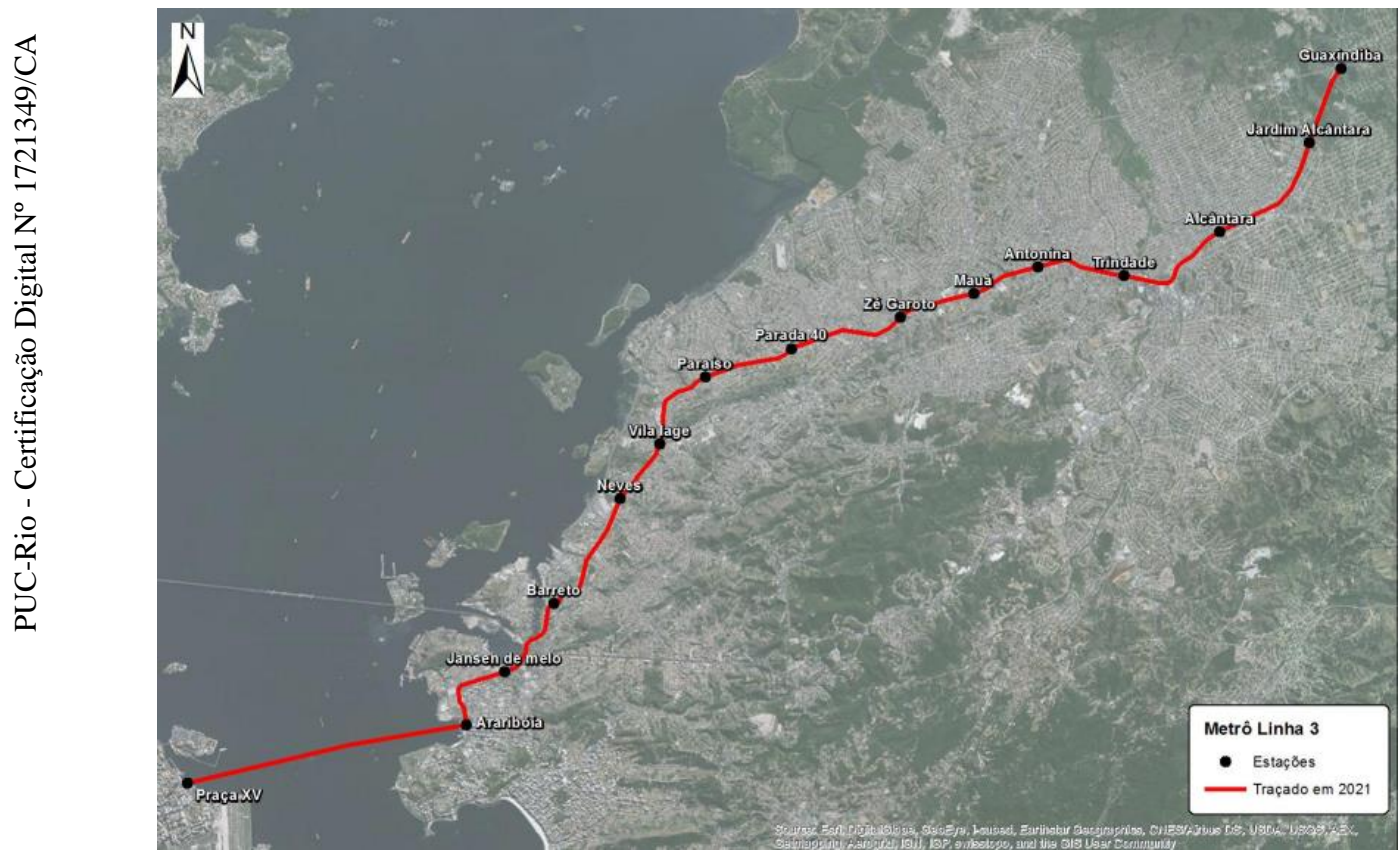

Figura 35: Traçado da linha 3 do metrô-rio em 2021 (PDTU-2012) 


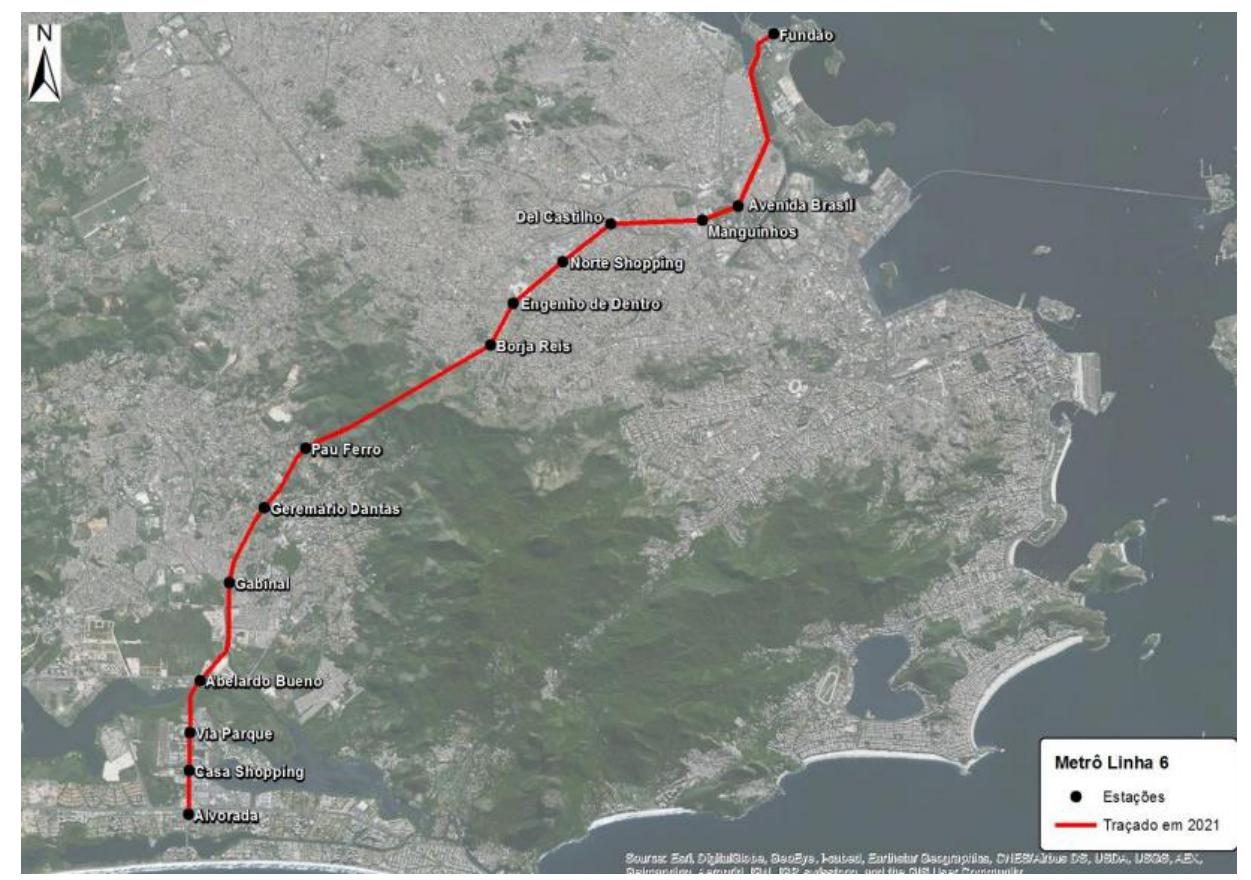

Figura 36: Traçado da linha 6 do metrô-rio em 2021 (PDTU-2012)

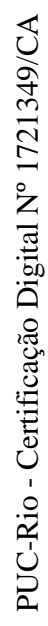

\subsubsection{Ferrovias}

A rede ferroviária descrita para o ano de 2016 estava de acordo com a realidade do ano. A rede no ano de 2019 (Figura 38) continua a mesma que do ano de 2016 (Figura 37). Observando os cenários do ano de 2021, é possível observar uma ampliação na rede, sendo que o governo do Rio de Janeiro não tem perspectiva de novas obras para a rede ferroviária. A tarifa para os cenários dos anos de 2016 e de 2021 era R \$ 2,90, quando na verdade em 2016 era $\mathrm{R} \$ 3,70$ e em 2019 era de $\mathrm{R} \$ 4,60$.

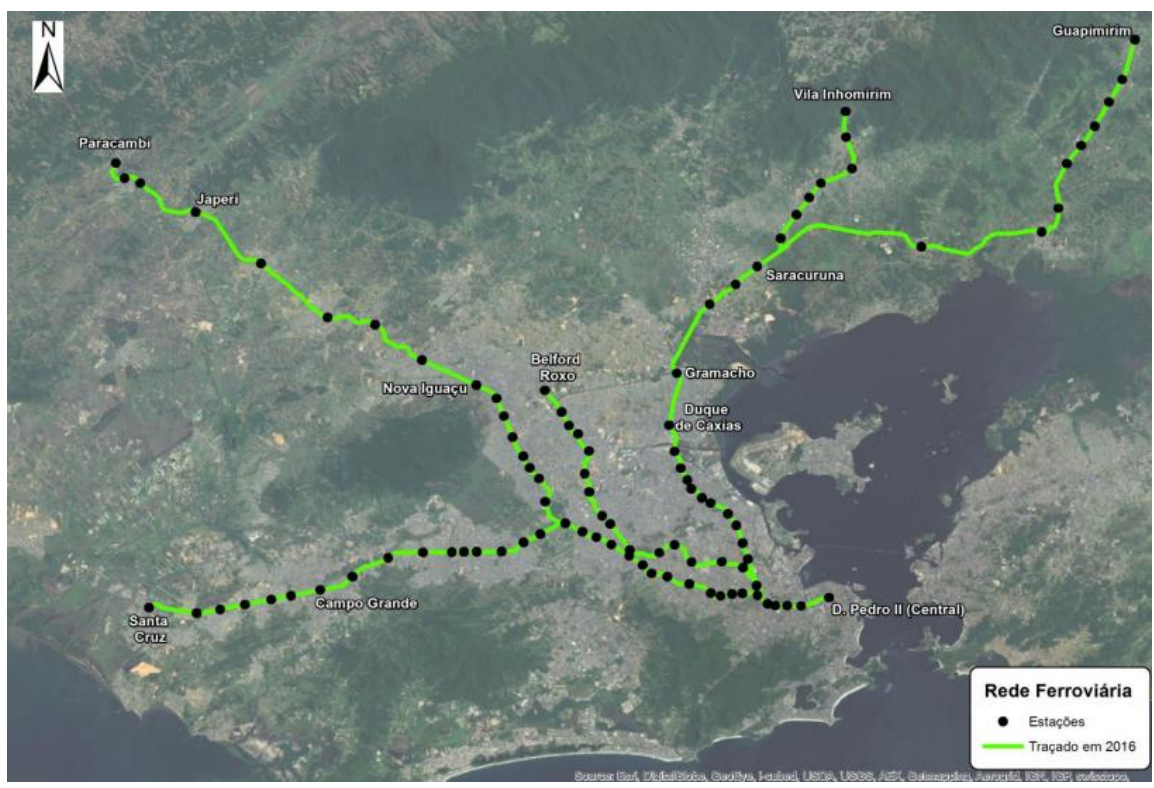

Figura 37: Traçado da linha ferroviária do rio em 2016 (PDTU-2012) 


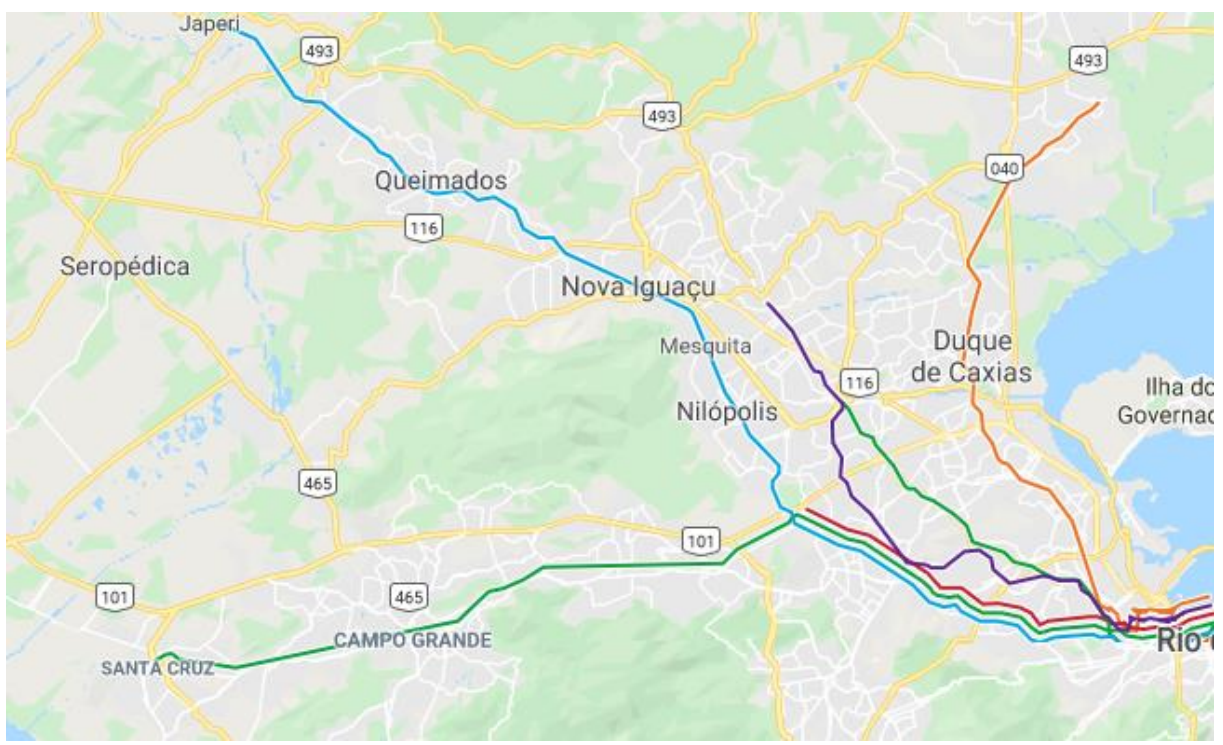

Figura 38: Traçado da linha ferroviária do rio em 2019 (Google)

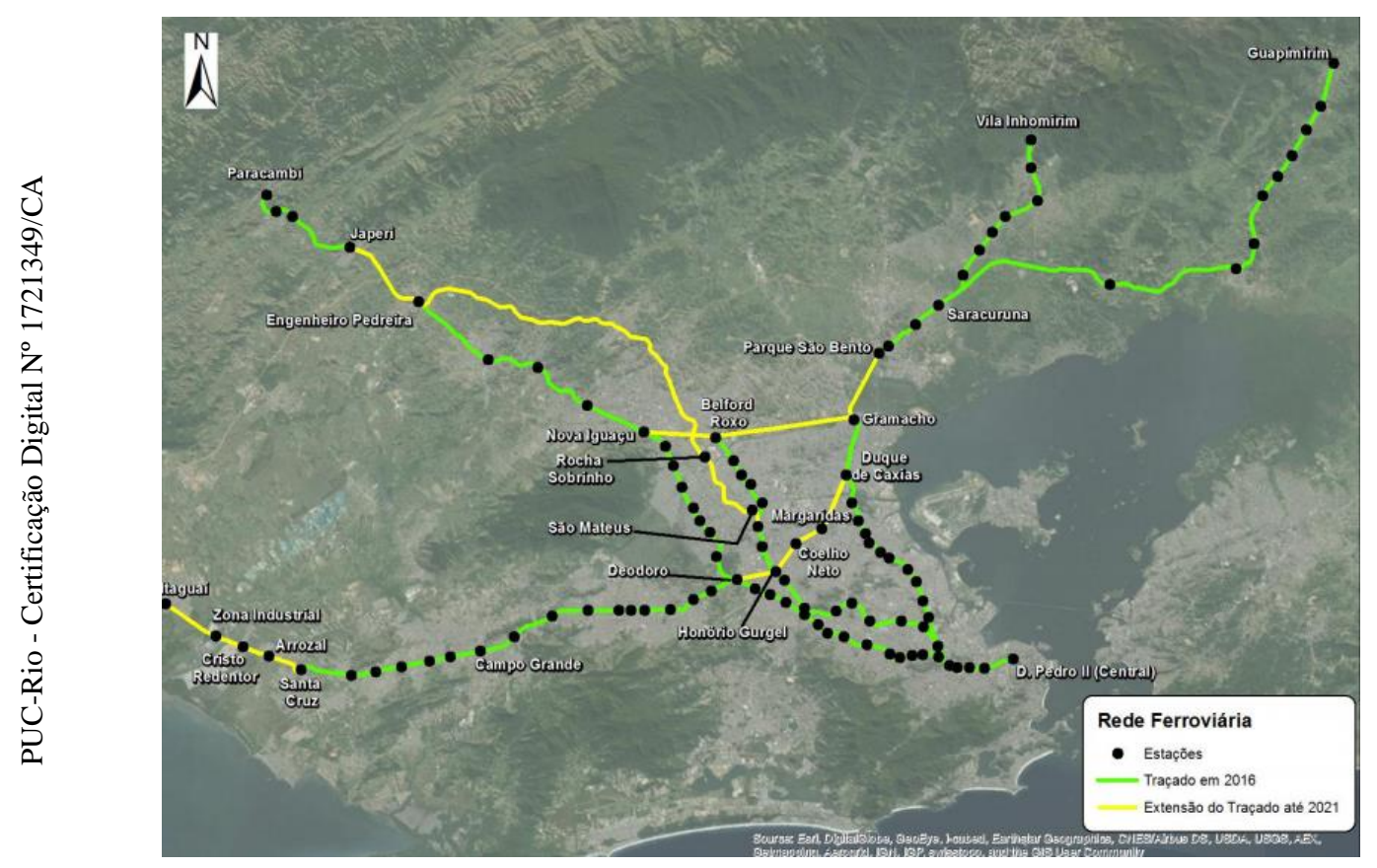

Figura 39: Traçado da linha ferroviária do rio em 2021 (PDTU-2012)

\subsubsection{BRT}

Olhando para o BRT no cenário 2016, observa-se 5 corredores sendo que na realidade para o ano de 2016 só foi possível finalizar a obra de 3 corredores, sendo eles TransOeste (Campo grande $\leftrightarrow$ Jardim Oceânico), TransCarioca (Alvorada $\leftrightarrow$ Galeão) e TransOlímpica (Recreio $\leftrightarrow$ Vila Militar). O corredor TransBrasil ainda segue em 2019 sem estar finalizado, mas com estações já funcionando. Contudo as estações operantes funcionam no sistema BRS, por onde circulam também ônibus tradicionais e não somente os ônibus articulados. Já o corredor transOceânico entrou em operação em 2019, contudo 
diferentemente do que ocorre nos outros corredores, os ônibus não trafegaram apenas no leito do corredor expresso, possuindo portas dos dois lados para também circular pelas ruas e avenidas que não contam com a via exclusiva. Dessa forma, o trajeto foi ampliado em relação ao cenário de 2016 (Figura 45). A tarifa a R \$2,75 para os cenários em 2016 e 2021 enquanto na verdade o valor era $\mathrm{R} \$ 3,80$ no ano de 2016 e R\$ 4,05 em 2019.

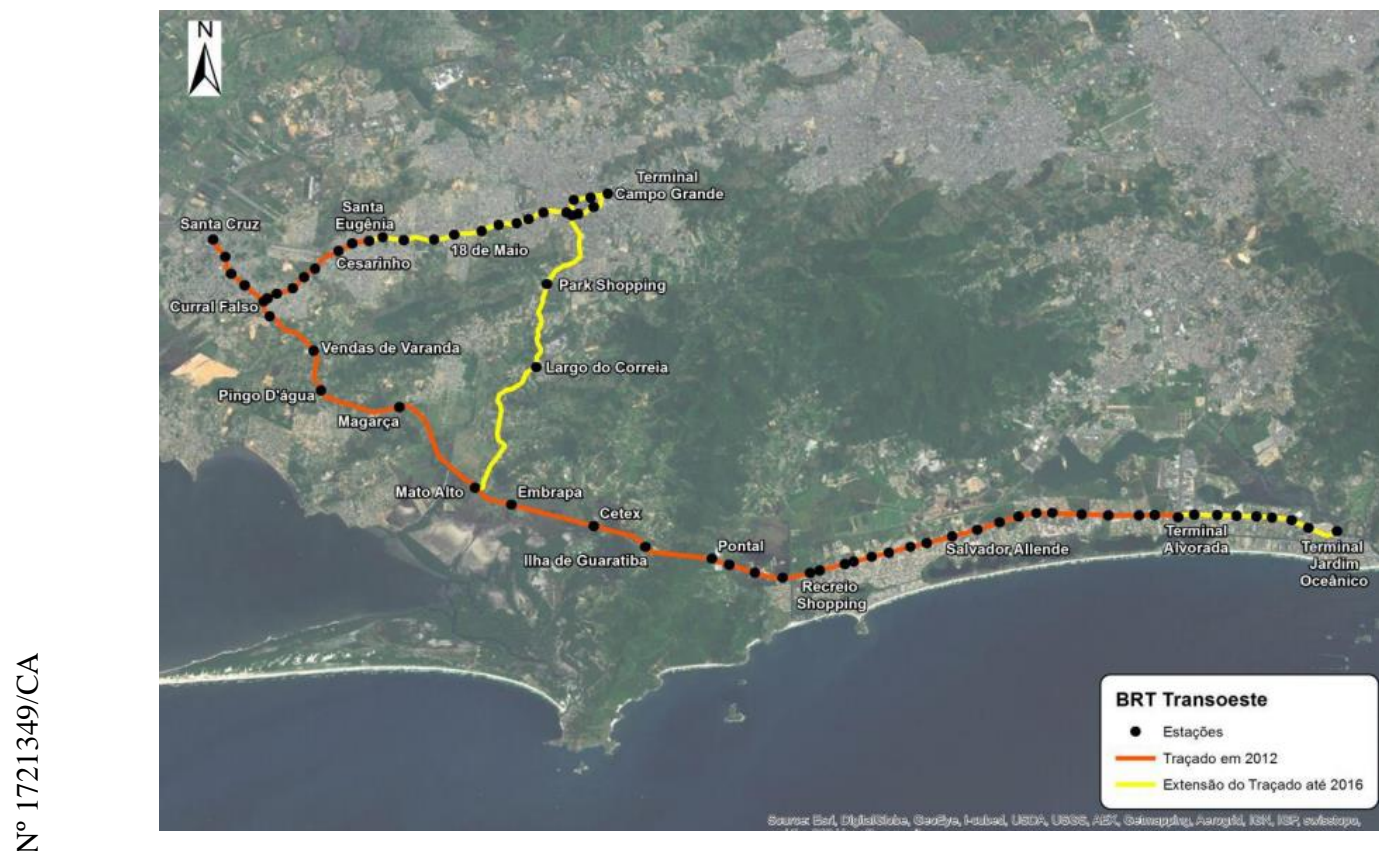

Figura 40: Traçado do BRT TransOeste em 2016 (PDTU-2012)

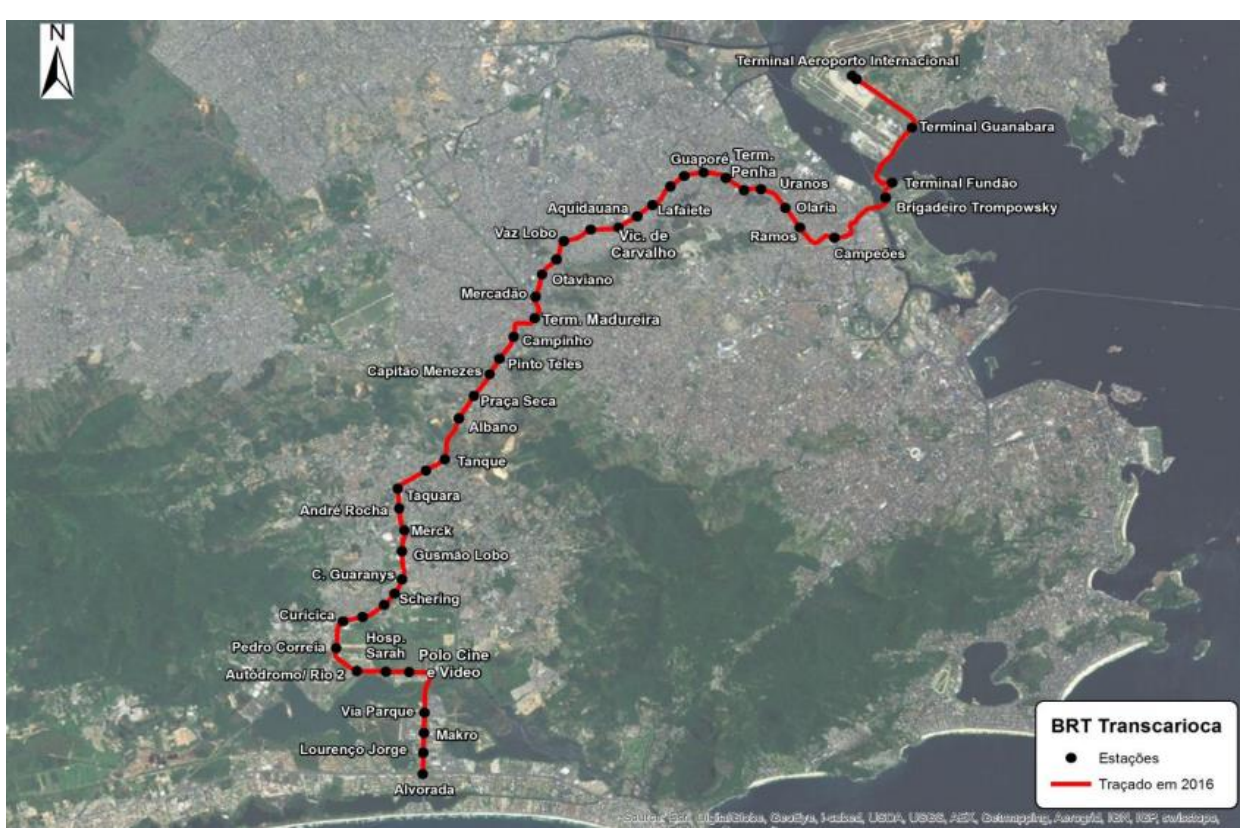

Figura 41: Traçado do BRT TransCarioca em 2016 (PDTU-2012) 


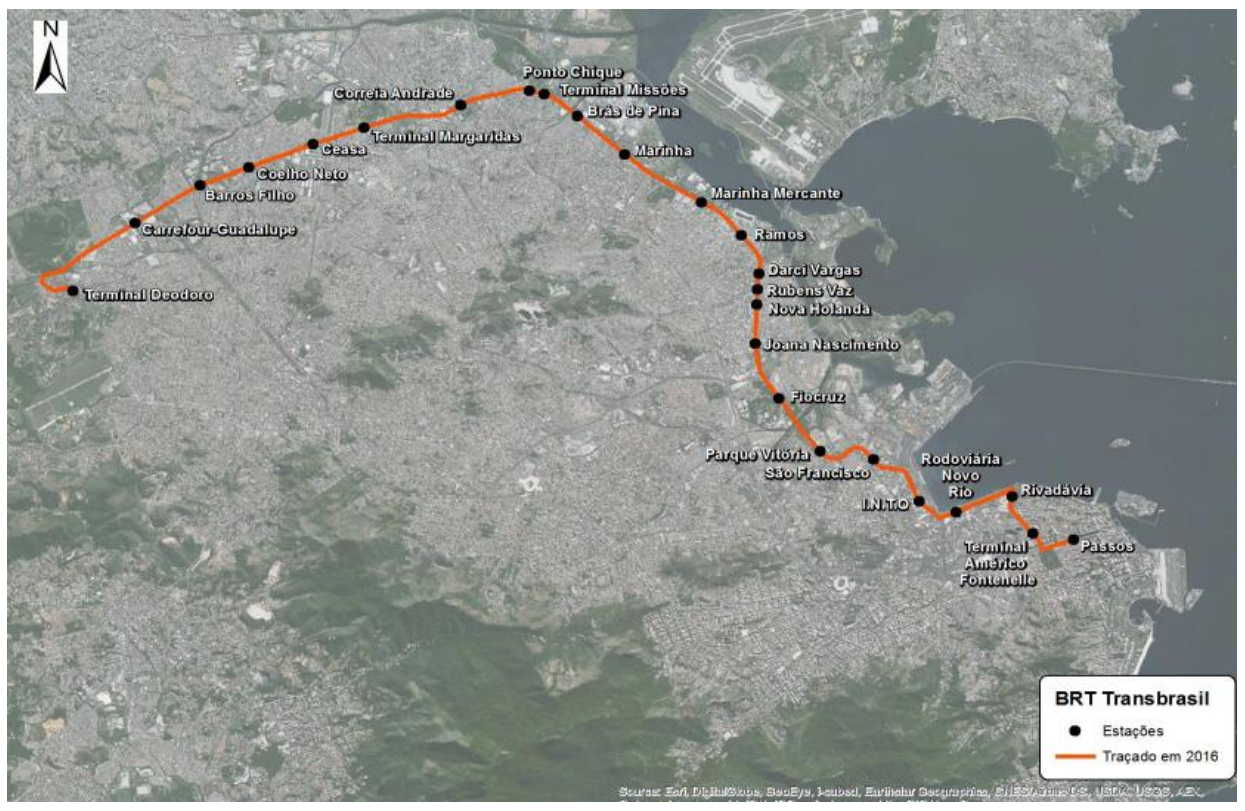

Figura 42: Traçado do BRT TransBrasil em 2016 (PDTU-2012)

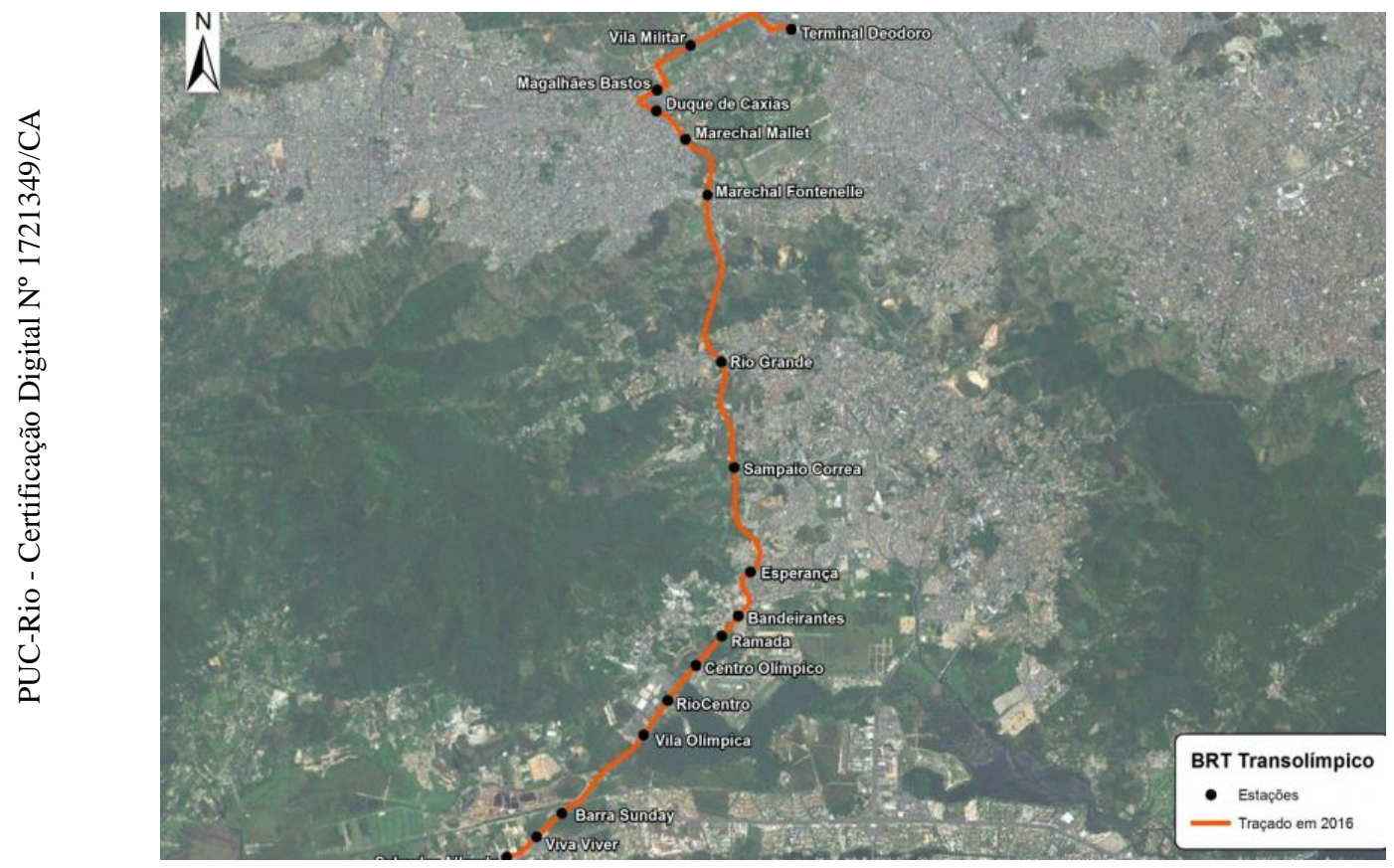

Figura 43: Traçado do BRT TransOlímpico em 2016 (PDTU-2012) 


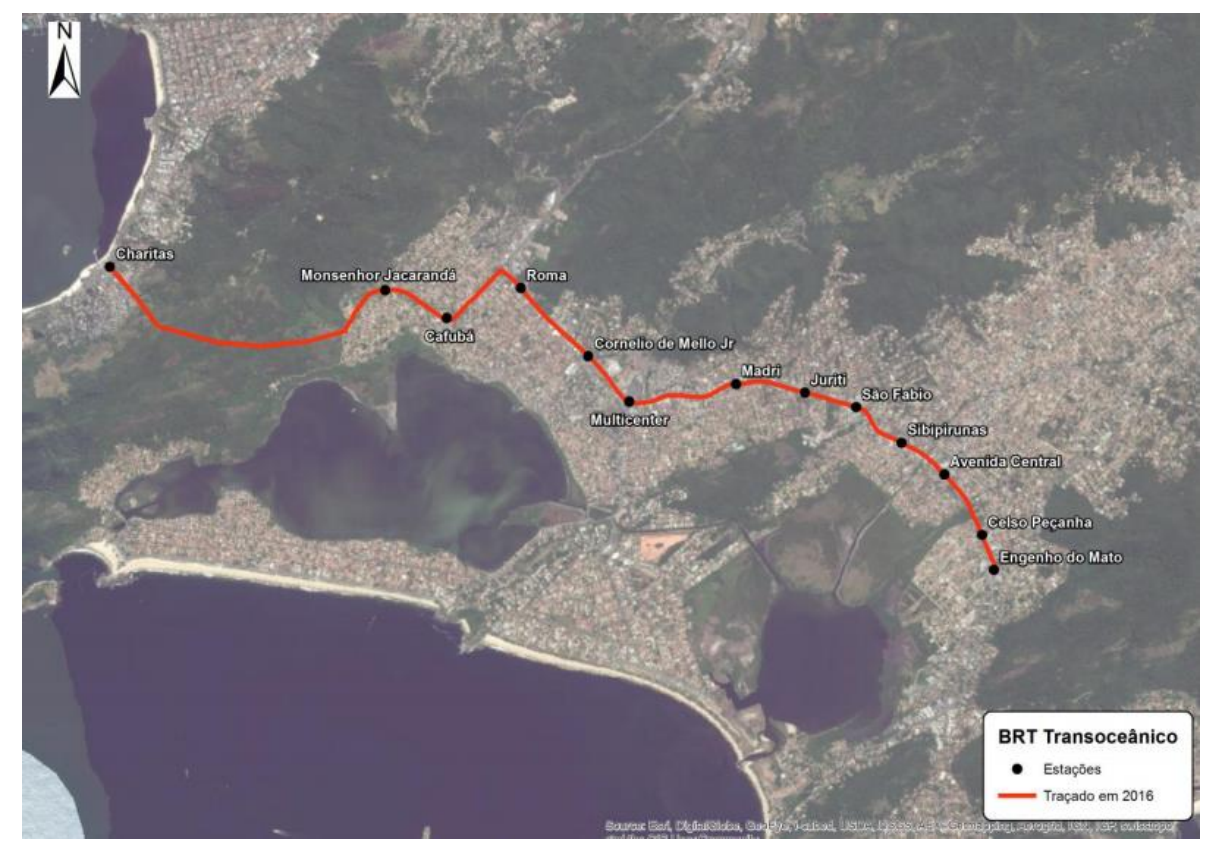

Figura 44: Traçado do BRT TransOceânico em 2016 (PDTU-2012)

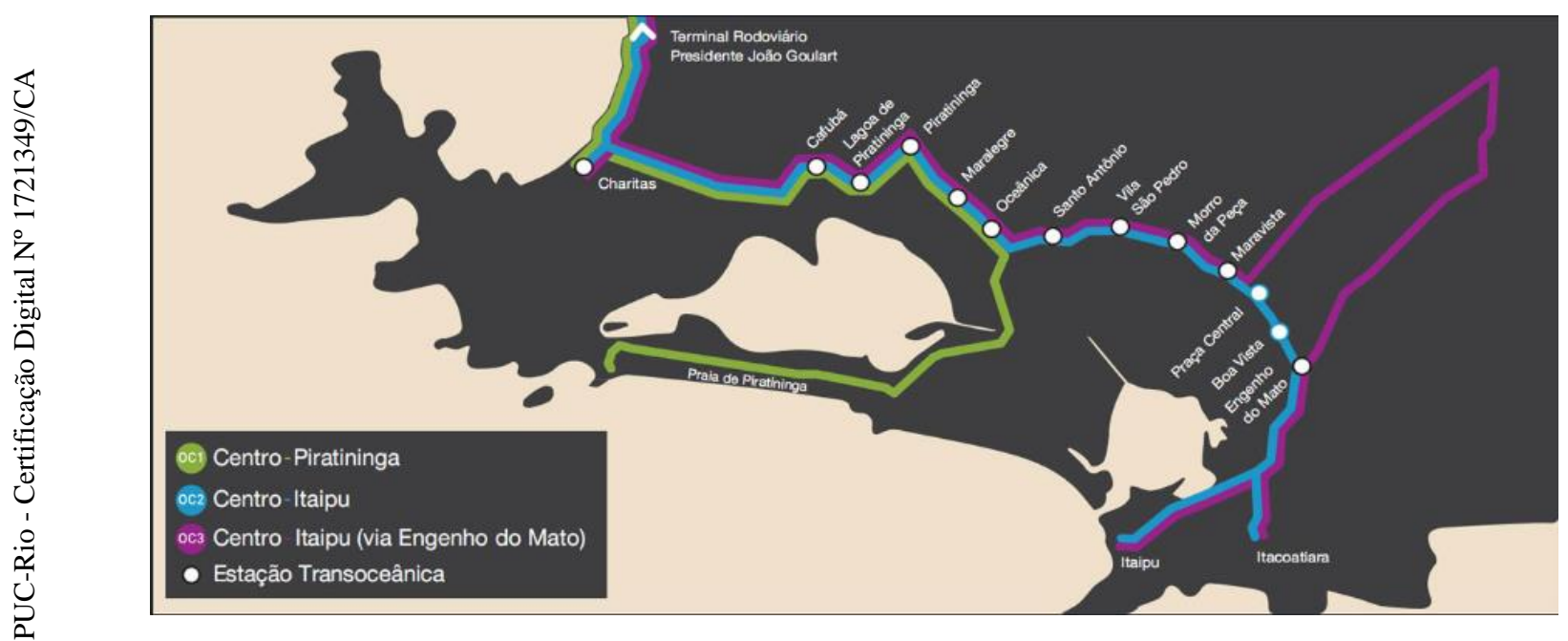

Figura 45: Traçado do BRT Transoceânico em 2019 (site TransOceanicaNiteroi)

Olhando para o BRT nos cenários do ano de 2021, observa-se uma ampliação do corredor TransCarioca com adição do trecho entre Galeão e Cocotá, que não teve suas obras iniciadas nem previsão de construção. O corredor BRT RJ-104 (Terminal João Goulart $\leftrightarrow$ Manilha), BRT RJ-106 (Terminal Maricá $\leftrightarrow$ Parque Marajó) e BRT Magarça (Magarça $\leftrightarrow$ Av. Brasil) também não tem previsão de construção. 


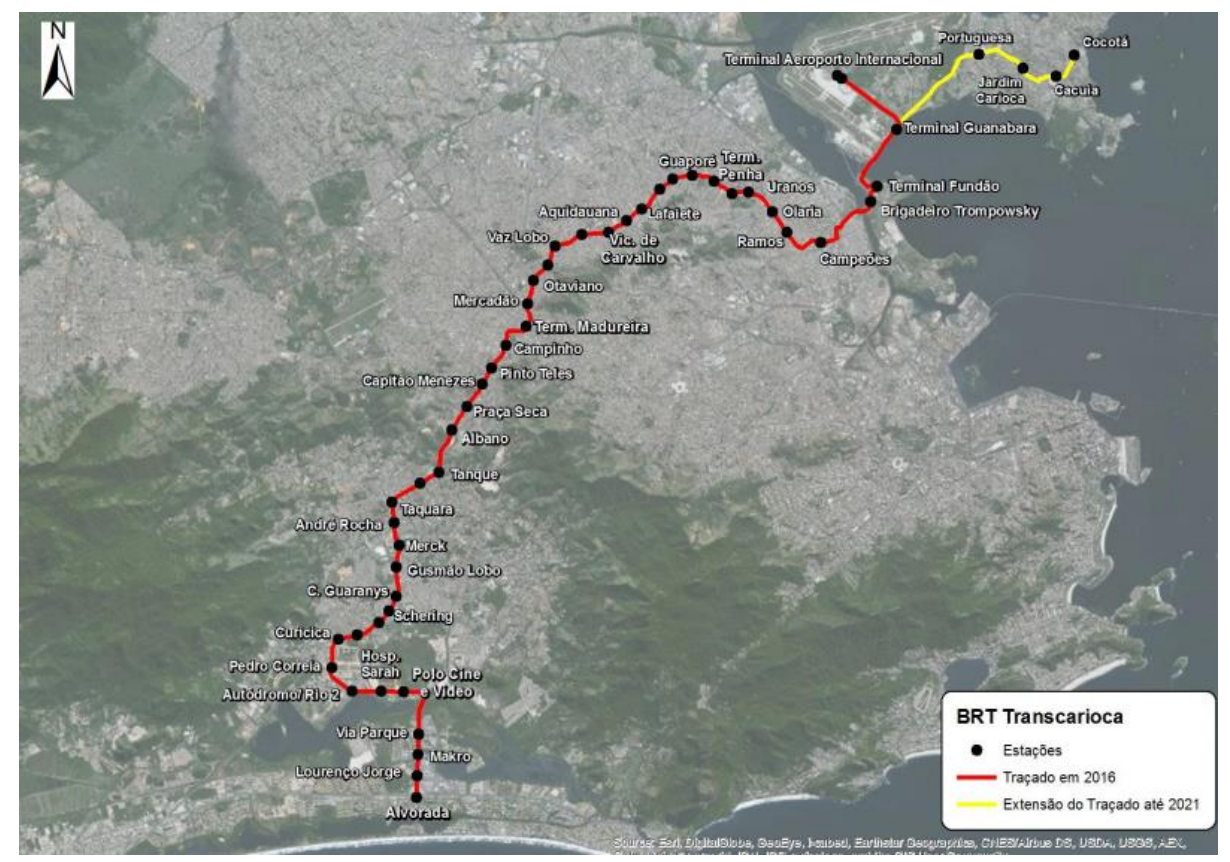

Figura 46: Traçado do BRT Transcarioca em 2021 (PDTU-2012)

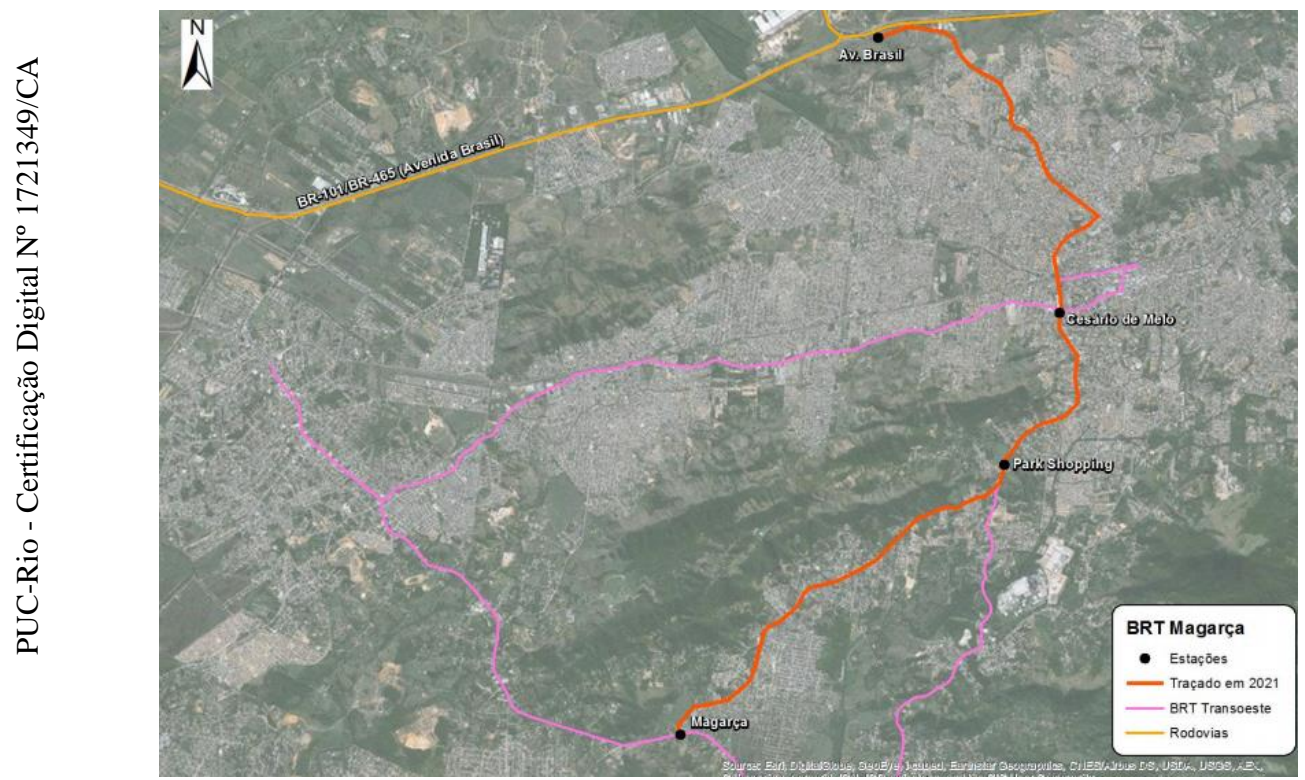

Figura 47: Traçado do BRT Magarça em 2021 (PDTU-2012) 


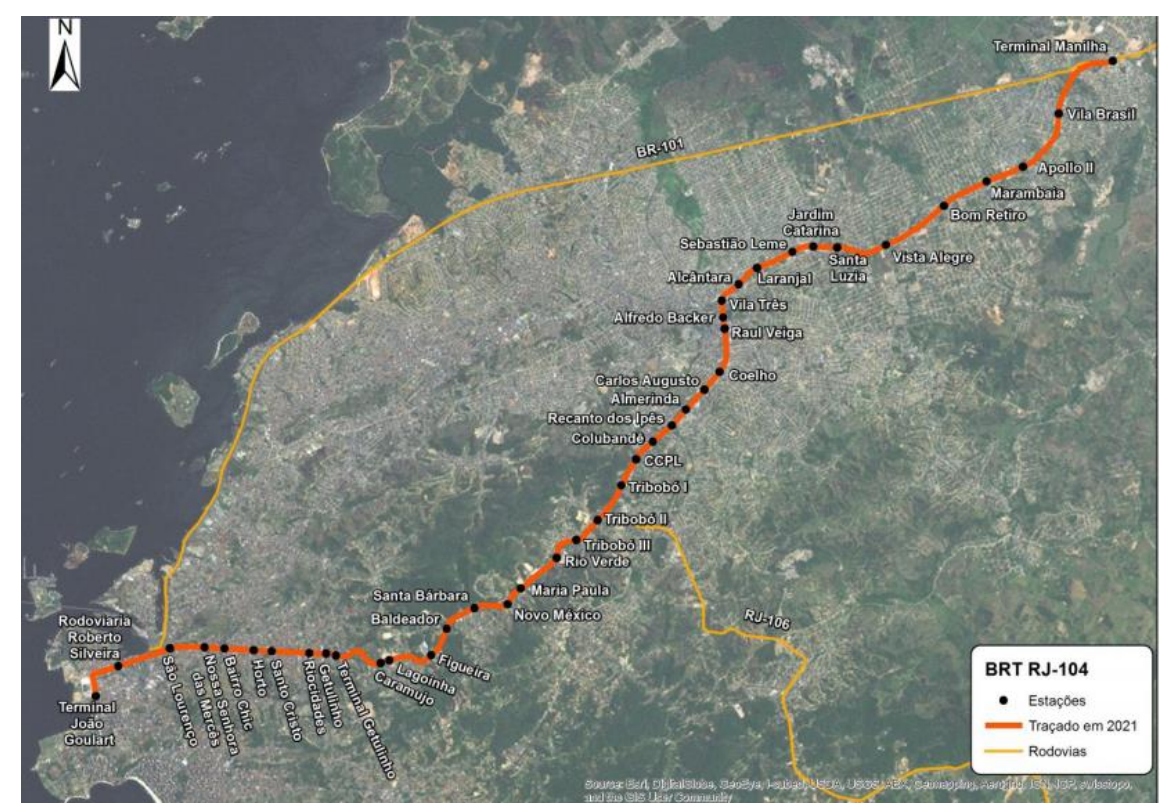

Figura 48: Traçado do BRT RJ-104 em 2021 (PDTU-2012)

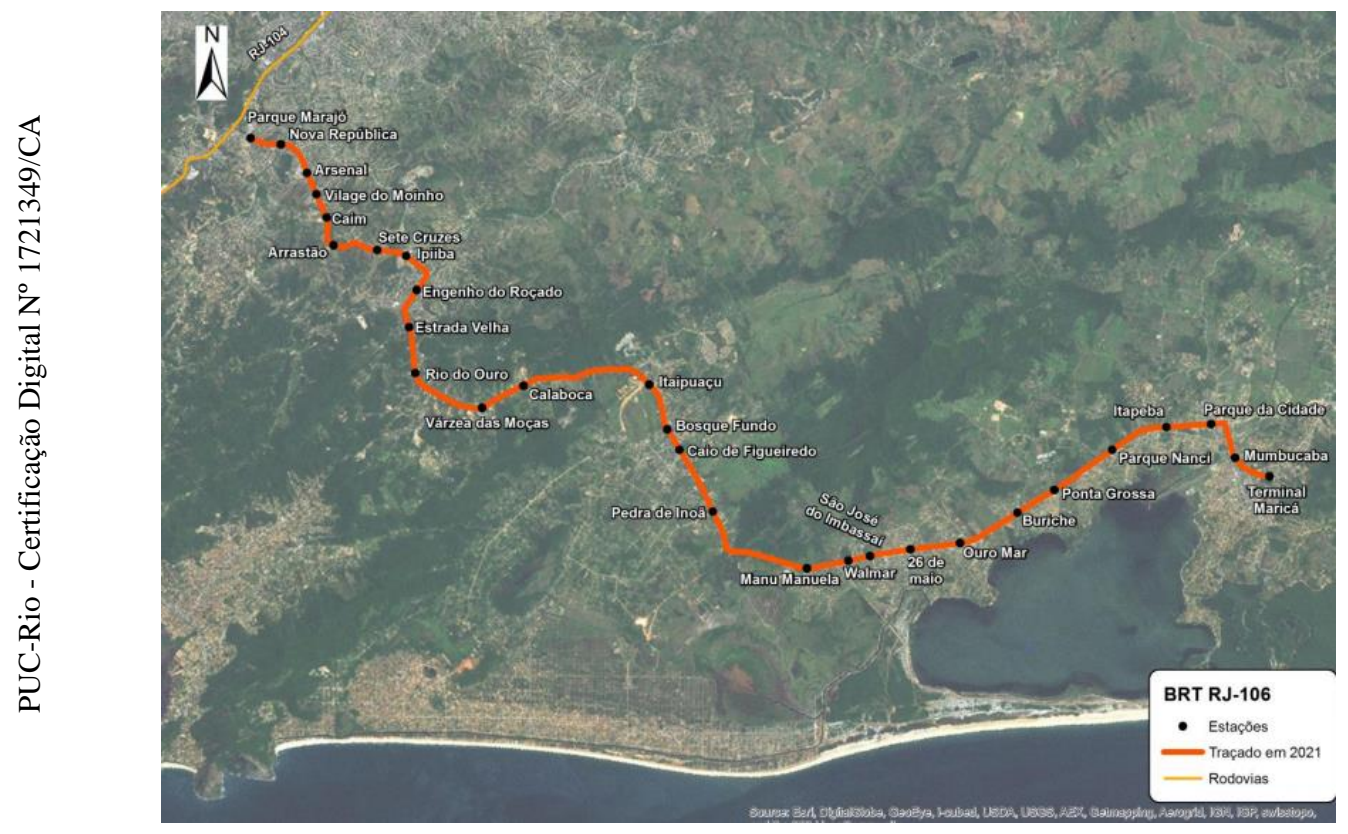

Figura 49: Traçado do BRT RJ-106 em 2021 (PDTU-2012)

\subsection{Cenários}

Os cenários que são desenvolvidos nessa dissertação são focados no metrô e em conexões do BRT com os trens da Supervia. Ao todo foram desenvolvidos 5 cenários que serão detalhados nas próximas seções.

Esses cenários foram escolhidos, primeiramente, por já terem uma infraestrutura préexistente, ou seja, estações já construídas ou que já entraram em processo de construção. Esse fato facilitaria a aplicação desse cenário no cotidiano da população, além da economia 
que os governos teriam aproveitando estações já construídas. Também foi levado em consideração o apelo para o desenvolvimento sustentável dos sistemas de transportes. E por fim, devido à integração que esses modos podem trazer para a cidade do Rio de janeiro fazendo com que os passageiros ganhem mais acesso à cidade, pois há conexão entre mais bairros.

\subsubsection{Cenário 1: Linha de metrô Gávea $\leftrightarrow$ Carioca}

O desenvolvimento da linha de metrô Gávea $\leftrightarrow$ Carioca seria um segmento da linha 4 do metrô no cenário de 2021. Ela teria 8 estações sendo elas: Gávea, Jardim Botânico, Humaitá, Dona Marta, General Glicério, Pinheiro Machado, Passeio e Carioca (Figura 50). Essa linha faria uso da estação Gávea, localizada no subsolo do estacionamento da Pontifícia Universidade Católica do Rio de Janeiro (PUC-Rio), que teve sua construção iniciada em 2013, com inauguração inicialmente prevista para 2016. Contudo as obras estão atualmente paralisadas sem alguma previsão de retomada.

Atualmente há uma batalha judicial para decidir sobre o futuro da estação da Gávea, se ela deve ser aterrada ou concluída a construção. Esse cenário foi desenvolvido também com o intuito de avaliar o uso potencial dessa estação já que ela seria uma estação estratégica de ligação entre diversas linhas do metrô e $48 \%$ das obras previstas para a construção já foram executadas.

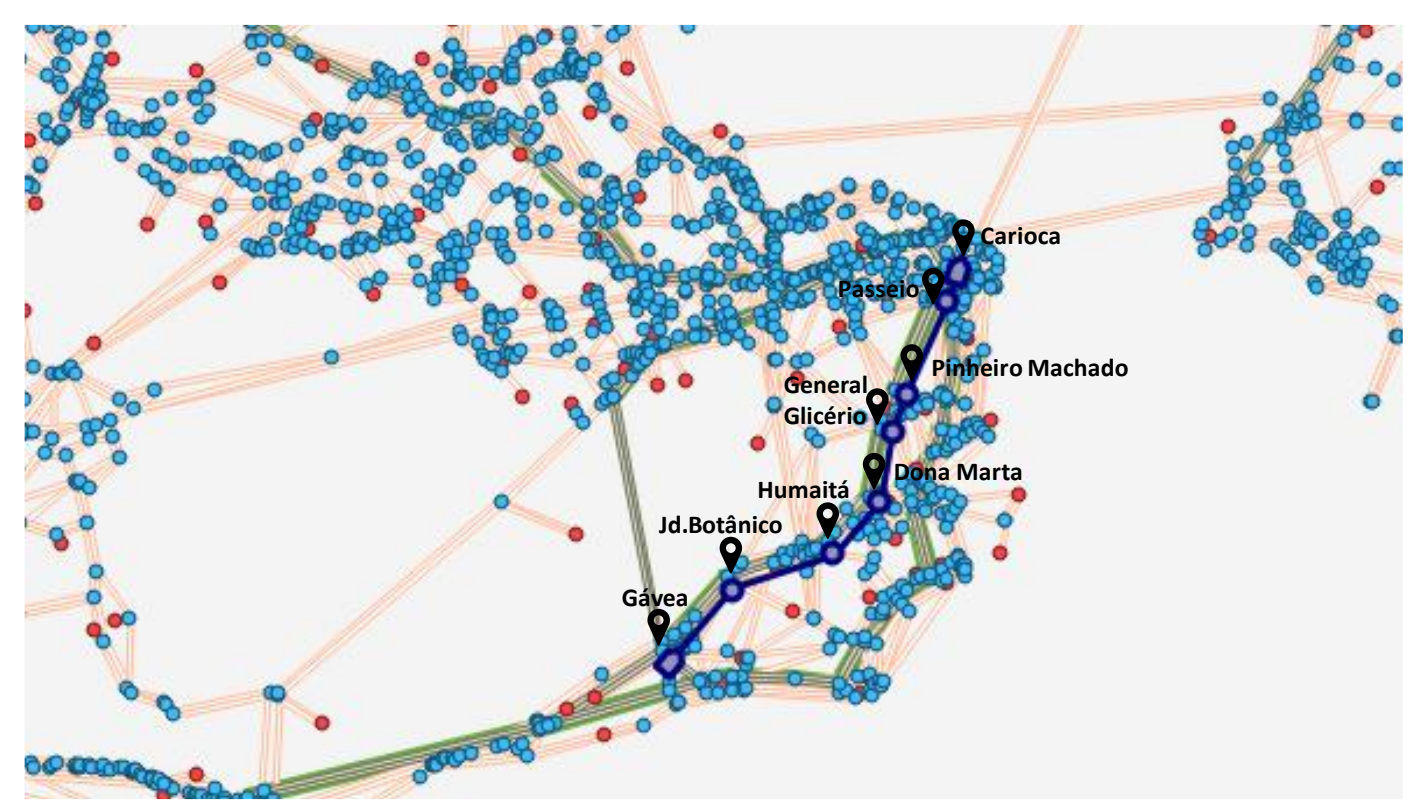

Figura 50: Linha Gávea $\leftrightarrow$ Carioca do metrô 


\subsubsection{Cenário 2: Linha de metrô Gávea $\leftrightarrow$ Uruguai}

O desenvolvimento dessa linha de metrô ligaria a estação Gávea a estação Uruguai, formando o que chamamos de anel metroviário. Contudo para que isso aconteça deve-se escavar ainda um túnel de 1,2 km que ligará a estação General Osorio no Leblon e a estação da Gávea. Essa linha pode ser observada na Figura 51. Além disso, ela faria uma importante conexão entre a zona Norte e Sul do Rio de Janeiro num curto espaço de tempo. Esse cenário também serve para reafirmar a função estratégica da estação da Gávea, respaldando a importância da finalização da construção dessa estação.

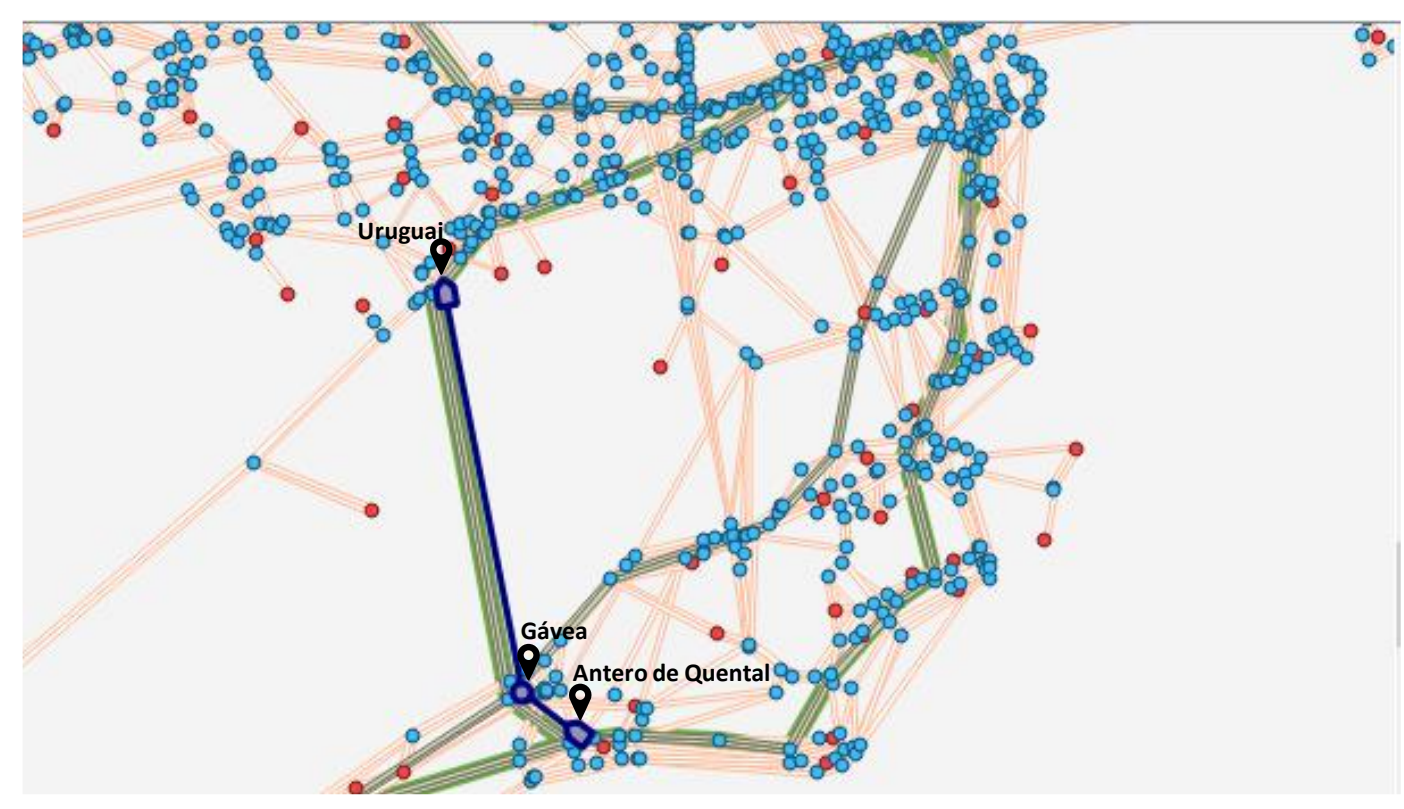

Figura 51: Linha Gávea $\leftrightarrow$ Uruguai do metrô

\subsubsection{Cenário 3: Retorno da utilização do terminal BRT de Campo Grande e conexão do BRT com a Supervia em Campo Grande}

Neste cenário coloca-se novamente em utilização duas linhas do BRT da Transoeste que fazem uso do terminal de Campo Grande (Figura 52 e Figura 53). Desde maio de 2018, este terminal e mais 21 paradas no eixo da Cesário de Mello do BRT Transoeste se encontram inoperantes devido a questões de segurança. Campo grande é um importante bairro da Zona Oeste e o mais populoso do Rio de Janeiro com 328 mil habitantes (Censo IBGE, 2010), portanto o funcionamento de um terminal de BRT nesse bairro é muito relevante e esse cenário vem pra mostrar a importância da ativação desse terminal. 


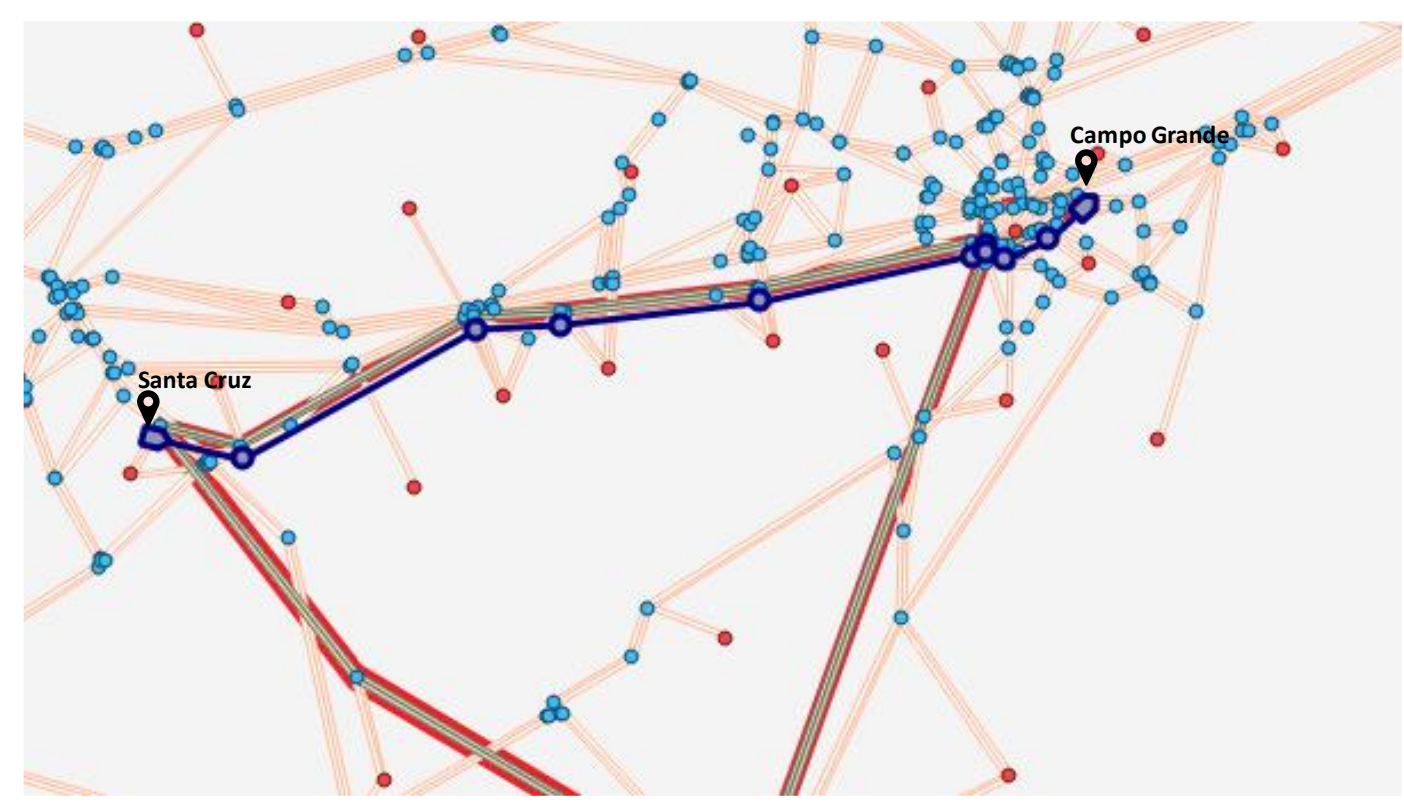

Figura 52: Linha Santa Cruz $\leftrightarrow$ Campo Grande do BRT

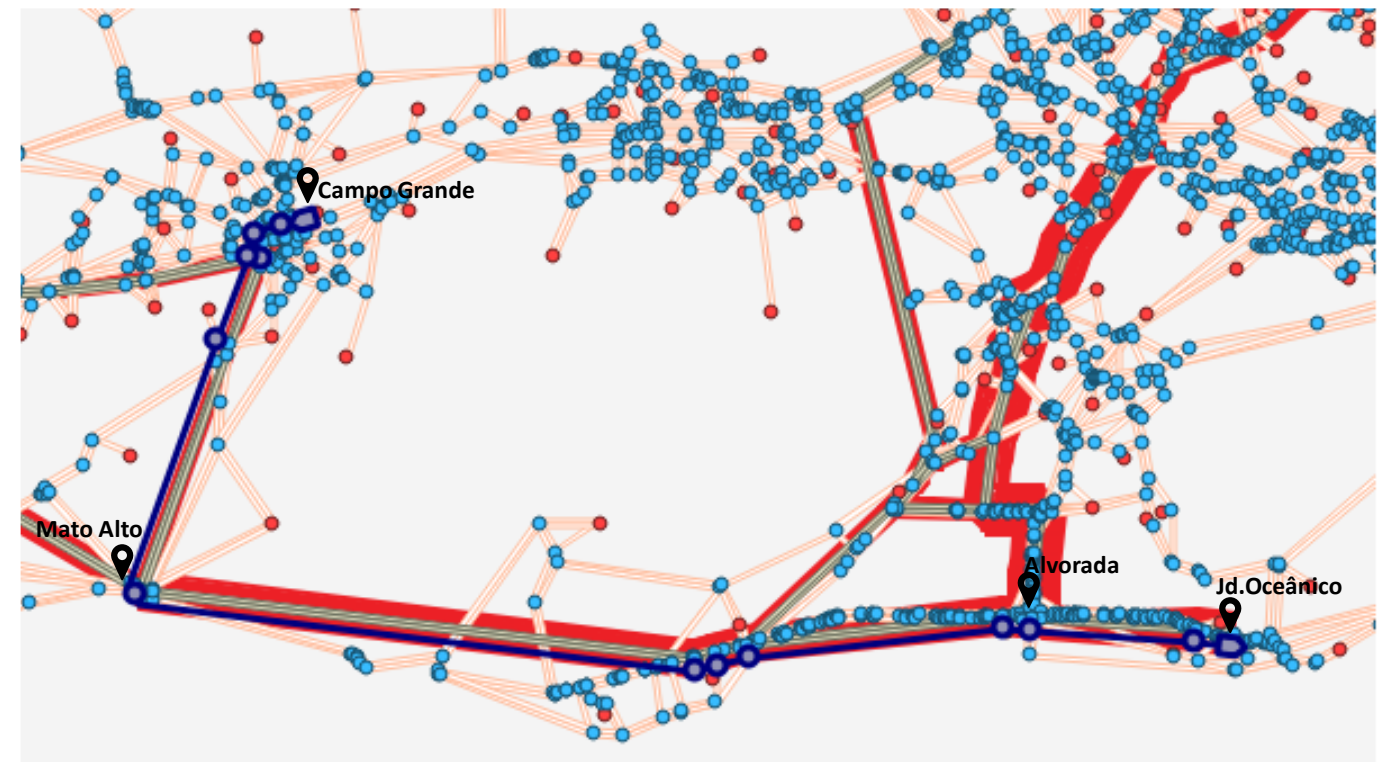

Figura 53: Linha Campo Grande $\leftrightarrow$ Jardim Oceânico do BRT

Além disso, nesse cenário também é desenvolvido a conexão do terminal do BRT com a Supervia em Campo Grande (Figura 54). Essa conexão entre os modos seria feita pelo usuário a pé, assim como é feito atualmente nas integrações entre metrô e supervia. A supervia é um dos principais modos de transporte coletivo que chega a essa região, e o terminal do BRT de Campo Grande sendo ativado novamente possibilitaria o acesso a mais bairros em menos tempo. É importante salientar que essa conexão entre BRT e Supervia envolveria a construção de passarelas para interligar essas duas estações, assim como ocorre, atualmente, na integração entre BRT e Supervia em Madureira (Figura 55). Na figura 55 podemos a conexão por passarelas entre o BRT e a Supervia por onde os usuários 
fazem a transferência de um modal para o outro a pé. A passarela está circulada de vermelho no mapa para melhor identificação da estrutura.

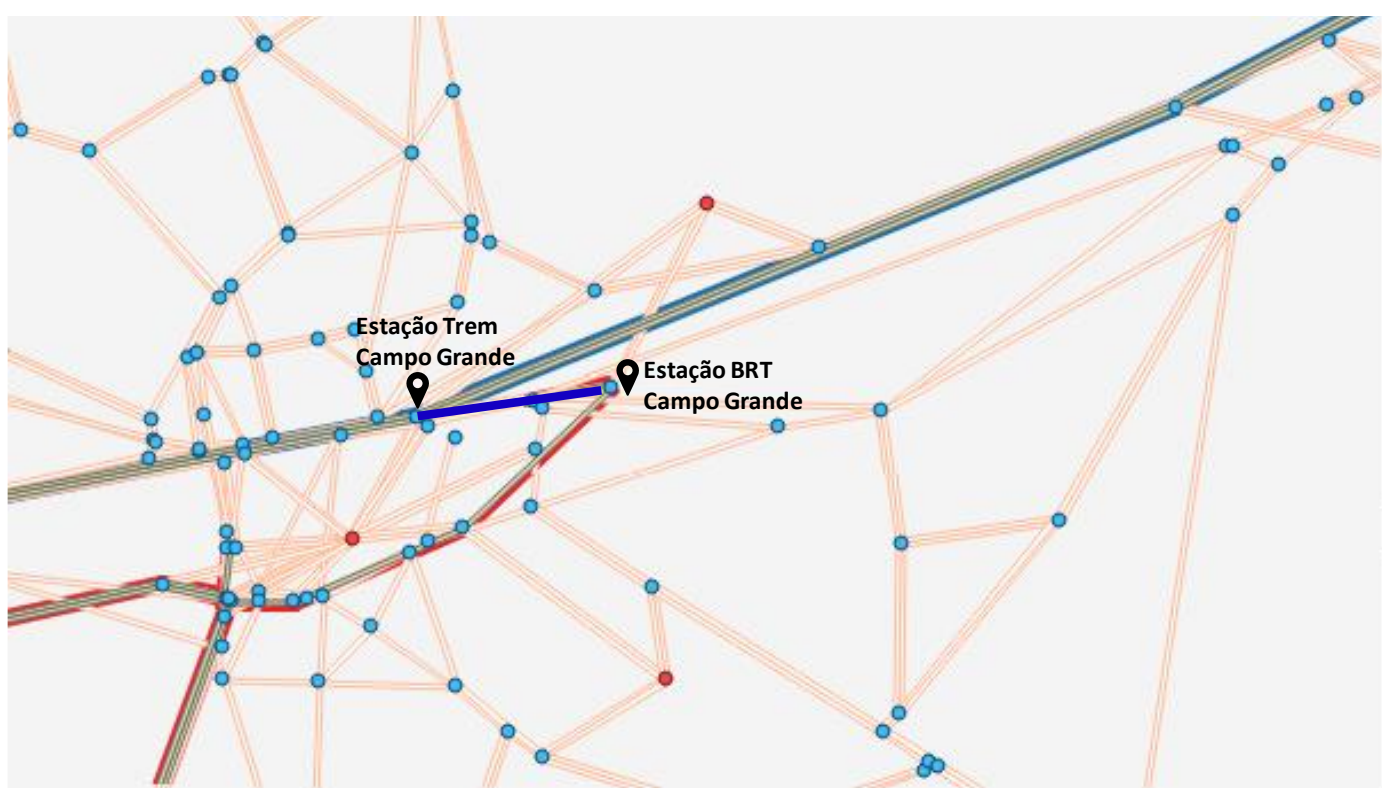

Figura 54: Conexão entre Supervia e BRT em Campo Grande

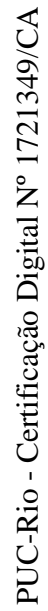

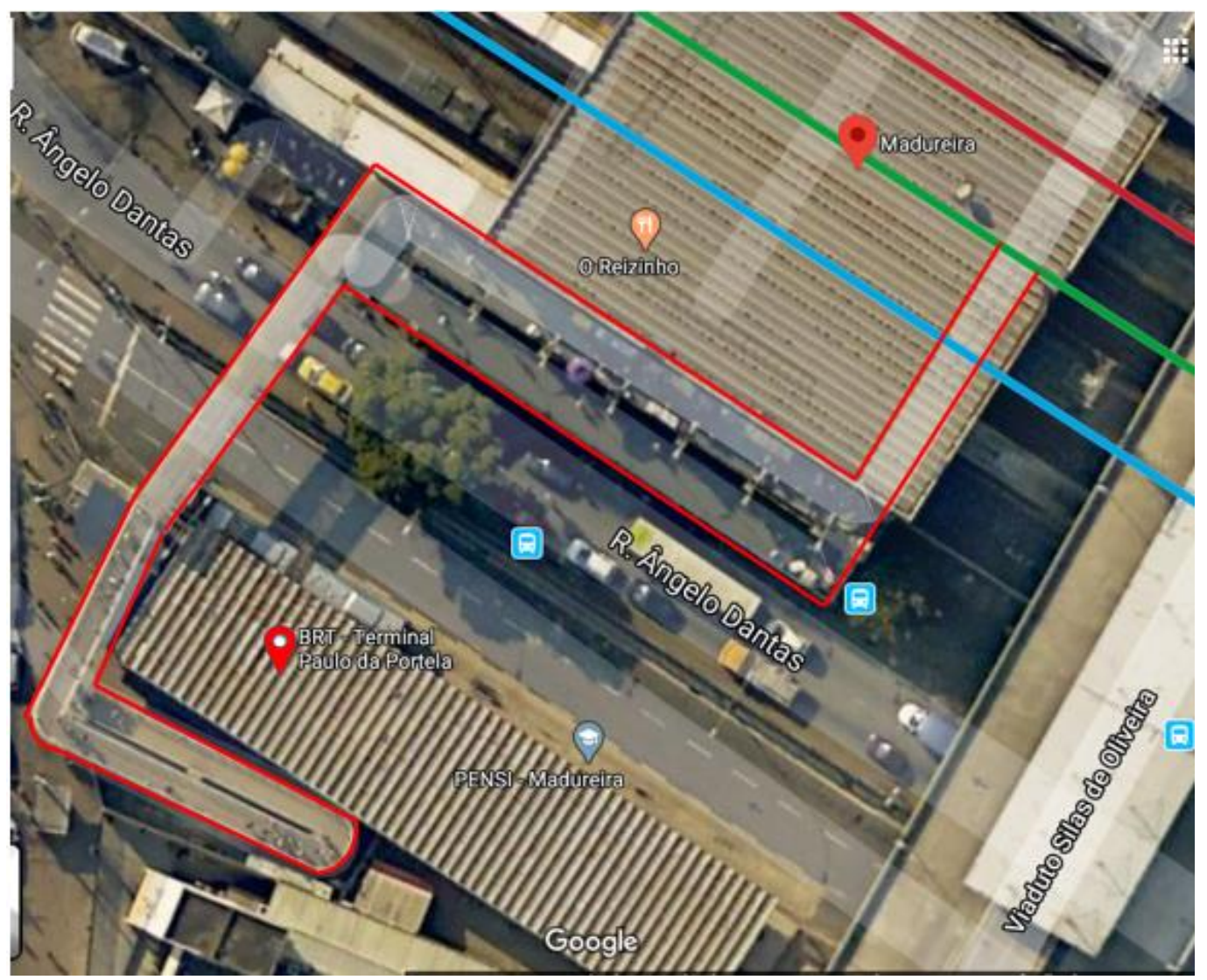

Figura 55: Conexão entre Supervia e BRT em Madureira feito por passarelas (Google) 


\subsubsection{Cenário 4: Conexão do BRT com a Supervia em Santa Cruz}

No cenário 4 também foi desenvolvido a conexão do BRT com a Supervia, mas no bairro de Santa Cruz (Figura 56). Santa Cruz também é um dos bairros mais importantes da Zona Oeste, ficando em terceiro lugar no número de habitantes, 217 mil (Censo IBGE, 2010). Portanto estudar o efeito da integração entre importantes modais que chegam nessa região seria de grande utilidade. Hoje em dia, tanto a estação ferroviária quanto a estação do BRT em Santa Cruz estão ativas e a conexão entre elas seria, assim como no cenário 3, feita a pé pelo usuário, como no exemplo da figura 55.

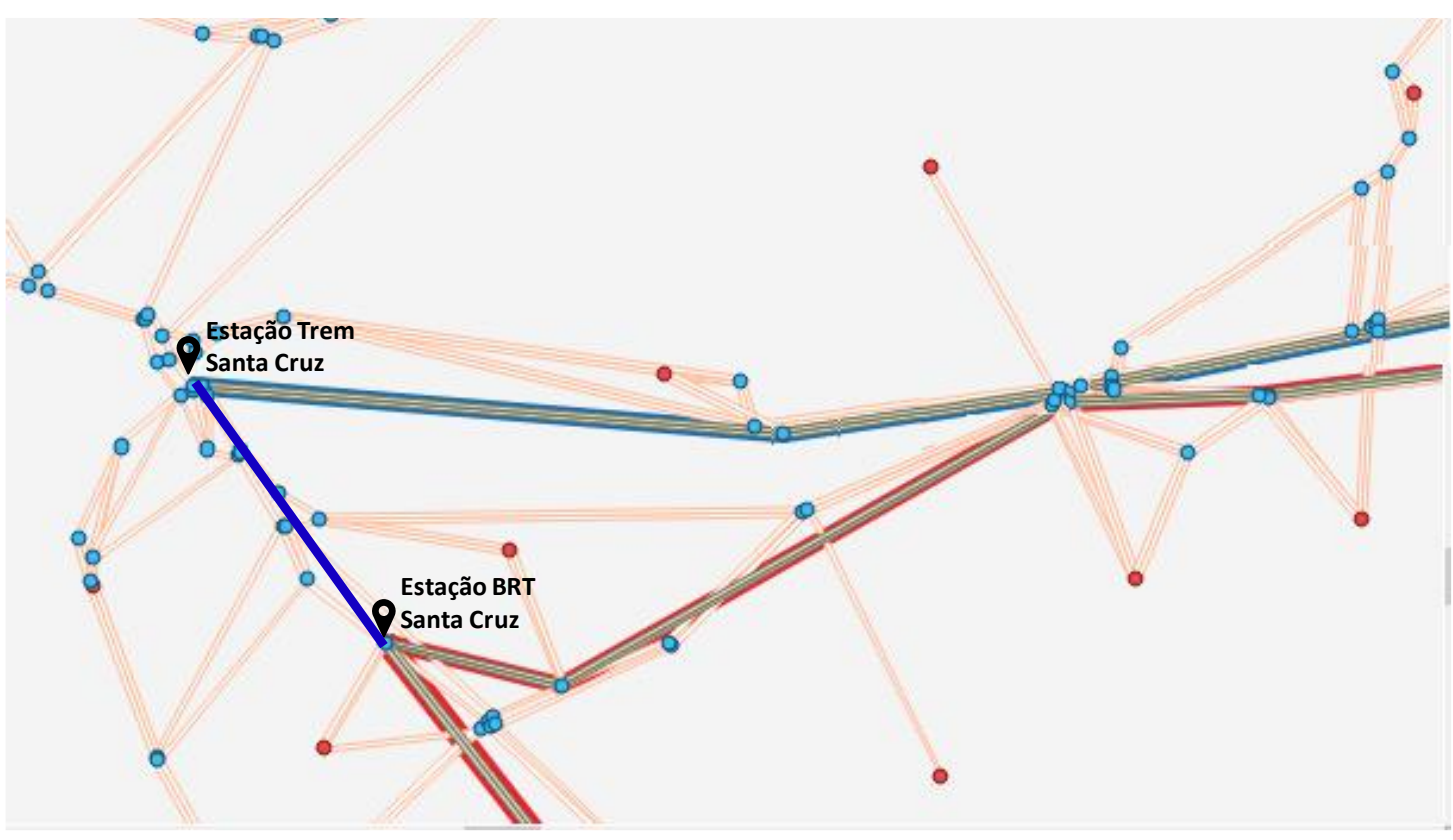

Figura 56: Conexão do BRT com a Supervia em Santa Cruz

\subsubsection{Cenário 5: União de todos os cenários anteriores}

Nesse último cenário, foi colocado todas as infraestruturas descritas nos cenários anteriores juntas para estudar o efeito delas unidas na rede viária da RMRJ.

\subsection{Limitações da Pesquisa}

Para o desenvolvimento desta dissertação, a rede de transporte urbanos da região metropolitana do Rio de Janeiro foi representada no software EMME de maneira simplificada. Como a versão utilizada do software para esse estudo era a versão 2 , há restrições em relação a capacidade se comparado com a versão 7 utilizada no PDTU 2012.

Outra limitação deste estudo é a atualização das linhas de ônibus da Região Metropolitana do Rio de Janeiro. Como existe uma quantidade muito grande de linhas, 
fazer a atualização de todas as 776 linhas seria um trabalho muito extenso e difícil devido também a simplificação que a rede sofreu com a racionalização das linhas de ônibus. Quando se fez uso do software (Silva Júnior e Leal, 2016) para simplificação da rede, automaticamente as linhas de transporte são simplificadas, eliminando as linhas menores para atender o número máximo de linhas da licença de tamanho 2. As linhas de BRT, metrô, ferrovia e VLT foram atualizadas para se chegar o mais próximo da atualidade, com exceção das linhas de ônibus regulares.

\subsection{Estrutura de dados de entrada no EMME}

O EMME tem uma sintaxe bem específica para fazer a importação de dados. Cada linha de comando começa com um caractere que identifica o comando a ser executado. Em seguida é adicionado um espaço em branco e os dados que se deseja adicionar. Os principais comandos são descritos pela letra " $\mathrm{t}$ " que define o tipo de dado a ser utilizado na linhas seguintes onde " $\mathrm{t} " \in\{$ matrices, nodes, links, modes, vehicles, transit lines, linkvertices \}, "a" para adicionar o dado do tipo "t", "d" para apagar o dado, "c" para realizar um comentário e "a*" para adicionar um nó do tipo centroide representando uma zona.

Um cenário no EMME é formado por uma rede base contendo a definição dos nós (nodes) e arcos (links), por uma lista de modos de transporte (modes), de veículos (vehicles), de linhas de transporte coletivo (transit lines) e de nós que compõe o desenho (shape) de um arco (linkvertices).

Antes de realizar as alocações, foi realizada uma atualização das linhas de BRT, metrô e VLT, pois o traçado delas no cenário do PDTU foi modificado quando elas foram construídas. Contudo ao ampliar ou reduzir uma transit line é importante manter a conexão com a rede, assim como na criação das linhas para os cenários. Dessa forma, foram criados novos links de conexão entre os nós que foram adicionados a uma transit line e os centroides. Na Figura 57 pode-se observar alguns tipos de arcos que foram usados no PDTU e seus códigos. 


\begin{tabular}{|c|l|}
\hline Código & \multicolumn{1}{c}{ Tipo de Arco } \\
\hline 99 & Conectores de Centroides \\
\hline 101 & Ligações com torres de integração a pé \\
\hline 400 & Ligações metroviárias entre estações \\
\hline 401 & Ligações metroviárias a pé \\
\hline 500 & Ligações ferroviárias entre estações \\
\hline 501 & Ligações ferroviárias a pé \\
\hline 600 & Ligações com balsas entre estações \\
\hline 601 & Ligações com balsas a pé \\
\hline 701 & Torres de integração \\
\hline
\end{tabular}

Figura 57: Tipo de arcos e códigos

Para fazer a atualização da rede foi escolhido usar os arcos do tipo 701 para a criação dos novos links de conexão entre os nós e os centroides. Já nos cenários 1 e 2 , além dos links de conexão do tipo 701, foram usados links do tipo 400 para criar as novas linhas de metrô. No cenário 3 e 4, usou-se o tipo 501 para fazer a conexão a pé entre a Supervia e o BRT. Como as duas linhas de BRT usadas no cenário 3 já existiam e somente estão desativadas atualmente, não houve necessidade de se adicionar nenhum link, só criar uma transit line que passasse por esses links.

Além do tipo de link, é necessário especificar o tipo de transporte utilizado naquele link. De acordo com a Figura 58, podemos ver os tipos de transporte e seus códigos.

\begin{tabular}{|c|c|c|}
\hline Código do Modal de Ligação & Tipo de Modal Permitido & Tipo de Modal \\
\hline c & Carro & Automóvel \\
\hline I & Caminhão & Veiculo Auxiliar \\
\hline b & Ônibus & Transporte Público \\
\hline m & Metrô & Transporte Público \\
\hline t & Trem & Transporte Público \\
\hline s & BRT & Transporte Público \\
\hline n & VLT & Transporte Público \\
\hline f & Barcas & Transporte Público \\
\hline w & A pé & Não motorizado \\
\hline
\end{tabular}

Figura 58: Tipos de modais e códigos

$\mathrm{Na}$ atualização da rede, algumas linhas de BRT foram reduzidas e outras foram ampliadas, já que a rotas que se encontravam no PDTU estavam diferentes da realidade e algumas foram desativadas. Dessa forma chegamos ao total de 17 linhas de BRT, enquanto o BRT trabalha com 26 linhas hoje. As que não são consideradas é porque o BRT trabalha 
com algumas linhas expressas, e nesta dissertação a rede é representada de forma simplificada, então optou-se pela retirada dessas linhas.

Em relação ao VLT, as linhas foram modificadas para chegar o número de 3 linhas que existem atualmente (Praia Formosa $\leftrightarrow$ Santos Dumont, Praia Formosa $\leftrightarrow$ Praça XV, Central $\leftrightarrow$ Santos Dumont). Já no caso no do metrô, a linha 2 foi reduzida, já que no PDTU o traçado ia da Pavuna até Ipanema, enquanto na verdade ela só chega até Botafogo.

Além disso o atributo que representa a tarifa da linha de transporte em R \$ (ut3) foi atualizado também de acordo com os valores atuais descritos na seção 5.1.

\subsection{Carregamento da Rede}

Para a realização de todas as alocações foi escolhida a matriz mf101 que está no banco de dados do PDTU. Esta matriz está relacionada com o transporte público (separação realizada com a etapa da divisão modal) no horário de pico da manhã (entre $6 \mathrm{~h}$ e $8 \mathrm{~h}$ da manhã) e com a demanda entre casa e trabalho que representa o maior motivador de viagens em 2016. Todos os custos de passagem também foram atualizados de acordo com os valores no ano de 2019 que estão descritos na seção 5.1.

A rede atualizada ficou definida como o cenário base que servirá para eventuais comparações. Foi realizada uma alocação nesse cenário base e é possível ver o resultado desta na Figura 59.

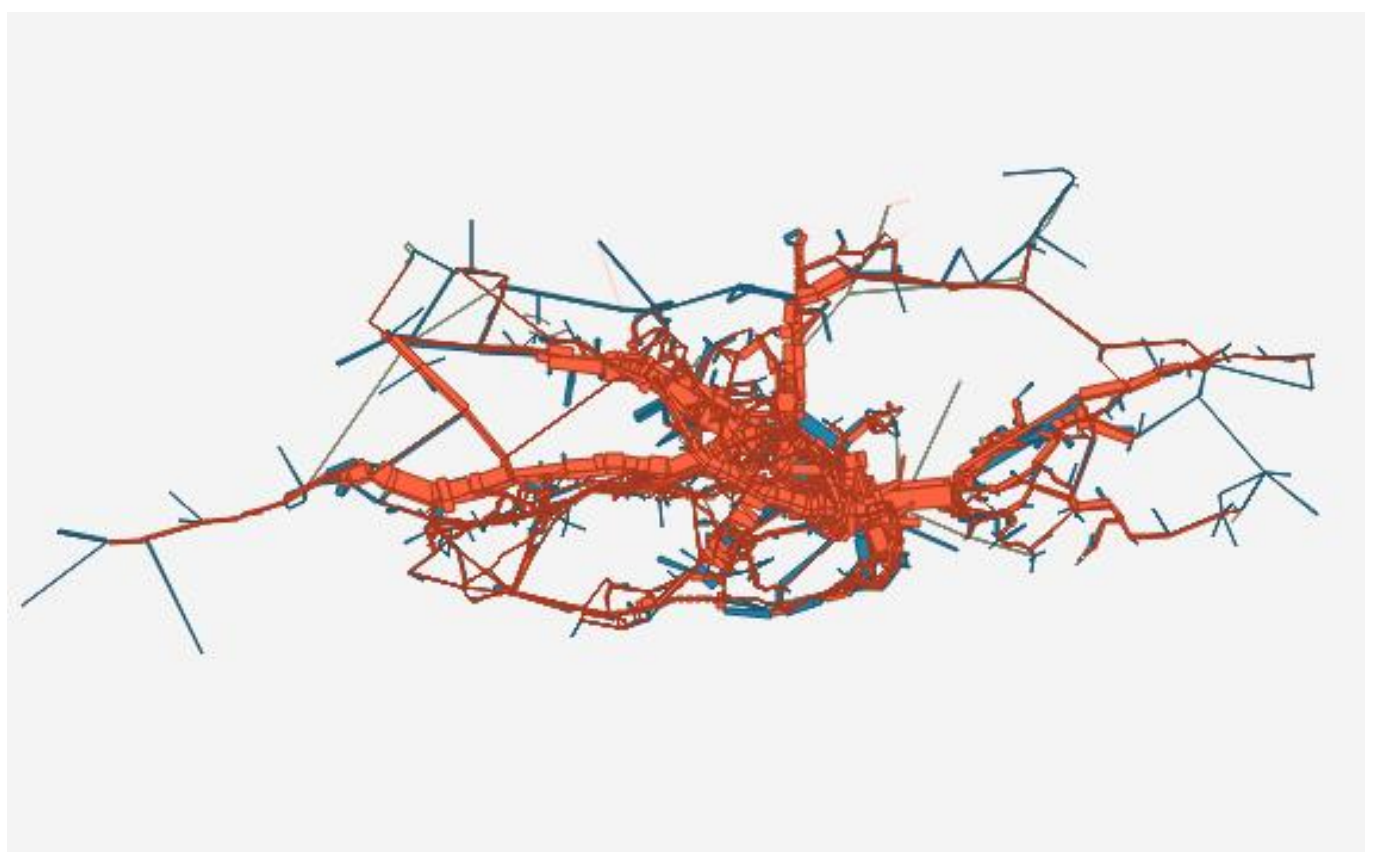

Figura 59: Resultado da alocação no EMME no cenário base 
Toda alocação realizada no EMME tamanho 2 gera uma imagem como a Figura 58. Contudo a leitura de dados a partir dessa imagem é um pouco difícil, então a abordagem adotada foi exportar esses dados para o Excel e tratá-los a partir de lá, focando nos modos de transporte BRT e metrô que são os trabalhados nos cenários definidos para esse estudo.

$\mathrm{Na}$ alocação do cenário base, tem-se o metrô transportando 80.650 passageiros ao todo, sendo $56 \%$ da linha 1 e $44 \%$ da linha 2 no pico da manhã. É importante frisar que a linha 1 e 2 compartilham 10 estações. Já o BRT transporta 272.540 pessoas ao todo.

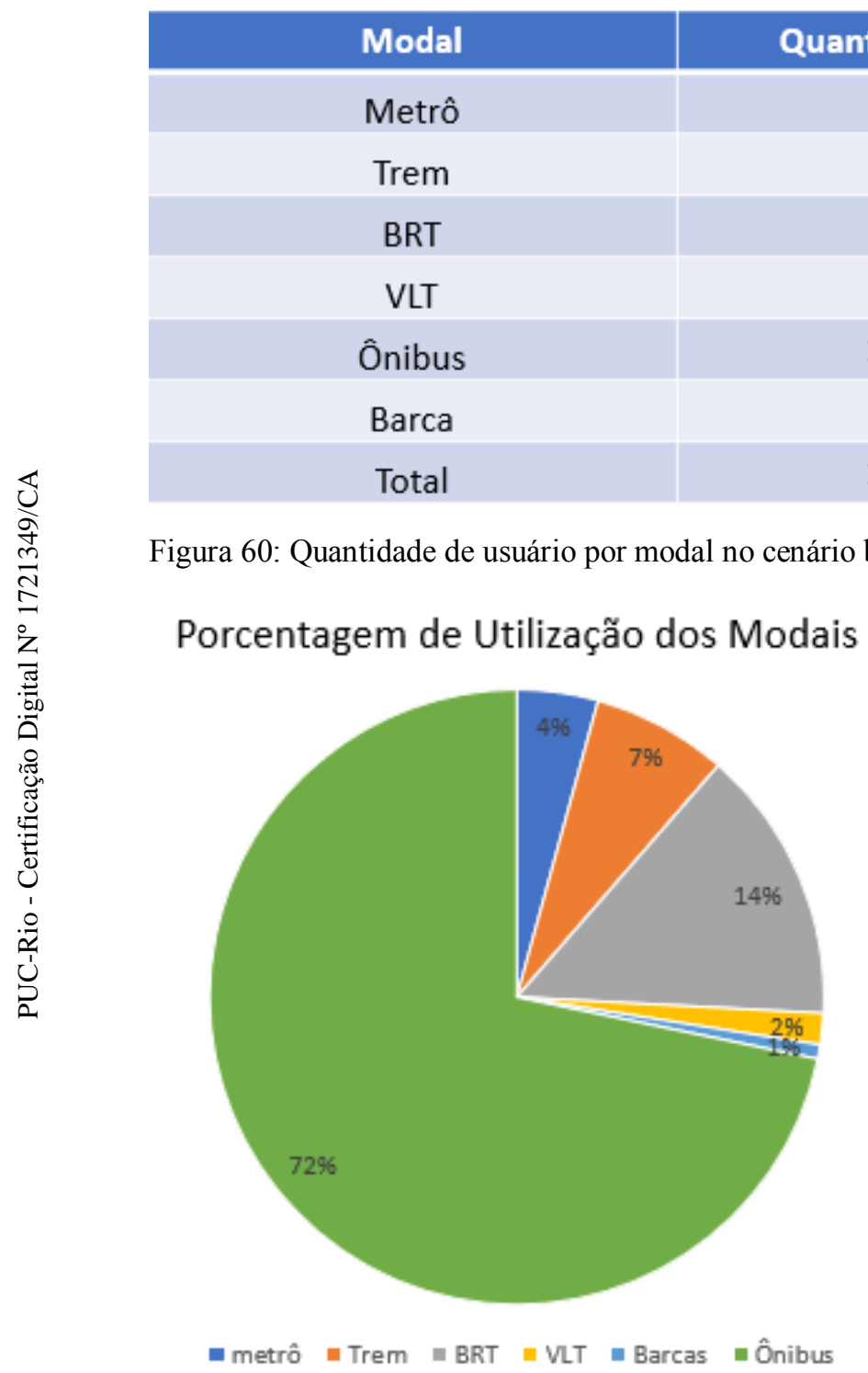

Figura 61: Porcentagem de utilização dos modais no cenário base

Cenário 1: Na alocação do cenário 1, o metrô teria um aumento de $9 \%$ de utilização, transportando 88.150 passageiros (Figura 62). A linha Gávea $\leftrightarrow$ Carioca, seria usada por 
17.458, representando um total de $19,8 \%$ dos usuários. Acredita-se que o número maior de usuários se deva ao fato dessa linha passar por mais bairros.

\begin{tabular}{|c|c|}
\hline Modal & Quantidade usuários \\
\hline Metrô & 88.150 \\
\hline Trem & 134.783 \\
\hline BRT & 277.823 \\
\hline VLT & 33.496 \\
\hline Ônibus & 1.338 .326 \\
\hline Barca & 15.218 \\
\hline
\end{tabular}

Figura 62: Quantidade de usuário por modal no cenário 1

Analisando as outras linhas, a principal queda seria na linha 1 que deixaria de representar o total de $56 \%$ das viagens para representar $43 \%$, o que representa transportar um total de 38.251 usuários. A maior redução de passageiros está no trecho entre a estação Antero de Quental e a Carioca, já que usuários que antes necessitavam pegar o ônibus Metrô na Superfície na Gávea até a estação de metrô Antero de Quental e embarcar na linha 1, agora podem embarcar direto na linha Gávea $\leftrightarrow$ Carioca. É possível observar pela tabela que os outros modos, com exceção do ônibus, sofrem um aumento. Acredita-se que esse aumento esteja relacionado ao trecho da linha que permite mais um caminho ao centro do Rio de Janeiro onde ocorre a integração de vários modais. Já a estação da Carioca passaria a ter um fluxo consideravelmente maior de passageiros, já que ela receberia o fluxo de 3 linhas, dando um salto de 8.943 para 12.182 passageiros. A linha 2, sentiria menos o impacto com uma queda equivalente a $8 \%$ e passaria a transportar 32.440 passageiros. E essa queda pode ser reflexo das estações compartilhadas com a linha 1. A estação Gávea nesse cenário receberia 8.092 passageiros, $46 \%$ do total de usuários da linha, o que revela um grande potencial para a estação.

\begin{tabular}{|c|c|c|c|c|}
\hline Metrô & \multicolumn{2}{|c|}{ Cenário Base } & \multicolumn{2}{c|}{ Cenário 1 } \\
\hline Linha 1 & 45.164 passageiros & $56 \%$ & 38.251 passageiros & $43 \%$ \\
\hline Linha2 & 35.486 passageiros & $44 \%$ & 32.440 passageiros & $37,2 \%$ \\
\hline Linha Gávea $\leftrightarrow$ Carioca & - & - & 17.458 passageiros & $19,8 \%$ \\
\hline
\end{tabular}

Figura 63: Comparação entre as linhas do metrô no cenário base e no cenário 1

Cenário 2: $\mathrm{Na}$ alocação do cenário 2, o metrô teria um aumento de $6 \%$ de seus usuários, passando a transportar 86.213 passageiros (Figura 64). A linha do Metrô Gávea $\leftrightarrow$ Uruguai, seria usada por 10.912 pessoas, representando um total de $12,65 \%$ dos usuários. Esse número alto de usuários para uma linha com poucas paradas se dá ao fato da 
agilidade de ligar a Tijuca a Gávea, o que atrairia bastante passageiros. Analisando a Figura 64, percebe-se que houve um aumento da quantidade de usuários do metrô, os demais modos tiveram um aumento muito menor se comparado ao cenário 1 e o ônibus também teve uma redução. Acredita-se que devido a trecho terminar no Uruguai, onde não há integração para VLT e Trem seja o motivo do aumento ter sido menor. E, portanto, a redução maior de passageiros foi em linhas de ônibus concorrentes com o trecho do metrô.

\begin{tabular}{|c|c|}
\hline Modal & Quantidade usuários \\
\hline Metrô & 86.213 \\
\hline Trem & 135.091 \\
\hline BRT & 275.396 \\
\hline VLT & 31.791 \\
\hline Ônibus & 1.347 .965 \\
\hline Barca & 14.334 \\
\hline
\end{tabular}

Figura 64: Quantidade de usuário por modal no cenário 2

O principal efeito colateral também seria observado na linha 1 que teria uma redução na porcentagem de utilização passando a representar 47\% (41.101 passageiros), o que representa uma queda de 4.063 usuários. Isso se deve principalmente pelo fato de ambas as linhas terminarem no mesmo local, o que permitiria que usuários mudassem a rota para chegar ao mesmo destino em menor tempo. A linha 2 já sentiria menos o efeito, mas também teria uma queda passando a transportar 34.199 passageiros. Com isso, percebe-se que a construção de uma linha atrai mais pessoas para a utilização do modal, além de deixar as linhas existentes menos congestionada, com exceção da estação Uruguai que teria um aumento significativo no número de usuários que recebe. Como tanto a Linha 1 como a linha Gávea $\leftrightarrow$ Uruguai terminam no mesmo local, é possível perceber um aumento de passageiros no terminal Uruguai, que agora recebe duas linhas metroviárias. Seu fluxo sairia de 2.346 para 11.037 passageiros. Enquanto a estação Gávea receberia 9.112 usuários.

\begin{tabular}{|c|c|c|c|c|}
\hline Metrô & \multicolumn{2}{|c|}{ Cenário Base } & \multicolumn{2}{c|}{ Cenário 2 } \\
\hline Linha 1 & 45.164 passageiros & $56 \%$ & 41.101 passageiros & $47 \%$ \\
\hline Linha2 & 35.486 passageiros & $44 \%$ & 34.199 passageiros & $37,2 \%$ \\
\hline Linha Gávea $\leftrightarrow$ Uruguai & - & - & 10.912 passageiros & $12,65 \%$ \\
\hline
\end{tabular}

Figura 65: Comparação entre as linhas do metrô no cenário base e no cenário 2 
Com o desenvolvimento do cenário 1 e 2 podemos avaliar a importância da finalização da estação gávea, que receberia por volta dos 19 mil usuários na estação, fazendo importantes conexões entre a zona Norte e Sul do Rio de Janeiro e revelando seu potencial estratégico. Além disso, a construção da estação Gávea já foi iniciada o que possibilitaria uma economia para a prefeitura nesse sentido.

Cenário 3: Na alocação do cenário 3, a linha Campo Grande $\leftrightarrow$ Santa Cruz voltaria a ativa com 13.759 usuários, enquanto a linha Campo Grande $\leftrightarrow$ Jardim Oceânico transportaria 65.145 passageiros. Analisando as estações que compõem esses duas linhas, a estação de Campo Grande recebe em torno de 2.500 usuários, enquanto a estação que recebe o maior número é a Alvorada com 9.166 passageiros. A linha Transoeste do BRT que seria onde a linha Campo Grande $\leftrightarrow$ Santa Cruz e Campo Grande $\leftrightarrow$ Jardim Oceânico circularia, possui 68 estações ao todo. Analisando a Figura 66 podemos ver que a estação Campo Grande está na $7^{\circ}$ posição do ranking das estações com maior fluxo de passageiros, mostrando seu potencial de reativação.

\begin{tabular}{|c|c|}
\hline Estação & Quantidade usuários \\
\hline Alvorada & 9166 \\
\hline Jardim Oceânico & 7015 \\
\hline Mato alto & 7499 \\
\hline Salvador Allende & 5266 \\
\hline Santa Cruz & 2445 \\
\hline Bosque Marapendi & 3756 \\
\hline Campo Grande & 2445 \\
\hline Pingo D’agua & 2936 \\
\hline Santa Eugênia & 1949 \\
\hline General Olímpio & 1090 \\
\hline
\end{tabular}

Figura 66: Lista das 10 estações com maior fluxo de passageiros.

Nesse cenário também é avaliado a conexão entre o BRT e a Supervia. Essa integração entre modais seria realizada por 2.346 passageiros. Como estamos reativando um importante terminal no bairro mais populoso da cidade do Rio de Janeiro, e fazendo a conexão entre dois modais importantes, foi possível constatar o aumento da porcentagem de utilização desses modais. O BRT passaria a ser usado por 285.342 usuários, tendo um aumento de 4,5\%, enquanto a Supervia teria um 3,8\% tendo um salto de 5.319 passageiros. A estação da Supervia mais impactada seria a de Campo Grande que passaria a receber um fluxo maior de usuários devido a integração, indo de 7.452 para 10.041 usuários, mas as 
demais estações também teriam um aumento devido a maior quantidade de passageiros no ramal Santa Cruz que conta com 16 estações.

\begin{tabular}{|c|c|}
\hline Modal & Quantidade usuários \\
\hline Metrô & 82.698 \\
\hline Trem & 140.102 \\
\hline BRT & 285.342 \\
\hline VLT & 31.233 \\
\hline Ônibus & 1.334 .634 \\
\hline Barca & 14.459 \\
\hline
\end{tabular}

Figura 67: Quantidade de usuário por modal no cenário 3

Esse número de usuários em ambas as linhas tende a aumentar pois com a conexão entre os modais é possível chegar a mais pontos na cidade com um custo menor (Figura $68)$.

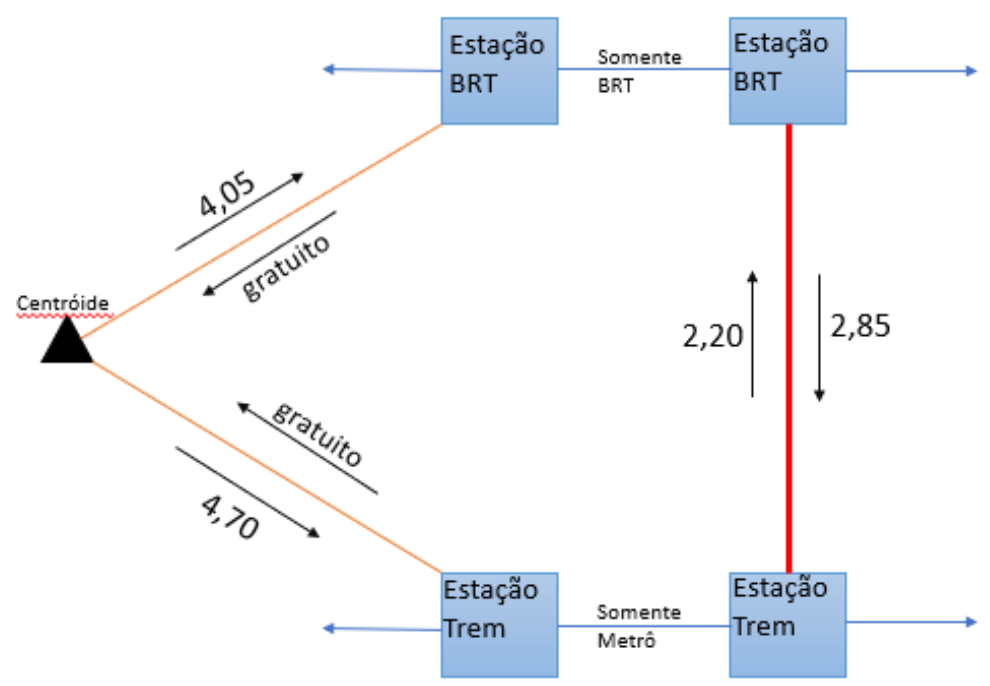

Figura 68: Demonstração integração tarifária entre BRT e trem da Supervia.

Na figura 68 podemos observar como realizar a integração entre esses dois modais seria mais barato para o usuário do que no cenário que não existe a integração. Com a integração o usuário pagaria $\mathrm{R} \$ 6,90$ e sem a integração o custo seria de $\mathrm{R} \$ 4,05$ do BRT mais $\mathrm{R} \$ 4,70$ do Trem valendo $\mathrm{R} \$ 8,75$.

Cenário 4: Na alocação do cenário 4, só é avaliado a conexão entre os modais do BRT e da Supervia agora em Santa Cruz. Essa integração seria realizada por 6.540 pessoas. 
As linhas BRT10 (Santa Cruz $\leftrightarrow$ Alvorada), BRT11 (Campo Grande $\leftrightarrow$ Santa Cruz) e BRT20 (Santa Cruz $\leftrightarrow$ Recreio) tiveram um aumento na quantidade de usuários (Figura 69). Já o ramal Santa Cruz da Supervia também tem a quantidade de usuários aumentada de 39.013 para 46.215 usuários. Como o princípio da integração entre os modais é o mesmo descrito no cenário 3 e ilustrado na Figura 67 é de se esperar esse aumento de utilização devido ao menor custo.

\begin{tabular}{|c|c|c|}
\hline Linha & $\begin{array}{c}\text { Quantidade usuários - Cenário Base } \\
\text { (usuários) }\end{array}$ & $\begin{array}{c}\text { Quantidade usuários - Cenário } 4 \\
\text { (usuários) }\end{array}$ \\
\hline BRT10 & 812 & 953 \\
\hline BRT11 & 741 & 862 \\
\hline BRT20 & 579 & 630 \\
\hline
\end{tabular}

Figura 69: Aumento de usuários das linhas de BRT.

Quando voltamos a análise para as estações, é possível observar aumento do fluxo tanto na estação do BRT quanto da Supervia em Santa Cruz (Figura 70).

\begin{tabular}{|c|c|c|}
\hline Estação & $\begin{array}{c}\text { Quantidade usuários - Cenário Base } \\
\text { (usuários) }\end{array}$ & $\begin{array}{c}\text { Quantidade usuários - Cenário } 4 \\
\text { (usuários) }\end{array}$ \\
\hline Estação BRT Santa Cruz & 3.103 & 10.023 \\
\hline Estação Supervia Santa Cruz & 5.002 & 12.489 \\
\hline
\end{tabular}

Figura 70: Aumento de usuários nas estações de BRT e Supervia em Santa Cruz.

Com o cenário 3 e 4 podemos avaliar como o retorno de linhas impacta no tráfego, fazendo com que mais pessoas tenham acesso a esse modal. Além disso o impacto também é revelado no aumento de usuários do trem, que seria em torno de 6 mil pessoas e pode ser explicado pelas conexões entre a Supervia e o BRT. Contudo esse número pode ser considerado pequeno em relação a quantidade total de usuários do sistema ferroviário, e pode ser explicado pelo custo monetário que envolve a integração entre os modais. Enquanto a utilização de ônibus + BRT não implica em nenhum custo adicional, a utilização de Trem+ BRT tem uma adição de 2,85.

Cenário 5: Na alocação do cenário 5, podemos avaliar o impacto que todas essas infraestruturas têm ao serem integradas na mesma rede viária. A figura 71, mostra a proporção de utilização de cada modal, já a figura 72 mostra a quantidade de usuários por modal. 
Porcentagem de Utilização dos Modais

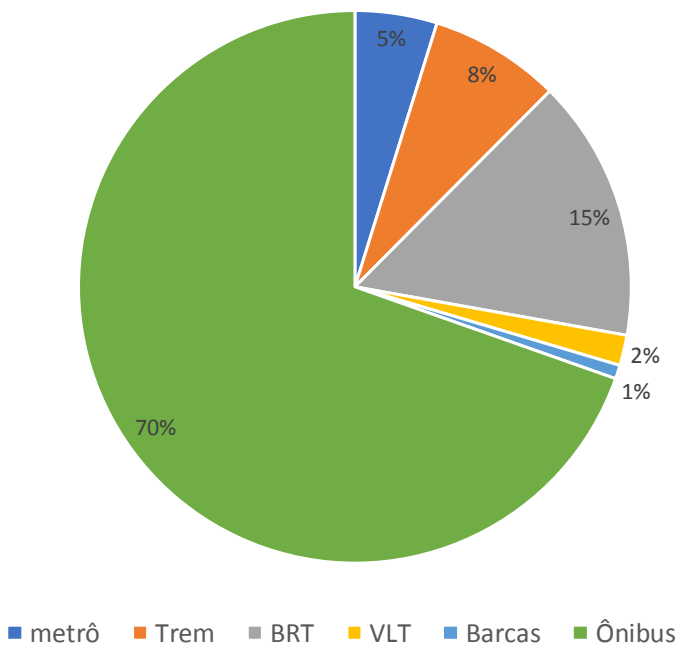

Figura 71: Porcentagem de utilização dos modais no cenário 5

\begin{tabular}{|c|c|}
\hline Modal & Quantidade usuários \\
\hline Metrô & 90.713 \\
\hline Trem & 144.654 \\
\hline BRT & 289.884 \\
\hline VLT & 33.596 \\
\hline Ônibus & 1.314 .458 \\
\hline Barca & 15.161 \\
\hline
\end{tabular}

Figura 72: Quantidade de usuários por modal no cenário 5

Pode-se perceber que o modal que teve o maior aumento de utilização em relação ao cenário base foi o BRT. Esse aumento pode estar associado a região de implantação das novas infraestruturas do BRT, que é uma das regiões mais populosas do Rio de Janeiro. Esse aumento chega a 15\% em relação ao cenário base. Outro modal que acaba sendo influenciado pelo BRT já que tem integração com este modal é o trem, que teve um aumento de $8 \%$ em relação ao cenário base.

Já o modal ônibus teve uma diminuição assim como em todos os outros cenários. Nesse cenário, a queda de sua utilização chega a $\%$ em relação ao cenário base, o que faz com que a porcentagem de participação do ônibus no transporte público diminua para $70 \%$.

Outro modal que teve destaque nas análises dessa dissertação foi o metrô. Nesse cenário há um aumento de $5 \%$ da utilização dele em relação ao cenário base, que pode ser 
explicado exatamente pela maior integração da rede viária, especialmente no centro da região metropolitana, que é uma importante região de conexão entre todas os modais.

Como os caminhos para essa região são ampliados, o acesso a modais como as barcas e VLT são facilitados, o que desencadeia o aumento da utilização destes também.

Nesse cenário é possível perceber que diversos modais se conectam causando uma maior integração da rede viária do Rio de Janeiro. Com isso os usuários podem escolher a melhor opção de caminho diante de diversas possibilidades, ou seja, aquela que fornece a maior função utilidade.

Diante de todos esses cenários, é possível perceber que o modal que teria algum impacto negativo seria o ônibus municipal, principalmente as linhas concorrentes das novas linhas testadas nos cenários (Figura 73). O ônibus teria a quantidade de usuários reduzida, o que faz sentido já que é o modo de transporte em que o usuário permanece mais tempo no sistema se comparado com BRT, Trem e metrô.

Percebe-se que a integração faz com que os modais que estejam sendo integrados sejam mais utilizados e os passageiros ganhem mais acesso à cidade, pois há conectividade entre os diversos bairros. Contudo é importante frisar que para que a integração seja considerada efetiva deve-se ter um equilíbrio entre as diferentes tarifas de integração para que uma não seja muito mais barata que as demais e os usuários acabem tendendo a escolha da mais econômica. Deve-se, também ter um planejamento para que as viagens conseguiam ser dinamizadas de fato e o usuário economize tempo.

\begin{tabular}{|c|c|c|c|c|c|c|}
\hline Modal & $\begin{array}{c}\% \\
\text { Quantidade usuários } \\
\text { no cenário base }\end{array}$ & $\begin{array}{c}\% \\
\text { aumento/ } \\
\text { redução no } \\
\text { cenário 1 }\end{array}$ & $\begin{array}{c}\% \\
\text { aumento/ } \\
\text { redução no } \\
\text { cenário 2 }\end{array}$ & $\begin{array}{c}\% \\
\text { aumento/ } \\
\text { redução no } \\
\text { cenário 3 }\end{array}$ & $\begin{array}{c}\% \\
\text { aumento/ } \\
\text { redução no } \\
\text { cenário 4 }\end{array}$ & $\begin{array}{c}\% \\
\text { aumento/ } \\
\text { redução no } \\
\text { cenário 5 }\end{array}$ \\
\hline Metrô & 80.650 & $9,3 \%$ & $6,9 \%$ & $2,5 \%$ & $2,9 \%$ & $12,5 \%$ \\
\hline Trem & 134.783 & $0,5 \%$ & $-0,4 \%$ & $3,9 \%$ & $5,3 \%$ & $7,3 \%$ \\
\hline BRT & 272.540 & $1,9 \%$ & $1,0 \%$ & $4,7 \%$ & $2,5 \%$ & $6,4 \%$ \\
\hline VLT & 30.879 & $8,5 \%$ & $-1,0 \%$ & $1,1 \%$ & $1,0 \%$ & $8,8 \%$ \\
\hline Barca & 1.355 .467 & $7,6 \%$ & $-0,2 \%$ & $2,2 \%$ & $1,7 \%$ & $7,2 \%$ \\
\hline Ônibus & 14.149 & $-1,3 \%$ & $-0,6 \%$ & $-1,5 \%$ & $-1,4 \%$ & $-3,0 \%$ \\
\hline
\end{tabular}

Figura 73: Resumo dos aumentos e reduções nos 5 cenários 


\section{Conclusões e Recomendações}

Neste capítulo são apresentadas as considerações obtidas com a realização da pesquisa, além das propostas para trabalhos futuros.

\subsection{Conclusão}

Ao longo dessa dissertação pode-se ver o desafio que é a mobilidade urbana em grandes cidades como o Rio de Janeiro. Por isso muitos estudos para a melhoria da mobilidade urbana, principalmente com foco no desenvolvimento sustentável da rede de transportes tem surgido. Como o estado do Rio de Janeiro vem enfrentando uma crise econômica, não conseguindo destinar recursos para estudos recorrentes desse tema e como qualquer variação nas linhas, tarifas, tecnologias impactam o fluxo de passageiros na rede, afetando o tempo de viagem percebeu-se um gap que valeria um estudo para indicar melhorias no desempenho da rede de transportes metropolitana do Rio de Janeiro.

O desenvolvimento do presente estudo representou a rede de transporte do Rio de Janeiro de forma simplificada no software EMME e analisou algumas alternativas de transportes para otimizar a rede. Com os dados fornecidos ao software foi realizada a alocação, e pode-se perceber que ao se construir novas linhas sejam elas de metrô sejam de BRT, há um aumento do número de pessoas que utilizam esses modais, porque eles acabam cobrindo mais pontos da cidade. E como são meio de transportes mais rápidos, há uma migração de usuários para eles. Esse número só não é maior devido ao aumento de custo implicado nas transferências já que manter-se no mesmo tipo de modal não gera não custo adicional na passagem do usuário.

Com os cenários 1 e 2 foi possível analisar o potencial estratégico de utilização da estação de metrô da Gávea, se tornando um incentivo para finalizar a construção desta, assim como as linhas de metrô que fazem uso desta estação, já que elas aumentaram a quantidade de usuários do modal, como podemos observar na figura 73. Com os cenários 3 e 4 foi possível avaliar a importância da reativação de estações e linhas de BRT num dos bairros mais populosos na região do Rio de Janeiro, assim como a importância de realizar mais integrações entre os modais. Já com o cenário 5 podemos perceber que quanto maior 
a integração nos meios de transporte coletivo na cidade, mais usuários optam pela utilização do transporte público.

Todos os cenários se mostram ótimos investimentos para a cidade do Rio de Janeiro. Contudo sabe-se da situação econômica que o município vive. Portanto se houvesse uma ordem de priorização para a prefeitura investir, a integração entre os modais deveria ser priorizada já que dessa forma, mais pontos da cidade seriam cobertos e mais passageiros ganhariam acesso a mais bairros. Além disso, os cenários desenvolvidos utilizam infraestruturas já existentes, o que traria uma economia para a prefeitura. Foi possível perceber também, o impacto positivo do retorno de uma linha importante do BRT, mostrando que a prefeitura deve investir em segurança, já que esse foi o motivo da suspensão, para que as estações possam ser usadas.

Já o metrô apesar de mais rápido e mais sustentável, ficaria por último na priorização em uma situação de restrição de recursos pois seu custo de construção é maior (200 a 500 milhões por quilômetro) se comparado ao BRT ( 10 a 30 milhões por quilômetro) no Brasil (Lourenço, 2015).

Todas os cenários propostos visam o desenvolvimento sustentável da rede de transportes, sejam de forma mais leve com a integração dos modais, ou mais profunda com investimentos em transportes não rodoviários. A questão que mais impacta na escolha do investimento é a atual conjuntura econômica que se encontra o Rio de Janeiro.

\subsection{Propostas de trabalhos futuros}

Uma das propostas de trabalhos futuros seria a execução da alocação com uma matriz Origem-Destino atualizada para o ano de 2020. Nessa dissertação optou-se por usar uma disponível do PDTU já que para realizar essa atualização haveria a necessidade de uma coleta de dados de pesquisas na via (contagem de tráfego), no sistema de transporte (pesquisa em pontos de embarque e desembarque e no cordão externo), além de entrevistas com a comunidade. Sabe-se que esse é um estudo extenso e que dependendo da quantidade de amostras, altos custos.

A prefeitura de Rio de Janeiro em 2016, reduziu o número de linhas na Região Metropolitana, além de ter encurtado algumas rotas de ônibus. Outra proposta seria superar uma das limitações desse trabalho com a atualização das rotas de ônibus para o ano de 2019, assim como foi feito com os demais modos e refazer a alocação após a atualização, podendo inclusive fazer um comparativo para analisar o impacto de modificações em rotas de ônibus na cidade. 


\section{Referências}

AKINBAMI, J.F.K. e FADARE, S.O. Strategies for Sustainable Urban and Transport Development in Nigeria. Transport Policy, v. 4, p. 237-245,1997.

ARAGÓN, F. R. e LEAL, J. Alocação de fluxos de passageiros em uma rede de transporte público de grande porte formulado como um problema de inequações variacionais. Pesquisa Operacional, v. 23, pp. 235-264, 2003.

ASMAEL, N. M.; ALKAWAAZ, N. G. A. The Influence Change of Private Car Ownership on Patterns of Mode Choice in Baghdad city. IOP Conference Series: Materials Science and Engineering. IOP Publishing, 2019. p. 022025.

AVIN, U. P. e DEMBNER, J. L. Using scenarios to improve plan-making. ACSP Conference, Atlanta, Georgia. 2000.

AYARI, B.; GENDRAU, M. e NGUYEN, S. An Equilibrium-Fixed Point Model for Passenger Assignment in Congested Transit Networks. Publication 1001, Centre de Recherche sur les Transports, Université de Montréal. 1995.

BAI, T. ; LI, X. e SUN, Z. Effects of cost adjustment on travel mode choice: analysis and comparison of different logit models. Transportation research procedia, v. 25, pp. 2649-2659, 2017

BANISTER, D. The sustainable mobility paradigma. Transport Policy, v.15, p. 73-80,2008.

Brasil. (2012, 3 de janeiro). Lei $n^{0} 12.587$, de 3 de janeiro de 2012. Dispõe sobre as diretrizes da Política Nacional de Mobilidade Urbana. Brasília: Diário Oficial da União. Recuperado em novembro de 2019, de www.planalto.gov.br/ ccivil_03/_ato2011-2014/2012/lei/112587.htm

Bruynooghe A., Gibert A. e Sakarovitch M. Une méthode d'affectation du traffic. Proceedings of fourth symposium on the theory of traffic flow (Karlsruhe), 1968.

BRUTON, M. J. Introdução ao Planejamento dos Transportes. $1^{\text {a }}$ ed. Editora Interciência, São Paulo, 1979.

CAMPOS, V. Planejamento de Transportes: Conceitos e Modelos de Análise. 2013. 
CARTER, E.C. e HOMBURGER, W.S., Introduction to Transportation Engineering. Reston Publishing, Reston, VA, 1978.

CARVALHO, A. Desenho universal, acessibilidade e integração modal estudo exploratório no transporte coletivo no Rio de Janeiro. Tese de Mestrado, Programa de Engenharia de Transportes, Universidade Federal do Rio de Janeiro. 2005

CASTRO A. ; FERNANDO R. e LEAL, J. E. Alocação de fluxos de passageiros em uma rede de transporte público de grande porte formulado como um problema de inequações variacionais. Pesquisa Operacional, v. 23, pp. 235-264, 2003.

CEPERJ. Mapa do Estado do Rio de Janeiro, Regiões de Governo e Municípios, 2014. Disponível em: < http://www.ceperj.rj.gov.br/ceep/info_territorios/divis_politico_ administrativo.html >. Acesso em: 29 maio 2019

CERVERO, R. Road expansion, urban growth, and induced travel: A path analysis. Journal of the American Planning Association, v. 69, p. 145-163, 2003.

CHIMA, C. Transport planning, management and development in Nigeria. In Transport and National Development in Nigeria, eds E. P. Adegbeyeni and 0. J. Rapu. B. G. Publishers, Lagos and Kaduna. 1990

CLAY, M. J. et al. Data development for implementing integrated landuse and transportation forecasting models in medium-sized metropolitan planning organizations. Planning Practice and Research, v. 27, pp. 263-274, 2012.

CONSÓRCIO HALCROW - SINERGIA - SETEPLA. Atualização do PDTU 2011 da RMRJ: Atividade 6.5 - Análise da Evolução e Tendências Futuras do Uso do Solo, 2013a. Disponível em: < http://www.rj.gov.br/web/setrans/exibeconteudo?gen\%C3\%A9rica\&acaomenu=m enufu nc28\%27PDTU27\%29;\&article-id=626280>. Acesso em: 21 maio. 2019.

DE CEA, J.; FERnÁnDEZ, J.E. e CROVETTO, G. (1990). Análisis comparativo de tres modelos de asignación a redes de transporte público basados en el concepto de ruta. Apuntes de Ingeniería, V.39, pp. 5-22, 1990.

DE CEA, J. e FERNÁNDEZ, E. Transit Assignment for Congested Public Transport Systems: An Equilibrium Model. Transportation v. 27, pp.133-147, 1993-II. 
FEITELSON, E. e COHEN-BLANKSHTAIN, G. Public transport planning in a spatially segmented city: The case of Jerusalem. Transportation Research Part A: Policy and Practice, v. 107, pp. 65-74, 2018.

FERREIRA JR, J. et al. Information infrastructure for research collaboration in land use, transportation, and environmental planning. Transportation Research Record: Journal of the Transportation Research Board, n. 2183, pp. 85-93, 2010.

GENDRAU, M. Étude approfondie d'un modèle d'équilibre pour l'affectation des passagers dans les réseaux de transport en commun. Publication 384, Centre de recherche sur les transports, Université de Montréal, Canadá, 1984.

GIVONI, M.; BEYAZIT, E. e SHIFTAN, Y. The use of state-of-the-art transport models by policymakers-beauty in simplicity?. Planning Theory \& Practice, v. 17, pp. 385-404, 2016.

GRAY, G. E.; HOEL, L. A. Public transportation: planning, operations, and management. 1979.

HANSSON, L. Visual representation in urban transport planning: Where have all the cars gone?. Transportation Research Part A: Policy and Practice, v. 133, pp. 1-11, 2020.

IBGE. Censo demográfico 2000: agregado por Setores censitários dos resultados do universo. Rio de Janeiro: IBGE, 2002.

JACKIVA, I. Y. e BUDOLOVICH, E. Evaluating Riga Transport System Accessibility. Procedia Engineering, v. 178, p. 480 - 490, 2017.

KANE, L. e ROMANO, D. L. Changes in transport planning policy: Changes in transport planning methodology, Transportation Conference, v. 30, pp. 113-131, 2003.

KENWORTHY, J. R. The eco-city: Tem key transport and planning dimensions for sustainable city development. Environment and Urbanization, v.18, p. 67-85, 2006.

LINDNER, A.; PITOMBO, C. S. Modelo logit binomial com componentes principais para estimação de preferência por modo de transporte motorizado. Journal of Transport Literature, v. 10, p. 5-9, 2016

LITMAN, T. Introduction to multi-modal transportation planning, Victoria Transport Policy Institute, 2011. 
LITMAN, T. Towards More Comprehensive and Multi-modal Transport Evaluation, Victoria Transport Policy Institute, 2013.

LOURENÇO. R. S. Rio de Janeiro além de 2016: Um Projeto para a Nova Geração de Infraestrutura em Transportes. Instituto de Pesquisa Econômica Aplicada, 2015.

LÖFGREN, S. ; NILSSON, K. L. e JOHANSSON, C. M. Considering landscape in strategic transport planning. Transportation Research Part D: Transport and Environment, v. 65, pp. 396-408, 2018.

MACHADO, L. e PICCININI, L. S. Challenges for the effectiveness of the implementation of urban mobility plans: a systematic review. Revista Brasileira de Gestão Urbana, v. 10, p. 72-94, 2018.

MACIOROWSKI, M. M.; DE FARIA LIMA, M. L. T.; SOUZA, J. C. O Papel da Integração Modal na Construção da Mobilidade Urbana Sustentável. XXXI Congresso Nacional de Pesquisa em Transporte ANPET, 2017.

NOVAES, A. G. Sistema de Transportes.Volume1: Analise da Demanda. $1^{\mathrm{a}}$ ed. Editora Edgard BLucher LTDA.1986

ORTUZAR, J. D.; WILluMSEN, L. G. Modelling Transport. 4.ed. New Delhi: John Wiley \& Sons, 2011.

PEREZ, A. E. F. Estimativa de Matrizes Origem-Destino Para Veículos de Carga no Âmbito do Estudo do Plano Diretor de Transporte Urbano da Região Metropolitana de Rio de Janeiro (PDTU-RMRJ). Pontifícia Universidade Católica do Rio de Janeiro. 2015

PDTU-RMRJ. Plano Diretor de Transporte da Região Metropolitana do Rio de Janeiro, 2012. Disponível em: < http://www.pdtu.rj.gov.br/sobre-o-plano.html>. Acesso em: 29 abril 2019.

PMUS. Plano de Mobilidade Urbana Sustentável, 2016. Disponível em: < https://www.rio.rj.gov.br/web/pmus/sobre>. Acesso em: 02 maio 2019.

PORTA, A., MIGLIORI, S., PAOLONE, F., E POZZOLI, M. Integrated Transport Planning: The'Rehabilitation'of a contested concept in UK bus reforms. Journal of Cleaner Production, v. 232, pp. 1297-1308, 2019.

QIAN, Z. Master plan, plan adjustment and urban development reality under China's market transition: A case study of Nanjing. Cities, v. 30, pp. 7788, 2013. 
RAKKESH, S.T.; WEERASINGHE, A.R. e RANASINGHE, R.A.C. Effective Urban Transport Planning using Multimodal Traffic Simulations Approach. Moratuwa Engineering Research Conference (MERCon). 2016

SANTOS, M. A. e COSTA, M. A. Relatório de pesquisa: análise comparativa da gestão das Fpics na RM de Rio de Janeiro. Ipea. Rio de Janeiro, 2013.

SILVA, E. L.; MENEZES, E. M. Metodologia da pesquisa e elaboração de dissertação. 4. ed. Florianópolis, 2005.

SILVA JUNIOR, O. S. e LEAL J. Relatório Técnico-Científico: Definir uma rede reduzida, compatível com a versão do Emme disponível na PUC. 2016

SIMS, R. et al. Climate Change 2014: Mitigation ofClimate Change. Contribution of Working Group III to the Fifth Assessment Report ofthe Intergovernmental Panel on Climate Change. Cambridge University Press,Cambridge, United Kingdom and New York, USA

SONG, Y.; DING, C. e KNAAP, G. Envisioning Beijing 2020 through sketches of urban scenarios. Habitat International, v. 30, pp. 1018-1034, 2006.

SORENSEN, C. H. e GUDMUNDSSON, H. The impact of governance modes in sustainable transport- The case of bus transport in Greater Manchester, UK. World Review of Intermodal Transportation Research, v.3, p. 825,2010 .

SPIESS, H. e FLORIAN, M. Optimal strategies: A new assignment model for transit networks. Transportation Research B, v.23, pp.83-102,1989.

SPIESS, H. On optimal route choice strategies in transit networks. Publication 286, Centre de Recherch sur les Transports, Université de Montréal, 1983.

$\mathrm{SU}, \mathrm{H}$. et al. A land use and transportation integration method for land use allocation and transportation strategies in China. Transportation Research Part A: Policy and Practice, v. 69, pp. 329-353, 2014.

TISCHER, V. e POLETTE, M. Sistema de avaliação de cidades de referência em transportes e mobilidade urbana sustentável. Cadernos Metrópole, v. 21, pp. 481-509, 2019.

UNECE. Sustainable Urban Mobility and Public Transport in UNECE capitals, 2015 
WARDROP, J.G., Some Theoretical Aspect of Road Traffic Research Proceedings, Institution of Civil Engineering, 1, part 2, p. 325 - 378, 1952.

WEN, L.M, e RISSEL, C. Inverse associations between cycling to work, public transport, and over weight and obesity: Findings from a population bases study in Australia. Preventive Medicine, v.46, p. 29-32, 2008.

Williams, K. M.; Claridge, T. e CARROLl, A. Multimodal Transportation Planning Curriculum for Urban Planning Programs. NITCED-851. Portland, OR: Transportation Research and Education Center (TREC), 2016.

WADDELL, P. et al. Incorporating land use in metropolitan transportation planning. Transportation Research Part A: Policy and Practice, v. 41, n. 5, p. 382-410, 2007.

WANG, L.; WADDELL, P. e OUTWATER, M. L. Incremental Integration of Land Use and Activity-Based Travel Modeling: Workplace Choices and Travel Demand. Transportation Research Record, v. 2255, pp. 1-10, 2011.

WRIGHT, L e HOOK, W Manual de BRT: Bus Rapid Transit - Guia de Planejamento. Institute For Transportation and Development Policy: New York. 2008

ZHAO, L., Zhong-Ren Peng, Z.R. An Integrated Bi-Level Model to Explore the Interaction between Land Use Allocation and Transportation. In: The 89th Transportation Research Board (TRB) Annual Meeting, Washington, D.C. January 10-14. 2010

XIANG, W. e CLARKE, K.C. The use of scenarios in land-use planning. Environment and planning B: planning and design, v. 30, n. 6, pp. 885909, 2003.

VAN DER HEIJDEN, K. Scenarios: the art of strategic conversation. John Wiley \& Sons, 2011. 